\begin{abstract}
UNIVERSIDADE DE SÃO PAULO
ESCOLA DE ARTES, CIÊNCIAS E HUMANIDADES

PROGRAMA DE PÓS-GRADUAÇÃO EM CIÊNCIAS DA ATIVIDADE FÍSICA
\end{abstract}

THIAGO SOCIO DE SÁ

Talento esportivo: uma revisão sistemática

São Paulo 
THIAGO SOCIO DE SÁ

\title{
Talento esportivo: uma revisão sistemática
}

\author{
Versão corrigida
}

Dissertação apresentada à Escola de Artes, Ciências e Humanidades da Universidade de São Paulo para obtenção do título de Mestre em Ciências pelo Programa de Pós-Graduação em Ciências da Atividade Física.

Versão corrigida tendo as alterações solicitadas pela comissão julgadora em dia de mês de ano. A versão original encontra-se em acervo reservado na Biblioteca da EACH/USP e na Biblioteca Digital de Teses e Dissertações da USP (BDTD), de acordo com a Resolução CoPGr 6018, de 13 de outubro de 2011.

Área de Concentração:

Atividade Física, Saúde e Lazer

Orientador:

Prof. Dr. Marcelo Massa

São Paulo 
Autorizo a reprodução e divulgação total ou parcial deste trabalho, por qualquer meio convencional ou eletrônico, para fins de estudo e pesquisa, desde que citada a fonte.

Sá, Thiago Socio de

Talento esportivo: uma revisão sistemática / Thiago Socio de Sá ; orientador, Marcelo Massa. - 2019

107 f. : il.

Dissertação (Mestrado em Ciências) - Programa de Pós-

Graduação em Ciências da Atividade Física, Escola de Artes, Ciências e Humanidades, Universidade de São Paulo.

Versão corrigida

1. Desempenho esportivo. 2. Talento esportivo. I. Massa, Marcelo, orient. II. Título

CDD 22.ed. - 796 
Nome: SÁ, Thiago Socio de

Título: Talento esportivo: Uma revisão sistemática

Dissertação apresentada à Escola de Artes, Ciências e Humanidades da Universidade de São Paulo para obtenção do título de Mestre em Ciências do Programa de Pós-Graduação em Ciências da Atividade Física.

Área de Concentração:

Atividade Física, Saúde e Lazer

Aprovado em: 01 / 07 / 2019

\section{Banca Examinadora}

Prof. Dr. Paulo Henrique de Araújo Guerra

Julgamento: Aprovado

Prof. Dra. Jaqueline Freitas de Oliveira Neiva

Julgamento: Aprovado

Prof. Dr. Dalton Lustosa de Oliveira

Julgamento: Aprovado
Instituição: Universidade Federal da Fronteira Sul

Assinatura:

Instituição:

Assinatura:

Instituição:

Assinatura: 


\section{Agradecimentos}

Ao Prof. Dr. Marcelo Massa, pela paciência, confiança, incentivo e sobretudo, pela grande oportunidade de realizar esse projeto.

Ao Prof. Dr. Paulo Henrique de Araújo Guerra e Prof. ${ }^{a}$ Dra. Jaqueline Neiva pela disponibilidade e apoio no decorrer da pesquisa.

À Universidade de São Paulo, pelos conhecimentos que obtive e portas que me abriu, desde o primeiro instante.

Ao meu local de trabalho, pela oportunidade de exercer à profissão que estudei com afinco ao longo dos anos.

Aos meus alunos, com os quais troco aprendizados diários e me permitem, a cada pequena conquista, me realizar profissionalmente, mantendo a esperança e força na caminhada!

Aos meus pais por terem me criado e ajudado com tudo possível.

À Natali Azevedo por ser a minha principal apoiadora, me incentivando e dando esperanças de que ainda existem pessoas genuinamente boas e me lembrando o porque é importante mantermos nossos valores.

Agradeço a qualquer manifestação de energia sobrenatural que me proporcionou força para a confecção deste trabalho.

E por fim, agradeço à todas as pessoas que estiveram direta ou indiretamente envolvidas com o meu processo de formação pessoal, profissional e acadêmica.

Obrigado! 


\section{RESUMO}

SÁ, Thiago Socio de. Talento esportivo: uma revisão sistemática. 2019. 107 f. Dissertação (Mestrado em Ciências) - Escola de Artes, Ciências e Humanidades, Universidade de São Paulo, São Paulo, 2019. Versão corrigida.

O termo talento esportivo é utilizado comumente para descrever pessoas que possuem grande aptidão para o desempenho em determinada modalidade esportiva. Com isso, tem-se a ideia de que o talento diz respeito a o potencial para o desenvolvimento e a parte inata do sujeito ao manifestar determinada habilidade. O tema talento esportivo é bastante estudado no cenário mundial, tendo em vista que presume quais seriam as circunstâncias ideais para o desenvolvimento de atletas talentosos. Contudo, por ser um tema abrangente, há dificuldade em sumarizá-lo e estabelecer um consenso quanto ao que, de fato, pode intervir no desenvolvimento de um atleta talentoso. Desta forma, os objetivos do presente estudo foram: levantar o estado da arte dos artigos que abordam o talento esportivo que foram publicados no biênio de 2017 e 2018, sumarizar as principais características, contribuições e as modalidades esportivas mais abordadas pelas pesquisas disponíveis e ajudar no desenho de futuros estudos, identificar potências e fragilidades sobre o TE. Para isto, foi realizada uma revisão sistemática nas bases de dados: Web of Science, Scopus, SciELO, PsycINFO, SPORTDiscus, Google Scholar e Pubmed em busca de artigos que tratem sobre talento esportivo. Espera-se que as sínteses das informações contribuam para o debate, no sentido de oferecer uma compreensão global e comparativa quanto ao assunto. Através do processo de revisão, foram selecionados 75 artigos os quais garantiram grande variedade de informações, 44 deles abordavam estudos relacionados ao desenvolvimento do talento; 23 artigos tratavam sobre a detecção do talento; 07 artigos referiam-se à seleção do talento e finalmente, 1 artigo abordou a identificação e desenvolvimento do talento. Concluí-se que os aspectos fisiológicos, psicológicos, bem como fatores intrínsecos se correlacionam nos processos de seleção, deteção e desenvolvimento do talento esportivo, sendo necessários mais estudos com ideal epistemológico que abordem o assunto.

Palavras-chave: Talento esportivo. Esporte. Revisão sistemática. 


\begin{abstract}
SÁ, Thiago Socio de. Sport talent: A systematic review. 2019. 107 p. Dissertation (Master of Science) - School of Arts, Sciences and Humanities, University of São Paulo, São Paulo, 2019. Corrected version.

The term sports talent is used to describe people who have great fitness for performance in some sporting modality. With this, one has the idea that talent refers to the potential for the development of a part of the subject when manifesting a skill. The sport talent theme is well studied on the world stage, in order to presume which are the ideal circumstances for the development of a sport talent. Why, a comprehensive problem, a difficulty in summarizing and establishing a consensus as to what, in fact, can be a problem of developing a skill. In this way, the objectives of this study were: Raise the state of the art to approach the sports talent that was published in the biennium of 2017 and 2018, to help the project of an future studies, identify potencies and fragilities in the sport talent. To that purpose, was made an systematic review on some databases: Web of Science, Scopus, SciELO, PsycINFO, SPORTDiscus, Google Scholar and Pubmed searching for articles about sport talent. It is hoped that the sintesis of the information can help on the academic discussions, there is a sense of global and comparative understanding of the subject. Through the review process, 75 articles were selected that guaranteed a wide variety of information, 44 had their studies related to the development of talent; 23 articles dealt with the detection of talent; 07 articles referred to the selection of talent and finally, 1 article addressing the identification and development of talent. Finally, it is concluded that the physiological, psychological, and intrinsic factors are related in the process of selection, detection and development of sports talent. More studies with an epistemological ideal are needed.
\end{abstract}

Keywords: Sport talent. Sistematic review. Sport. 


\section{LISTA DE FIGURAS}

Figura 1 - Fluxograma PRISMA para Revisão Sistemática................................... 23 


\section{SUMÁRIO}

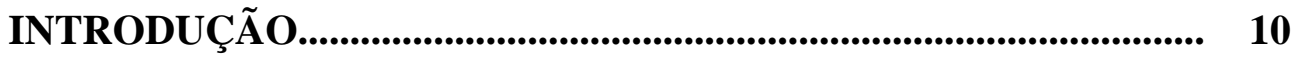

O problema e sua importância........................................................ 10

1.1.1 Modelo de Bloom......................................................................... 14

1.1.2 Modelo de Csikszentmihalyi.............................................................. 15

1.1.3 Modelo de Ericsson....................................................................... 16

1.1.4 Determinação, detecção, seleção e promoção do talento esportivo........... 17

1.1.5 O talento esportivo e o treinamento a longo prazo................................ 19

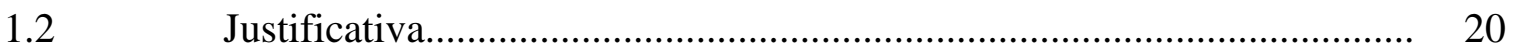

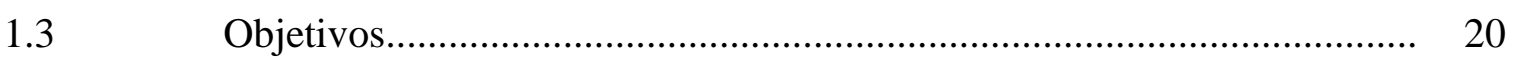

$2 \quad$ PROCEDIMENTOS METODOLÓGICOS....................................... 21

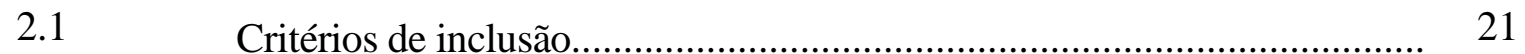

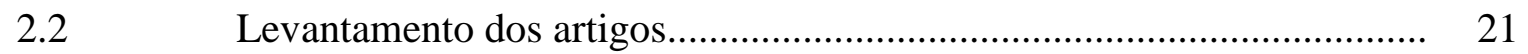

2.3 Extração de dados e síntese......................................................................... 21

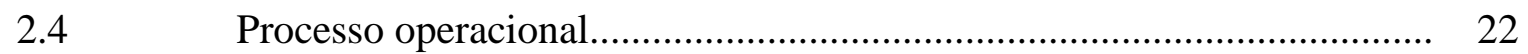

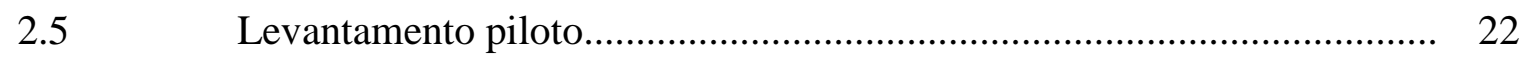

$3 \quad$ RESULTADOS E DISCUSSÃO....................................................... 23

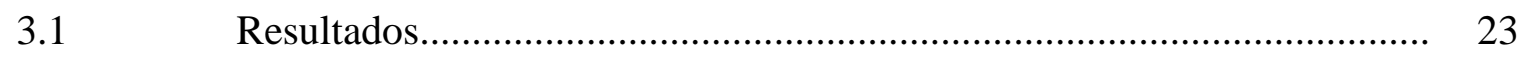

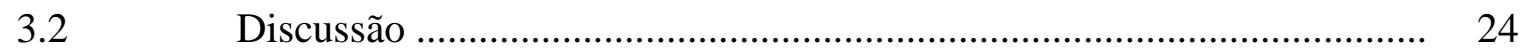

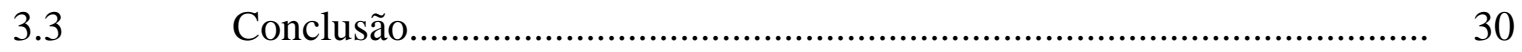

REFERÊNCIAS ................................................................................... 32

ANEXO A - TABELA 1 - CARACTERÍSTICAS DESCRITIVAS

DOS ARTIGOS................................................................................... 42

ANEXO B - TABELA 2 - CARACTERÍSTICAS DESCRITIVAS

DOS ARTIGOS............................................................................................... 57

ANEXO C - TABELA 3 - CARACTERÍSTICAS DESCRITIVAS

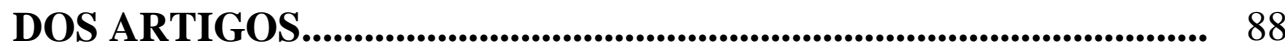




\section{INTRODUÇÃO}

\subsection{O problema e sua importância}

O talento é um tema atrativo para ser pesquisado e gerido, até mesmo por conta da "mística" envolvida nele, pois muitas vezes a capacidade em realizar determinada atividade propaga uma discussão quase "sobrenatural" (KISS et al., 2004).

Sobre o contexto que envolve o talento, se pode compreender inicialmente que esta é uma temática estudada em diversas áreas do conhecimento, tais como a educação, gestão do talento humano, artes, no esporte, etc (ALENCAR, 2003; ALENCAR et al., 2004; SOUSA et al., 2001).

Pensando na grande quantidade de características que um sujeito possui, de acordo com Siqueira etal.(1999), existem sete tipos de inteligências: linguística, musical, espacial, lógicomatemática, corporal sinestésica, interpessoal e intrapessoal, segundo ele, cada uma destas inteligências interfere na produção de determinado talento.

Neste sentido, o talento também apresenta um contexto social (BÖHME, 1994), por virtudes ou peculiaridades que são valorizadas culturalmente e historicamente (GUENTHER, 2000), inclusive porque determinadas características, possibilidades e incentivos para a evolução dependerão do ambiente social que o sujeito está inserido. Assim, pode-se verificar que o talento é um assunto bastante complexo, no qual há interferência de vários elementos para sua aparição e desenvolvimento.

O termo talento esportivo é utilizado geralmente para descrever aqueles sujeitos que possuem um potencial, aptidão especial ou uma grande aptidão para o desempenho esportivo. (BÖHME, 2007).

Pode-se dizer que existe uma vasta gama de fatores constitucionais, sociais, físicos e psicológicos que influenciam e devem ser considerados no processo de determinação do talento esportivo (WEINECK, 1991). Além disso, pode ser constatado o prognóstico de desempenho do talento esportivo, que diz respeito a uma estimativa sobre o que é esperado do atleta, ela é formulada através da avaliação do histórico do passado ou o presente do praticante da modalidade, desta forma, coletam-se informações biopsicossociais que podem auxiliar a alcançar melhores resultados (BÖHME, 1996).

Quando se fala sobre "talento esportivo", deve-se ter em mente que a manifestação do mesmo em atletas é um fenômeno multicausal e necessita de abordagens 
multidimensionais (ABBOT et al., 2005; VAEYENS et al., 2008; BURGESS, 2010; LI; WANG; PYUN, 2014), justamente por isso existe na literatura uma vasta gama de pesquisas que discorrem diversos métodos e abordagens, buscando assim, responder como ocorrem os processos envoltos nas modalidades esportivas.

Neste sentido, verificam-se estudos que desenvolvem o talento esportivo sob a ótica da aprendizagem e desenvolvimento motor (NOCE et al., 2012), fatores maturacionais (ABBOT et al., 2005; BOJIKIAN et al., 2007; LIMA et al., 2008; RÉ et al., 2003), fatores psicossociais (MASSA et al., 2010) e ambiente de prática (MENDONÇA et al., 2007) entre outros, propondo discussões que colaboram para o desenvolvimento da área do conhecimento em educação física e desempenho físico.

A detecção do talento pode ocorrer de distintas formas: (i) por meio dos processos de treinamento a longo prazo, (ii) em centros de treinamento, clubes ou escolas, por meio da criação de diversas categorias, subdividindo os praticantes das modalidades por faixas etárias e buscando ministrar determinados conteúdos para cada uma delas, a partir da prática destas tarefas físicas e motoras (LINDOR; CÔTÉ, HACKFORT, 2009).

Segundo Barbanti, (1997) e Böhme, (1999) o treinamento a longo prazo pode ser dividido em três fases: primeiro nível, que tem relação com a formação básica das capacidades coordenativas, no qual a escola desempenha um papel fundamental possibilitando o ensino por meio das aulas de educação física; segundo nível, quando a criança começa a receber treinamento básico, se especializando posteriormente em uma modalidade esportiva, podendo ser, inclusive, em um determinado clube e terceiro nível, no qual o praticante se especializa totalmente, com foco já no rendimento esportivo, normalmente neste nível o atleta pratica modalidade em clubes.

A partir disso, pode ser promovido este sujeito que é talentoso ou obteve destaque, através dos processos específicos de treinamento a longo prazo presentes em cada modalidade esportiva e utilizados por cada treinador, elevando o sujeito à níveis ainda mais altos de desempenho físico-motor ao longo do tempo (BÖHME, 2000; BÖHME, 2007).

No meio científico, é discutido e proposto conceitualmente sobre abordagens e formas lógicas de condução do talento esportivo (BÖHME, 2000; ABBOT et al., 2005; BÖHME, 2007; VAEYENS et Lal., 2008; LINDOR; CÔTÉ, HACKFORT, 2009; CLARK, 2012; PHILLIPS et al., 2010; QUIJADA 2015), porém é perceptível que em grande parte dos casos nos clubes e centros de formação, estes conhecimentos não são apropriados. Já para Filin, (1996) o processo de treinamento esportivo a longo prazo se divide em 
quatro diferentes etapas: (i) iniciação, que é descrita como etapa de desenvolvimento das habilidades básicas; (ii) etapa de formação esportiva, diz respeito ao aumento das cargas de treinamento e desenvolvimento motor, a parte competitiva passa a ter certo destaque; (iii) o treinamento especializado, nele o treino assume maior caráter especializado e as competições aumentam; (iv) e desempenho máximo, grandes quantidades de treinamento especializado buscando o alto desempenho esportivo.

As populares "peneiras", são outro expediente comum para a seleção de sujeitos, aparentemente habilidosos, com condições de participar de uma categoria mais avançada (BÖHME, 2000). Porém, nesta seleção, aqueles considerados inaptos pelos técnicos e treinadores são excluídos do processo e muitas vezes da própria prática da modalidade esportiva (RÉ et al., 2003). Estas exclusões podem ocorrer pela busca imediatista de fatores maturacionais, motores e motivacionais promovidos por técnicos e treinadores.

Por meio destas "peneiras", a literatura aponta que por vezes serão selecionados atletas que nem sempre continuarão a se destacar nas próximas categorias e apenas estão em evidência por terem passado por um processo de maturação ou de produção de resultados mais cedo (RÉ et al., 2003; BOJIKIAN et al., 2007; MASSA et al., 2010), isso associado com outros aspectos de desenvolvimento não lineares de outras características do desenvolvimento do atleta complexifica ainda mais a validação de testes utilizados pela ciência (ABBOT et al., 2005).

Frequentemente em diversas modalidades esportivas, são realizados os processos de detecção e seleção ineficientemente ou mesmo precoces, já que os profissionais envolvidos tendem a se atentar apenas ao rendimento atual dos atletas, ou seja, consideram o que eles estão produzindo de forma aguda e focam somente em atletas que se destacam, porém, este destaque não necessariamente se perpetuará (RÉ et al., 2003; BOJIKIAN et al., 2007; MENDONÇA et al., 2007; LIMA et al., 2008; MASSA et al., 2010;).

É preciso ponderar que a determinação do talento esportivo se compreende como uma série de fatores, que consideram as discussões teóricas e também evidências abstratas. Conforme Böhme (1995), sendo constatada a grande subjetividade no que tange a determinação, detecção, seleção e promoção dos talentos esportivos (UEZU et al., 2008; LINDOR; CÔTÉ, HACKFORT, 2009; BURGESS (2010), é importante considerar e revisar as abordagens do tema sob a ótica da ciência, e de que forma ela pode contribuir discorrendo acerca do assunto, identificando quais os principais apontamentos e carências relatadas na literatura, especialmente, tendo em vista o cenário competitivo de diversas modalidades 
esportivas (futebol, vôlei, natação, corrida, etc.), no qual se observa a necessidade de descobrir praticantes talentosos e prepará-los de maneira eficiente.

Desta forma, o meio científico pode contribuir substancialmente através de pesquisas nas mais variadas modalidades esportivas e visão holística sobre o assunto, a considerar que, cada modalidade possui características específicas, e a detecção do talento esportivo conforme os métodos e testes utilizados por técnicos e treinadores acabam não sendo pareadas ou eficientes. (UEZU et al., 2008; LINDOR; CÔTÉ, HACKFORT, 2009; BURGESS, 2010).

Por conseguinte, independente das óticas exploradas, é necessário que os conceitos fundamentais sejam apresentados na compreensão ampla que se trata o tema "talento esportivo", e na condução dos aspectos: determinação, detecção, seleção e promoção do talento, que se fazem presentes nas modalidades esportivas (BÖHME, 2000), assimilando assim, o que cada um diz respeito para compreender como ele ocorre e é feita a condução à excelência esportiva (VAEYENS et al., 2008).

Obviamente que, em meio ao às publicações nota-se a variedade de materiais voltados a desenvolver conceitualmente o que deve ser realizado na área esportiva, apontando as carências e novos passos lógicos a respeito do talento (BÖHME, 2000; KISS et al., 2004; ABBOT et al., 2005; BÖHME, 2007; VAEYENS et al., 2008; LINDOR; CÔTÉ, HACKFORT, 2009; PHILLIPS et al., 2010), todavia, são escassos os estudos de revisão sistemática, objetivando contrapor diversas linhas de pensamento e estabelecer consenso.

Assim sendo, notamos no cenário nacional a carência por estudos com diversas abordagens em modalidades esportivas variadas. Um exemplo deste dado pode ser observado em Lanaro Filho e Böhme (2001), que buscaram em um estudo de revisão, trazer informações sobre os processos de detecção, seleção e promoção de talentos utilizados na ginástica rítmica, concluindo que existe déficit de informações nesta modalidade esportiva. No cenário internacional muito é produzido no que diz respeito a estudos de revisão (LANARO FILHO; BÖHME, 2001; BURGESS, 2010; LI; WANG; PYUN 2014; QUIJADA, 2015), porém, tratando-se de pesquisas sobre o tema talento esportivo, ainda na atualidade, existe a necessidade de aprofundarmos estes achados.

Tendo em vista que o presente estudo é u ma revisão sistemática, a qual necessita primordialmente demonstrar dados e zelar pela imparcialidade dos achados, esta revisão de literatura estará principalmente pautada em discutir conceitualmente elementos essenciais para a compreensão e apropriação do que se trata o talento e seus modelos clássicos de abordagem, 
os processos de determinação, detecção, seleção e promoção dos talentos esportivos e por fim sobre o treinamento a longo prazo. Portanto, é importante trazer à tona os principais modelos teóricos que norteiam as discussões sobre o tema, tendo em vista o grande embate quanto ao que é inato ou adquirido acerca do talento.

\subsubsection{Moodelo de Bloom}

Um dos modelos que será retratado nesta revisão é o proposto por Bloom ( 1985), proposto com o seguinte título: "Developing talent in young people". Nele pode-se conferir uma linha desenvolvimentista, com a ideia que os estímulos e apoio que um sujeito recebe podem ser fatores cruciais no desenvolvimento do talento. No trabalho de Bloom, 1985 é estabelecida a ideia de que se os estímulos de qualidade que foram fornecidos pelos pais, treinadores, professores, mentores e ambientes de desenvolvimento são favoráveis e de qualidade, haverá maior probabilidade para o desenvolvimento do talento em uma determinada habilidade.

No referido trabalho que foi proposto por Bloom, 1985 realizou-se um estudo longitudinal, com uma amostra selecionada de 86 homens e 36 mulheres que eram considerados talentosos em suas áreas de domínio (pianistas de concerto, escultores, matemáticos, pesquisadores neurológicos, nadadores olímpicos e tenistas) e que haviam atingido destaque antes dos 35 anos de idade. Neste estudo, sucederam-se entrevistas buscando identificar semelhanças nos processos de aprendizagem de cada sujeito. No seu trabalho (BLOOM, 1985), após a aplicação do roteiro de entrevistas, segundo o relato, constatou- se a existência de um padrão e consideradas fases sensíveis para a formação dos talentos nos grupos:

Anos iniciais de aprendizagem: este foi considerado o período onde ocorre a inserção do sujeito à prática de tarefas divertidas e prazerosas, nesta introdução a criança passa a gostar de praticá-las, recebendo suporte e incentivo dos pais, professores e treinadores. Nesta etapa o interesse em praticar a atividade foi elementar para a criança permanecer se desenvolvendo e prosseguindo nas etapas seguintes de desenvolvimento, juntamente com os técnicos e professores, nesta fase, muitas crianças começavam a ser enxergadas e chamadas de talentosas 
Anos intermédios de aprendizagem: esta é uma etapa que ocorre entre os 11 e 15 anos de idade, na qual o praticante da habilidade alcança níveis superiores de produtividade e a prática é cada vez mais massiva. Os adolescentes, nesta etapa eram capazes de dispor mais concentração e comprometimento com as metas, começavam a manter foco nas atividades praticadas, para então alcançarem níveis ainda mais elevados de desempenho nas tarefas. Nesta fase, o apoio dos pais ainda pareceu essencial para os adolescentes, por dar incentivos morais e financeiros aos filhos e estes mantinham-se focados na tarefa de aprimoramento da habilidade.

Anos finais de aprendizagem: é descrito como período voltado ao desempenho ótimo da habilidade, sua prática nesta fase é sempre buscando o nível ótimo e maduro de desempenho, esta etapa é descrita também como um divisor entre quem pôde alcançar níveis superiores e quem não. Nesta última etapa, os talentos que permaneceram iveram acesso aos melhores recursos e meios para seu desenvolvimento, alcançando assim um desempenho ótimo.

Neste modelo proposto por Bloom (1985), é relatado ainda que, podem ocorrer diversas interferências contextuais no desenvolvimento do talento, por conta do ambiente econômico familiar ou institucional que o sujeito está inserido e que o talento que é constatado precocemente não necessariamente se perpetuará e vice-versa, sendo elemento fundamental a permanência no processo de treinamento para a fomentação do talento.

\subsubsection{Moodelo de Csikszentmihalyi}

No modelo proposto por Csikszentmihalyi, Rathunde \& Whalen (1997), é reforçado o que o conceito de que o desenvolvimento ocorre em um processo continuo de anos de prática e que sofre interferências do meio o qual está inserido. Sendo assim, é necessário que haja a oportunidade de desenvolvimento dos talentos e que estas sejam contextualizadas em um meio que seja favorável para seu amadurecimento (CSIKSZENTMIHALYI, RATHUNDE \& WHALEN, 1997). O modelo de Csikszentmihalyi apoia-se bastante na 
interação entre indivíduos, domínios e áreas, propondo por meio disto um modelo denominado de Fluxo de Experiência Ótima (“Flow”).

No Fluxo de Experiência Ótima defendido por Csikszentmihalyi, são desenvolvidos os conceitos de integração e diferenciação. A integração diz respeito às condições que facilitam a realização de uma tarefa, nela, o sujeito praticante se integra à realização tarefa a tal nível que não há presença da fadiga, perde-se a noção do tempo, além de nenhum outro elemento interferir na realização da tarefa. Na diferenciação é referente às mudanças e adaptações que promovem dificuldades e consequentemente desafios para a melhor aprendizagem de uma tarefa específica. Além disto, O Fluxo de Experiência Ótima se mostra relacionado com a necessidade de praticar de maneira pontual os conteúdos necessários para o desenvolvimento das habilidades. Assim sendo, o aprendizado pode ocorrer de maneira efetiva se nas instituições de ensino a integração aconteça em cada segmento necessário para o desenvolvimento deste talento de maneira efetiva.

\subsubsection{Moodelo de Ericsson}

Em Ericsson, Krampe e Tesch-Römer (1993), é ainda mais reforçada a ideia de que o talento é desenvolvido com o tempo de prática, mais especificamente segundo estes autores, para o aprendizado de determinada habilidade devem ser empregados 10 anos de prática ou 10.000 horas de prática intensiva. Outro ponto bastante defendido pelos pesquisadores é que diversos aspectos físicos (ex.: tamanho do coração, componentes metabólicos contráteis dos músculos, entre outros) e também fatores psicológicos podem ser melhorados com o tempo de prática e ela é desassociada de qualquer fator genético.

No estudo realizado por Ericsson, Krampe e Tesch-Römer (1993), foram avaliados sujeitos violinistas e pianistas, quanto à quantidade de horas de prática, concluindo que quanto mais elevada era a quantidade de prática da tarefa específica, maior era a habilidade. E por fim, existem alguns itens neste modelo, que se referem às restrições que ocorrem, desfavorecendo assim o processo de aprendizado da habilidade: (a) a restrição de recursos, (b) restrição de esforço e (c) a restrição de motivação. 
1.1.4 Determinação, detecção, seleção e promoção do talento esportivo

Quanto à determinação do talento esportivo, certa subjetividade é constatada quanto aos critérios que são utilizados para de fato determinar do que se trata de um talento esportivo. Ainda ocorre no cenário esportivo, propagado por muitos profissionais grande subjetividade no que tangencia a detecção do talento esportivo e os passos que o sucedem. Porém, por fim, a determinação de talentos esportivos carece de estudos que integrem de maneira efetiva em cada modalidade os elementos essenciais necessários para um atleta em determinada modalidade esportiva para seu rendimento ótimo.

A detecção do talento esportivo é descrita como a busca por fatores que naturalmente são encontrados em algum atleta ou são lapidados após certo treinamento, fatores estes que podem ser: antropométricos, físicos, fisiológicos e psicológicos (RÉGNIER, SALMELA e RUSSEL, 1993). Neste contexto, existem conceitos chamados: "Top Down” e o "Bottow Up”. No “Top Down”, é referente a utilização de um modelo teórico sem levar em conta a parte prática, já no "Bottow Up", ocorre o contrário, a parte prática é usada na formulação de uma teoria sem levar em conta achados prévios.

Como é proposto por Böhme (1995), uma forma de se trabalhar com a detecção de talentos esportivos é possuir um número grande de praticantes da modalidade esportiva e fazer uso do treinamento a longo prazo.

Como observado, o talento esportivo é um fenômeno multidimensional, então não há sentido a propagação de um diagnóstico precoce de talento já que ele pode ser um fator prejudicial para o seu desenvolvimento e consolidação.

Outro dado importante descrito por Marques (1991) é que existe grande necessidade na detecção dos talentos esportivos nas escolas, ou seja, existe uma grande centralização das buscas por talentos nos clubes, porém no ambiente escolar esta busca não se faz tão presente.

Desta forma Marques (1991), Hohmann e Seidel (2003) fortalecem este pensamento ao afirmar que a detecção de talentos deve estar voltada para crianças que não treinam formalmente e sistematicamente.

No Brasil, porém, infelizmente não existem programas voltados à detecção do talento esportivo, esta tarefa acaba cabendo à família, clubes e empresas fomentar este tipo de estímulos (MATSUDO \& MATSUDO, 1997).

Tendo em vista à necessidade imediata por resultados, através da formulação de algum tipo de perfil perfeito que é criado na busca do talento esportivo e para minimizar 
os danos causados por este fator, pode-se então propor o treinamento a longo prazo como uma boa ferramenta para a detecção do talento de maneira mais justa e menos enviesada (BÖHME, 2000).

O processo de seleção esportiva, diz respeito à forma como são admitidos determinados atletas para continuarem a praticar em níveis mais elevados de desempenho e excluídos aqueles que não tem condições, ou seja aqueles que apresentarem maiores condições de se manterem no treinamento a longo prazo são selecionados (BÖHME, 2000). Para reconhecimento de um talento esportivo é necessária a observação e avaliação do mesmo (SENF, 1990), para tal, existem três estágios que carecem de observação:

a) $\mathrm{Na}$ seleção inicial do talento esportivo, deve-se buscar avaliar as aptidões gerais e até onde elas se estendem, não as específicas além de selecionar crianças com perfis morfologicamente, funcionais e psíquicas para então poder desempenhar ótimos resultados, apenas tomando enfoque específico para cada modalidade na adolescência, por esta ser uma fase sensível para o rendimento (HOHMANN \& SEIDEL, 2003; SENF, 1990);

b) Nesta etapa, é importante que haja a delimitação de qual será a modalidade esportiva que será praticada pelos mais capacitados (HEBBELINCK, 1989). Ao longo dessa fase serão avaliadas características facilitadoras para os aprendizados futuros.

De acordo com Beyer (1987), Böhme (1995), a promoção do talento esportivo fala sobre a utilização de medidas exatas que facilitem o desenvolvimento ótimo. Esta produção de resultados, se bem guiada e conduzida, garantirá em meio a mais uma série de etapas do treinamento a longo prazo de maneira cíclica e contínua a atingir o melhor resultado (LANARO FILHO,2001). É claro que neste processo de promoção do talento esportivo há necessidade dos componentes de treinamento adequados, assim como condições sociais, na escola e o contexto onde o atleta está presente (BÖHME, 1995). Assim sendo, no processo de promoção de talentos esportivos, bem como nos de determinação, detecção e seleção, devem tomar atenção ao fato de que as seleções precoces, podem acabar dificultando ou até mesmo impossibilitando o processo de lapidação ocorrer. 


\subsubsection{O talento esportivo e o treinamento a longo prazo}

Com tudo o que já foi discutido anteriormente, fica claro que é importante o trabalho de desenvolvimento do talento (BLOOM, 1985; CSIKSZENTMIHALYI, RATHUNDE \& WHALEN, 1997; ERICSSON, KRAMPE \& TESCH-RÖMER, 1993) e com o talento esportivo não é diferente, ainda mais quando se pensa em esporte de alto nível (BÖHME, 1994, 2000). Acerca do talento esportivo, podem-se classifica-lo em três grupos (WEINECK, 1991):

- Talento motor geral: são os sujeitos que possuem facilidade no aprendizado de movimentos, isto acaba favorecendo o aumento do repertório motor.

- Talento esportivo: sujeitos que apresentam o potencial acima a média, pode- se alcançar altos níveis de desempenho esportivo.

-Talento esportivo específico: sujeitos que apresentam características físicas e psicológicas prévias para derminada modalidade esportiva. Pode-se pensar sobre o talento elucidando dois fatores, o estático e o dinâmico (JOCH,1994 apud BÖHME,2000), o componente estático leva em consideração quatro fatores: (i) disponibilidade; (ii) disposição, ou seja: a vontade e o poder do jovem realizar a um processo de treino para o desenvolvimento de suas potencialidades esportivas; (iii) as possibilidades reais presentes no meio ambiente onde está inserido, se fazendo presentes as possibilidades de treinamento a longo prazo e que são disponibilizadas no local onde se vive, assim como (iv) a apresentação de resultados adequados conforme a etapa do treinamento a longo prazo. De outra forma o componente dinâmico diz respeito aos processos interativos e de mudanças biopsicossociais aos quais podem ser notados no talento, neste contexto, ele deve ser conduzido segundo um processo competitivo bem preparado, com seus princípios e métodos bem consolidados.

Nesta breve revisão de literatura, foi possível verificar sobre o talento e como ele, nas mais diferentes áreas do conhecimento, está atrelado com a parte educacional e de aprendizado. Foram abordados os diferentes modelos (Modelo de Bloom, Modelo de Csikszentmihalyi e Modelo de Ericsson) bem como a forma como se assemelham e destoam entre si. Discorreu-se sobre o talento esportivo e o treinamento a longo prazo, o que é e para que serve e por fim, explanou-se sobre o talento esportivo e os seus processos de determinação, detecção, seleção e promoção esportivas. Por conseguinte, pode-se 
compreender o quão complexo, delicado e carente é o tema, especialmente no que diz respeito às pesquisas que busquem unificar esta gama de conhecimento. A dificuldade de assimilar este tema pela ciência de forma consensual, torna-se um empecilho na formulação dos estudos sobre o assunto. Desta forma, os objetivos do trabalho são: a) levantar o estado da arte dos artigos que abordem talento esportivo que foram publicados no biênio de 2017 2018; b) sumarizar as principais características, contribuições e as modalidades esportivas mais abordadas pelas pesquisas disponíveis; c) Ajudar no desenho de futuros estudos, identificar potências e fragilidades sobre o Talento esportivo. Posto isto, a seguinte pesquisa estima discorrer acerca das questões:

a) O que há publicado sobre talento esportivo?

b) Quais são os objetivos e principais resultados dos trabalhos que abordam o talento esportivo?

c) Segundo o que há disponível na literatura, quais são os potenciais ou desafios na área?

\subsection{Justificativa}

Necessidade de abordar o talento esportivo de maneira ampla para constituir uma síntese mais abrangente, que possa melhorar a compreensão do fenômeno.

\subsection{Objetivos}

Com o propósito de convergir o que há publicado sobre o talento esportivo, tanto quanto a sua determinação, detecção, seleção e promoção serão considerados os seguintes objetivos:

a) Apresentar o estado da arte dos artigos que abordam o talento esportivo, publicados no biênio de 2017-2018.

b) Sumarizar as principais características, contribuições e as modalidades esportivas mais abordadas pelas pesquisas disponíveis.

c) Ajudar no desenho de futuros estudos, identificar potências e fragilidades sobre o Talento esportivo. 


\section{PROCEDIMENTOS METODOLÓGICOS}

O presente estudo foi realizado por meio de uma revisão sistemática, para a sua confecção, foram respeitados os processos constantes na lista de verificação PRISMA (Liberati et al., 2009) e sua realização seguiu a ordem do fluxograma proposto na figura 1.

\subsection{Critérios de inclusão}

Para a composição da síntese, foram procurados artigos científicos completos, que apresentaram como temática primária, o estudo do talento esportivo, publicados no biênio de 2017 e 2018, nos idiomas: português, inglês e espanhol.

Não foram feitas restrições às características dos estudos, quanto à faixa etária, modalidades, local da pesquisa e propostas de trabalho.

\subsection{Levantamento dos artigos}

Os títulos e resumos foram localizados através de buscas sistemáticas em sete bases de dados eletrônicas: Web of Science (5), Scopus (92), SciELO (nenhum resultado), PsycINFO (19), SPORTDiscus (475), Google Scholar (34) e Pubmed (101).

Para a busca, foram utilizados os seguintes termos e combinações: "sport" OR "esporte" OR “sport talent” OR “talento esportivo” AND “expertise” OR “expert” OR “talent” OR "talento” O R “talent determination” OR “determinação do talento” OR "talent development" OR "desenvolvimento de talentos" OR "talent selection" OR "seleção de talentos" OR "talent promotion" OR "promoção de talento" OR "talent detection" OR "detecção de talento".

As buscas foram realizadas em 07/11/2018 e foram atualizadas em 15/01/2019, contando com as buscas manuais nos dias 17/01/2019 e 18/01/2019.

\subsection{Extração de dados e síntese}

Na Tabela 1 está reproduzida a planilha de extração. As principais informações para a composição da síntese descritiva foram organizadas em quatro domínios:

Características descritivas dos artigos (e.g. primeiro autor do artigo, ano de publicação, 
título do trabalho, jornal, local de realização, modalidade(s) abordada(s), objetivo primário; (2) Características metodológicas dos artigos (e.g. faixa etária, gênero, técnicas/instrumentos/testes utilizados para as medidas), (3) Resultados e (4) Conclusões, limitações do estudo e observações.

\subsection{Processo operacional}

De acordo com o que é sugerido em Liberati et al. (2009), de maneira independente, o pesquisador foi responsável pela aplicação das buscas sistemáticas nas bases de dados, identificação e exclusão das referências duplicadas. Também de forma independente, ocorreu a avaliação dos títulos e resumos, dos textos integrais e a extração dos dados. Para a solução de possíveis dúvidas e estabelecimento de consensos ao longo do processo de avaliação, a pesquisa contou com a participação de dois revisores sêniores.

\subsection{Levantamento piloto}

Para uma melhor experiência quanto ao desenho de pesquisa, no dia 19/01/2018, foi realizado um levantamento piloto nas sete bases de dados previamente apontadas, que, teve como objetivo verificar quais eram os melhores termos e/ou descritores para a identificação dos artigos que tenham relação com o tema. Como resultado desta busca, excluídos os artigos duplicados entre as bases de dados $(n=11)$, chegou-se ao valor de 791 títulos e resumos. 


\section{RESULTADOS E DISCUSSÃO}

3.1 Resultados

Ao todo foram obtidos 736 títulos e resumos os quais foram exportados para um programa organizador de referências (Mendeley), neste programa foram excluídas 99 duplicatas, totalizando um $\mathrm{N}$ de 637 títulos e resumos. Após a leitura e exclusão de 540 títulos e resumo, chegou-se ao $\mathrm{N}$ de 97 artigos para serem lidos na íntegra os quais 22 foram excluídos por não tratar sobre o tema de interesse.

Figura 1. Fluxograma PRISMA para Revisão Sistemática.

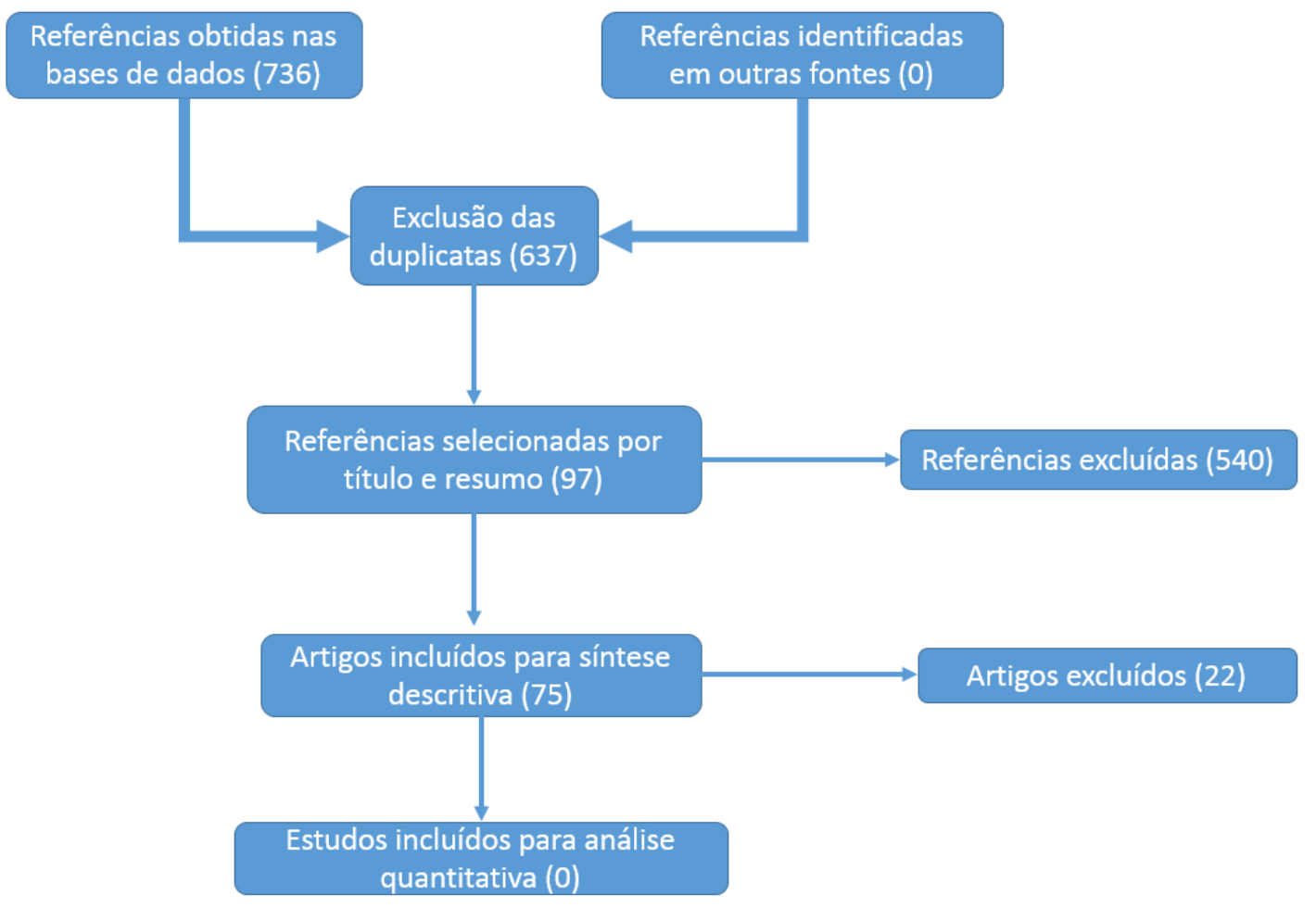

Fonte: Thiago Socio de Sá, 2019. 
A síntese descritiva foi construída a partir dos dados de 75 artigos originais, publicados nos anos de 2017 (40) e 2018 (35), que responderam adequadamente aos critérios de elegibilidade supracitados.

Dentre os 75 títulos, 44 deles abordavam estudos relacionados ao desenvolvimento do talento; 23 artigos tratavam sobre a detecção do talento; 07 artigos referiam-se à seleção do talento e finalmente, 1 artigo abordou a identificação e desenvolvimento do talento.

Foram incluídos estudos de diversos países, sendo: 14 do Reino Unido, 7 da Espanha, 6 da Austrália, 6 da Noruega, 5 do Canadá, 4 dos Países Baixos, 3 da Suíça, 3 da Suécia, 3 da Dinamarca, 3 da China, 2 de Portugal, 2 da Polônia, 2 da Itália, 2 da Inglaterra, 2 da Bélgica, 2 da Alemanha, 1 dos Estados Unidos, 1 da Nova Zelândia, 1 da Malásia, 1 da Irlanda, 1 da Grécia, 1 da Finlândia, 1 da Croácia, 1 do Brasil e 1 estudo com local não identificado.

Quanto ao sexo, $48 \%$ estudos foram realizados com amostras mistas, 30\% estudos descreveram que a amostra era composta apenas por sujeitos do sexo masculino, $12 \%$ estudos não descreveram o sexo investigado, $7 \%$ estudos identificaram que a amostra era composta apenas por sujeitos do sexo feminino e para $2 \%$ estudo a questão não se aplica.

A faixa etária, públicos-alvo e design foram bastante variados nos estudos, analisando indivíduos dos 7 até 45 anos de idade.

Houve grande variedade em toda a parte epistemológica em relação às análises / testes estatísticos utilizados, resultados, conclusões, limitações e meios de avaliação dos artigos. Os focos de investigação de cada estudo foram divergentes de maneira individual, em suma, abordavam quanto à busca de diferenças individuais (46\%), capacidades/ testes físicos (11\%), habilidades técnicas (10\%), aspectos comportamentais (10\%), artigos que desenvolviam o talento de maneira conceitual ou informativa (7\%), quanto à validação/aplicação de testes (4\%), talento esportivo em associação com a família (4\%), iniciação esportiva (3\%) e tempo de prática $(1 \%)$.

\subsection{Discussão}

Tendo em vista a massiva e divergente quantidade de informações, esta discussão se pautará em trazer à tona o panorama do que é possível discutir e foi obtido de informações de maneira clara na revisão sistemática de maneira qualitativa.

Entre os objetivos analisados, o principal foi auxiliar no desenho de futuros estudos, 
identificando as potências e fragilidades sobre o Talento Esportivo. Foram observados três aspectos recorrentes ao pesquisar o talento, sendo: fatores fisiológicos, fatores psicológicos, e aspectos subjetivos no desenvolvimento de um talento.

A partir de um cenário transnacional sobre as condições de aprendizagem no desporto profissional, Agengaard (2017), estudou as possibilidades de aprendizado nas comunidades e para os ativos de aprendizado dos encontros de fronteira. De acordo com o estudo, o intercâmbio cultural pode ser positivo para o desenvolvimento dos talentos de atletas nativos. A aprendizagem pode se desenvolver nas relações sociais e os conhecimentos práticos que um atleta adquire em contato com diferentes comunidades, além disso, parecem cruciais para seu desenvolvimento profissional. Os jogadores imigrantes deram aos jovens talentos nacionais a chance de experienciar abordagens para a prática do handebol profissional que são fundamentais em um cenário global. É preciso considerar a quebra do nacionalismo metodológico na governança do esporte. Ainda assim. Também é importante salientarmos que os padrões pessoais são essenciais para o desenvolvimento de habilidades, desta forma os treinadores devem encorajar os jogadores a buscarem uma vida social saudável, dentro e fora do ambiente esportivo (KLUND; SAETHER, 2017).

Neste sentido, em Collins \& Macnamara (2017), são exploradas as características psicológicas e propostas sugestões para o avanço e estímulo ao debate crítico entre profissionais, pesquisadores e formuladores de políticas. É também fomentado o apoio com questões mais amplas, como por exemplo, recuperação de lesões, oferecendo grande benefício educacional aos personagens envolvidos, por meio do uso crescente de várias abordagens.

Ainda sobre aspectos emocionais, Van Rens (2018), fala sobre as experiências de tensão nas carreiras duplas de atletas de elite podem influenciar negativamente o bem-estar e satisfação de vida do adolescente. $\mathrm{O}$ aumento das experiências de tensão relacionadas às carreiras duplas dos jogadores de elite júnior foi associado à redução da satisfação com a vida no âmbito do esporte, amizades, família, e a satisfação global com a vida de modo geral. Situações nas quais os jogadores acham que suas habilidades são subutilizadas também foram negativamente associadas à sua satisfação com a vida em vários aspectos. A satisfação com a vida está positivamente associada ao funcionamento físico, mental, social e emocional dos adolescentes. Compreender a satisfação com a vida dos jogadores de elite é, portanto, não só importante para desenvolver estratégias baseadas em condições para melhorar o bem-estar dos atletas juniores, mas também para evitar que seus desempenhos esportivos e acadêmicos sejam afetados.

Com foco em examinar de perto as Entrevistas de Avaliação em acampamentos de 
seleção de talentos, Kilger \& Jonsson (2017b), relatam em sua pesquisa um gênero narrativo estruturado para interagir de forma específica no processo de detecção do talento. As conclusões demonstram que um entrevistado de sucesso apresenta o equilíbrio entre o auto aperfeiçoamento, precisão e humildade. Além disso, em suas narrativas, os jogadores devem demonstrar o equilíbrio entre não exibir uma personalidade com muita ou pouca autoestima, isto é, a ponderação entre o orgulho e a modéstia, já que o egocentrismo pode ser visto como um traço mal adaptativo. Além disso, o objetivo do atleta deve ser mostrar potencial de desenvolvimento e autoconsciência, estar ciente das áreas passíveis de evolução, sem demonstrar um mau desempenho. No contexto de uma pessoa jovem que faz a transição da juventude para a elite na idade adulta, indicadores de desenvolvimento mostram-se através dos níveis de maturidade percebida.

Em outro trabalho (MORRIS et al., 2017), por meio de entrevistas semi-estruturadas, com cinco jogadores do sexo masculino, que passaram por uma transição do futebol juvenil em tempo integral para jogadores em tempo integral como atletas de elite em um clube de futebol, foi sugerido que ao invés de estarem contentes com o fato de pertencerem à nova categoria, os atletas perderam a motivação quanto à serem iniciantes bem-sucedidos na equipe. Aparentemente, as razões pelas quais os atletas sentem-se motivados, podem mudar antes e depois da transição, o que corresponde a mudanças em seus níveis de ansiedade e confiança, influenciando no desenvolvimento do talento esportivo. Os participantes do presente estudo alegaram que ao subir para a primeira equipe acreditavam que o futebol teria um padrão muito mais elevado do que o tinham experimentado a nível juvenil. Na pós-transição, todavia, os atletas não sentiram que acompanhar o padrão foi tão difícil quanto esperavam, e eles estavam menos ansiosos e mais confiantes sobre seus próprios níveis de habilidade. A experiência de transição que conduz o atleta ao nível profissional de elite, origina desafios psicológicos intensos. Geralmente, há muita pressão interna e externa para ser bem-sucedido, desta forma, sem o acompanhamento psicológico ideal, o atleta provavelmente terá maiores dificuldades no desenvolvimento de seu talento.

Desta forma um elemento que se faz importante para o atleta é a boa noção de suas capacidades reais, Matin \& Saether (2017), em um estudo, fizeram uso de perguntas autoavaliativas, nas quais os jogadores avaliaram suas próprias habilidades em comparação aos companheiros de equipe no que se refere a: desempenho técnico, tático, habilidades mentais, sociais e físicas, em uma escala Likert de 5 pontos, com objetivo de investigar quais habilidades os jogadores do ensino médio consideram mais importantes e como julgam suas próprias 
habilidades em comparação aos colegas, bem como quais habilidades os treinadores de clube consideram mais relevantes. Os resultados mostraram que os jogadores com melhores desempenhos consideraram habilidades técnicas e mentais como mais importantes do que os jogadores de nível inferior de desempenho. Estes resultados condizem com o destacado como importante no processo para identificação de talentos realizados por treinadores de nível superior, o que indica que os jogadores e treinadores concordam sobre a importância dessas duas habilidades.

Em um estudo realizado por Klund \& Sæther (2017), após uma sessão de treinamento nos clubes, utilizando a Escala Multidimensional de Perfeccionismo de Futebol, uma coleta de dados foi realizada com para avaliar o perfeccionismo dos atletas, considerando respostas dadas em uma escala de Likert de cinco pontos. Foi constatado que as auto avaliações quanto às dimensões do perfeccionismo eram maiores para os padrões pessoais e menores para a percepção da pressão dos pais. Além disso foi constatado que os jogadores menos habilidosos percebiam maior pressão dos pais e dos treinadores.

Dentro deste e outros contextos a família pode desempenhar um papel essencial para que o atleta alcance o melhor desempenho em suas modalidades. Ela é responsável por aspectos importantes ao longo do desenvolvimento do atleta, como: suporte financeiro, apoio informativo, apoio emocional, transmissão de valores e crenças, além das expectativas que deposita quanto ao desempenho do jovem (TAYLOR et al., 2017; TAYLOR et al., 2018; SILVA; SOUZA, 2018). Apesar disso, Silva \& Souza (2018), ressaltam que outros aspectos também são importantes para o desenvolvimento de um atleta de alto desempenho, como: relação estabelecida com o técnico, treinamentos de alta qualidade, acesso aos equipamentos mais aprimorados, alimentação adequada, patrocínio para participar de competições em outros locais e treinar com atletas de outros centros esportivos. $\mathrm{O}$ alcance de um desempenho elevado é resultado de uma combinação de fatores que possibilitam condições para que o atleta se aperfeiçoe constantemente, e seja capaz de superar os eventuais desafios que surgirão.

Outros pontos importantes podem ser constatados em Naisidou et al. (2017), que estudaram com atletas talentosas (com base nas opiniões de especialistas de três equipes nacionais de jovens talentos, que diferenciam jogadoras bem-sucedida ou menos bemsucedida), foram selecionadas atletas do sexo feminino durante um acampamento esportivo de 4 dias no início de julho 2015, quando as equipes participaram de jogos abertos de verão, com objetivo de identificar os atributos antropométricos e características de desempenho físico. Por meio de procedimentos de testes, os resultados demonstraram que a força muscular dos 
membros superiores e inferiores em combinação com estatura e agilidade, distinguiu o sucesso das jovens jogadoras das menos bem-sucedidas. $\mathrm{O}$ estudo constatou que as jogadoras de handebol feminino adolescentes bem-sucedidas, realizaram uma média maior na bateria de habilidades motoras e testes de habilidades técnicas. A morfologia da mão combinada com suas habilidades desempenha um papel decisivo no desempenho em esportes de equipe que usam uma bola. Além disso, como em outros esportes coletivos, atletas adultos de longa estatura apresentam vantagem para cobrir o espaço devido às suas longas extremidades e também se beneficiam no músculo, quanto a produção de energia através dos sistemas de alavancagem do corpo. Entretanto, os atributos antropométricos, físicos e habilidades combinadas com as características técnicas, devem ser avaliadas em constantes intervalos de tempo no período prépúbere. Uma vez que atletas selecionados com vantagem de maturação durante o início da adolescência tendem a não reter essas vantagens até a idade adulta. Por outro lado, a avaliação desses atributos fornece informações importantes sobre os pontos fortes e fracos dos atletas, bem como sobre adaptações individuais de treinamento. Entretanto, visando selecionar atletas que demonstram potencial de evoluir, outros parâmetros também devem ser considerados.

Para Gómez et al. (2017), a data de nascimento permanece sendo um fator crucial na seleção de jovens talentos, após estudo realizado com jogadores de handebol. A análise dos resultados demonstrou a existência de diferenças significativas, indicando que os atletas nascidos nos primeiros meses do ano são mais propensos a fazer parte de uma equipe campeã, tomando como base o trimestre e semestre de nascimento.

Dentro deste contexto, a idade relativa é destacada por Práxedes et al. (2017), como elemento impactante nos jogadores de futebol de acordo com o nível da equipe, foi possível analisar nos clubes amadores, o efeito da idade relativa dos jogadores de futebol, de acordo com o nível de perícia esportiva da equipe. Em relação as categorias formativas, foi possível observar que os jogadores nascidos no início do ano (relativamente mais velhos) têm mais vantagens quando comparados com os nascidos no final do ano (relativamente mais jovens), porque o desenvolvimento físico, fisiológico e psicológico aparentemente é mais avançado nos jogadores nascidos no início do ano. Ao estudar o efeito da idade relativa, conclui-se que a influência da maturidade como um fator decisivo na seleção de jogadores deve ser considerada. Os jogadores mais velhos se beneficiam do acúmulo de experiência no contexto prático, como consequência da idade relativa na formação. O problema da idade relativa pode ser neutralizado pelos técnicos dos clubes desportivos, introduzindo outros critérios para selecionar jogadores, de acordo com os objetivos formados, de modo que a prioridade seja à busca de talento esportivo em vez de 
alcançar resultados a curto prazo (RUBAJCZYK et al., 2017).

Em relação à comparação das medidas de maturação biológica, antropométrica, física e técnica entre jovens jogadores de futebol australianos talentosos e não talentosos, foi identificado que 16 jogadores talentosos eram biologicamente mais velhos, tinham maiores saltos estacionários e dinâmicos e habilidades superiores de handebol quando comparados com aos não-talentosos. $\mathrm{O}$ modelo mais forte de status incluiu altura em pé, dinâmica vertical não dominantes resultados de salto e handebol. A maturação biológica influencia de forma antropométrica as capacidades físicas que são vantajosas para o desempenho no futebol australiano. (CRIPPS et al., 2017).

Dentre os artigos é relatado que a força muscular, em combinação com a estatura e agilidade, tem grande influência no sucesso dos jovens atletas. No entanto, essas características ocorrem por maturação biológica no início da adolescência. Por isso, deve-se ter cuidado ao realizar seleções apenas baseadas nesses atributos, pois os jovens provavelmente, não reterão essas vantagens até a idade adulta (NAISIDOU et al., 2017; TAHA et al., 2018). Assim, os técnicos devem considerar a idade cronológica e a aceleração do crescimento puberal no que tange à detecção do talento, porque o mês de nascimento, a altura do corpo e o sexo foram fatores chaves para um melhor rendimento esportivo, conforme observado ao longo das analises (RUBAJCZYK et al., 2017).

Finalmente, os resultados revelam ainda que os técnicos esportivos experientes, possuem critérios subjetivos para identificar talentos. Ao identificar o potencial dos atletas, os treinadores utilizam critérios próprios, a partir dos fatores contextuais relacionados à cultura na qual estão inseridos e que, influenciam frequentemente a forma como as qualidades dos atletas serão ou não reconhecidas (JOKUSCHIES et al., 2017). Comumente, os treinadores baseiamse na própria experiência de vida, orientando suas decisões a partir de gostos e definições pessoais do que é talento (LUND; SÖDERSTRÖM, 2017). É interessante, porém, observar a eficiência constatada em um dos estudos, no qual o "olhar dos treinadores" se mostrou um método válido para reconhecer as características de maturação biológica nos atletas. Se comparado ao método tradicional de raio-x, o "olhar dos treinadores", ofereceu uma coleta de informações de maneira mais rápida, a um custo menor e sem exposição à radiação, ou seja: mais eficiente (ROMANN et al, 2017). De qualquer forma, os artigos concordam quanto à importância dos técnicos serem incentivados a especificar e aperfeiçoar seus critérios subjetivos de detecção de talentos. Existem ainda, algumas características fundamentais que estão associadas a identificação e desenvolvimento de atletas de sucesso, elas envolvem: o equilíbrio 
entre o autoaperfeiçoamento, precisão e humildade, além disso é necessário ponderar orgulho e modéstia (KILGER, 2017). Quanto ao ponto de vista dos atletas com carreiras já bem desenvolvidas, alguns pontos foram repetidamente citados, como importantes para alcançar o sucesso, como por exemplo "a importância de ter o personagem certo" na própria história e "ser um jogador de equipe". Notou-se um dilema recorrente entre os atletas quanto a ser um indivíduo notável e, ao mesmo tempo, ser benéfico ao coletivo. É preciso mais do que apenas habilidades para se tornar um talento notável (KILGER, 2017).

O presente estudo trouxe uma vasta gama de informações, porém possui algumas limitações no que tange a sintetização de qualquer comparação dos artigos, mesmo que todos tratem sobre talento esportivo, cada um adotou desenhos de pesquisa diferentes, tornando difícil a comparação e criação de subgrupos de maneira mais aprofundada.

\subsection{Conclusão}

A partir desta revisão sistemática foi possível concluir que a detecção, seleção, promoção e desenvolvimento do talento esportivo relacionam-se à fatores fisiológicos, psicológicos e de apoio, estes fatores são muito importantes no processo de condução à excelência esportiva. Trabalhos que procurem integrar o fenômeno "talento esportivo" com abordagens multifatoriais podem se complementar auxiliando os praticantes e modalidades esportivas se correlacionar e sintetizar trabalhos que possuam um ideal epistemológico muito mais preciso.

É notável a necessidade pela publicação e validação de modelos experimentais nos processos de consolidação do talento, e a vasta gama de publicações aparece de forma positiva quando de fato fomenta novidades na área da Educação Física e afins, porém em certos achados a publicação aparenta ter em vista somente a alimentação dela mesma.

Detectar atletas talentosos é uma tarefa complexa, pois envolve aspectos objetivos e subjetivos, que se desdobram geralmente, ao longo do tempo e são intrínsecos à personalidade de cada atleta e suas percepções como indivíduo, no entanto ainda existe muito o que ser feito para que exista uma melhor comunicação da parte prática e modelos experimentais.

Finalmente, foi constatada a carência de estudos que analisem o talento esportivo, de forma longitudinal, partindo da detecção do talento esportivo, até o final da carreira esportiva deste talento, que pode ser ainda nos períodos iniciais das peneiras, ou até mesmo numa possível aposentadoria. Compreender e encarar com naturalidade o ciclo do desenvolvimento do talento 
esportivo, poderia ser benéfico, na medida que técnicos e atletas usufruíssem de planejamentos que trouxessem condições ideais fisiológicas e psicológicas de maturação para desenvolver o talento, ao mesmo tempo, estando conscientes de um posterior declive natural ou ganhos reduzidos do rendimento esportivo, comuns à carreira de grandes atletas, seja pelo avanço da idade, possíveis lesões ao longo da carreira e outros aspectos. 


\section{REFERÊNCIAS}

ALENCAR, E. M. O aluno com altas habilidades no contexto da educação inclusiva. Revista Movimento, 7, 60-69, 2003.

ALENCAR, E. M.; FELDHUSEN, J. F.; FRENCH, B. Identificando talentos, aspirações profissionais e pessoas mais admiradas por estudantes. Psicologia Escolar e Educacional, v. 8, n. 1, p. 11-16, 2004.

ABBOTT, A.; BUTTON, C.; PEPPING, G. J.; COLLINS, D. Unnatural selection: Talent identification and development in sport. Nonlinear dynamics, psychology, and life sciences, v. 9, n. 1, p. 61-88, 2005.

AGERGAARD, S. Learning in landscapes of professional sports: transnational perspectives on talent development and migration into Danish women's handball around the time of the financial crisis, 2004-2012. Sport in Society, v. 20, n. 10, p. 1457-1469, 2017.

BARBANTI, V. J. A comparative study of selected anthropometric and physical fitness measurements of brazilian and american school children. Estados Unidos, 1982. Dissertação The University of lowa, 1992.

BARTULOVIC, D.; YOUNG, B. W.; BAKER, J. Self-regulated learning predicts skill group differences in developing athletes. Psychology of Sport \& Exercise, v. 31, p. 61-69, 2017.

BJØRNDAL, C. T.; RONGLAN, L. T.; ANDERSEN, S. S. Talent development as an ecology of games: a case study of Norwegian handball. Sport, Education \& Society, v. 22, n.7, p. 864-877, 2017.

BLOOM, B. S.; SOSNIAK, L. A. Developing talent in young people. Ballantine Books, 1985.

BOCCIA, G.; BRUSTIO, P. R.; MOISÈ, P.; FRANCESCHI, A.; TORRE, A.; SCHENA, F.; CARDINALE, M. Elite national athletes reach their peak performance later than non-elite in sprints and throwing events. Journal of science and medicine in sport, 2018.

BÖHME, M. T. Talento esportivo I: aspectos teóricos. Revista Paulista de Educação Física, v.8, n.2, p.90-100, 1994.

BÖHME, M. T. Talento esportivo II: determinação de talentos esportivos. Revista Paulista de Educação Física, v.9, n.2, p.138-46, 1995.

BÖHME, M. T. Detecção, seleção e promoção de talentos esportivos: determinação de critérios de desempenho nos aspectos bio-psico- social. Projeto de pesquisa interdisciplinar do Departamento de Esporte, 1996.

BÖHME, M. T. Aptidão física de jovens atletas do sexo feminino analisada em relação a determinados aspectos biológicos, idade cronológica e tipo de modalidade esportiva.

Dissertação. Escola de Educação Física e Esporte da Universidade de São Paulo, 1999. 
BÖHME, M. T. O treinamento a longo prazo e o processo de detecção, seleção e promoção de talentos esportivos. Revista brasileira de ciências do esporte, São Paulo, 21 (2/3), Jan/Maio 2000.

BÖHME, M. T. A contribuição do curso de Pós-graduação em Educação Física da Escola de Educação Física e Esporte no desenvolvimento da linha de pesquisa em Esporte infantojuvenil, Treinamento a longo prazo e Talento esportivo. Rev.bras. Educ. Fís. Esp., v.21, p.115-30, dez. 2007.

BOJIKIAN, J. C. M.; DA SILVA, A. V. O.; PIRES, L. C.; DE LIMA, D. A.; BOJIKIAN, L. P. Talento esportivo no voleibol feminino do Brasil: maturação e iniciação esportiva. Revista Mackenzie de educação física e esporte, v. 6, n. 3, 2009

BRAZO-SAYAVERA, J.; OLIVARES, P. R.; ANDRONIKOS, G.; MARTINDALE, R. J. Spanish version of the Talent Development Environment Questionnaire for sport: Cultural adaptation and initial validation. PLoS ONE, v. 12, n. 6, 2017.

BROWNLEE, T. E.; O’BOYLE, A.; MORGANS, R.; MORTON, J. P.; ERSKINE, R. M.; DRUST, B. Training duration may not be a predisposing factor in potential maladaptations in talent development programmes that promote early specialisation in elite youth soccer.

International Journal of Sports Science and Coaching, v. 13, n. 5, p. 674-678, 2018.

BRUSTIO, P. R.; LUPO, C.; UNGUREANU, A. N.; FRATI, R.; RAINOLDI, A.; BOCCIA, $\mathrm{G}$. The relative age effect is larger in Italian soccer top-level youth categories and smaller in Serie A. PloS one, v. 13, n. 4, p. e0196253-e0196253, 2018.

BURGESS, D. J.; NAUGHTON, G. A. Talent development in adolescent team sports: A review. International journal of sports physiology and performance, v. 5, n. 1, p. 103-116, 2010 .

CAMACHO-CARDENOSA, A.; CAMACHO-CARDENOSA, M.; GONZÁLEZCUSTODIO, A.; MARTÍNEZ-GUARDADO, I.; TIMÓN, R.; OLCINA, G.; BRAZOSAYAVERA, J. Anthropometric and Physical Performance of Youth Handball Players: The Role of the Relative Age. Sports (Basel, Switzerland), v.6, n. 2, 2018.

CHIAVENATO, I.; VILLAMIZAR, G. Gestión del talento humano. Mc Graw-Hill, 2002.

CLARK, S. J. S. Being 'Good at Sport': Talent, ability and young women's sporting participation. Sociology, v. 46, n. 6, p. 1178-1193, 2012.

COLLINS, D. J.; MACNAMARA, A. Making Champs and Super-Champs-Current Views, Contradictions, and Future Directions. Frontiers in Psychology, v.8, 2017.

COSTA, A. M.; GRAZINA, C.; MIRAGAIA, D.; CRISÓSTOMO, L.; CARVALHO, P. G. Contexto de desenvolvimento desportivo em clubes de natação: Um estudo preliminar sobre as perceções dos nadadores portugueses. Revista Iberoamericana de Psicologia del Ejercicio y el Deporte, v. 12, n. 2, p. 231-236, 2017. 
CÔTÉ, J. The influence of the family in the development of talent in sport. The Sport Psychologist, 1999, 13, 395-417.

CRIPPS, A. J.; JOYCE, C.; WOODS, C. T.; HOPPER, L. S. Biological maturity and the anthropometric, physical and technical assessment of talent identified U16 Australian footballers. International Journal of Sports Science \& Coaching, v. 12, n. 3, p. 344-350, 2017.

CSIKSZENTMIHALYI, M.; RATHUNDE, K.; WHALEN, S. Talented teenagers: The roots of success and failure. Cambridge University Press, 1997.

CUMMING, S. P.; LLOYD, R. S.; OLIVER, J. L.; EISENMANN, J. C.; MALINA, R. M. Bio-banding in Sport: Applications to Competition, Talent Identification, and Strength and Conditioning of Youth Athletes. Strength \& Conditioning Journal (Lippincott Williams \& Wilkins), v. 39, n.2, p. 34-47, 2017.

BOSSCHER, V.; DE RYCKE, J. Talent development programmes: a retrospective analysis of the age and support services for talented athletes in 15 nations. European Sport

Management Quarterly, v. 17, n. 5, p. 590-609, 2017.

MENDONÇA, M. T.; HONDA, R.; MASSA, M.; UEZU, R. Formação e desenvolvimento de talentos esportivos no handebol masculino. Revista Mackenzie de Educação Física e Esporte n. 6, p. 125- 135, 2007.

DEVANEY, D. J.; NESTI, M. S.; RONKAINEN, N. J.; LITTLEWOOD, M.;

RICHARDSON, D. Athlete Lifestyle Support of Elite Youth Cricketers: An Ethnography of Player Concerns Within a National Talent Development Program. Journal of Applied Sport Psychology, v. 30, n.3, p. 300-320, 2018.

ENGLISH, C.; NASH, C.; MARTINDALE, R. The effects of structural change: an investigation into the South African cricket development pathway. International Journal of Sport Policy, v. 10, n.2, p. 371-391, 2018.

ERICSSON, K. A.; KRAMPE, R. T.; TESCH-RÖMER, C. J. P. R. The role of deliberate practice in the acquisition of expert performance. Psychological review, v. 100, n. 3, p. 363, 1993.

ERIKSTAD, M. K.; HØIGAARD, R.; JOHANSEN, B. T.; KANDALA, N. B.; HAUGEN, T. Childhood football play and practice in relation to self-regulation and national team selection; a study of Norwegian elite youth players. Journal of Sports Sciences, v. 36, n. 20, p. 23042310, 2018.

FABER, I. R.; PION, J.; MUNIVRANA, G.; FABER, N. R.; NIJHUIS-VAN DER SANDEN, M. W. Does a perceptuomotor skills assessment have added value to detect talent for table tennis in primary school children? Journal of sports sciences, v. 36, n. 23, p. 2716-2723, 2018.

FERNÁNDEZ-ROMERO, J. J.; SUÁREZ, H. V.; CARRAL, J. M. C. Selection of talents in handball: Anthropometric and performance analysis. Revista Brasileira de Medicina do Esporte, v. 23, n. 5, p. 361-365, 2017. 
FILIN, V. P.; GOMES, A. C.; DA SILVA, S. G. Desporto juvenil: teoria e metodologia. Centro de Informações Desportivas, 1996.

GLEDHILL, A.; HARWOOD, C. Toward an Understanding of Players' Perceptions of Talent Development Environments in UK Female Football. Journal of Applied Sport Psychology. p. 1-11, 2018.

GÓMEZ-LÓPEZ, M.; GRANERO-GALLEGOS, A.; MOLINA, S. F.; RÍOS, L. J. C. Relative age effect during the selection of young handball player. Journal of Physical Education and Sport, Department of Physical Activity and Sport, v. 17, n. 1, p. 418-423, 2017.

GUENTHER, Z. C. Desenvolver capacidades e talentos: um conceito de inclusão. Vozes, 2000.

HANCOCK, D. J.; COUTINHO, P.; CÔTÉ, J.; MESQUITA, I. Influences of population size and density on birthplace effects. Journal of Sports Sciences, v. 36, n. 1, p. 33-38, 2018.

HJORT, A.; HENRIKSEN, K.; ELBÆK, L. Player-Driven video analysis to enhance reflective soccer practice in talent development. International Journal of Game-Based Learning, v.8, n. 2, p. 29-43, 2018.

HOHMANN, A.; SEIDEL, I. Scientific aspects of talent development. Journal of Physical Education, v. 40, p. 9-20, 2003.

HOULIHAN, B.; CHAPMAN, P. Talent identification and development in elite youth disability sport. Sport in Society, v. 20, n. 1, p. 107-125, 2017.

HUTTER, R. I. V.; VAN DER ZANDE, J. J.; ROSIER, N.; WYLLEMAN, P. Education and training in the field of applied sport psychology in Europe. International Journal of Sport \& Exercise Psychology, v. 16, n.2, p. 133-149, 2018.

JACOB, Y.; SPITERI, T.; HART, N.; ANDERTON, R. The Potential Role of Genetic Markers in Talent Identification and Athlete Assessment in Elite Sport. Sports (Basel, Switzerland), v.6, n. 3, 2018.

JOKUSCHIES, N.; GUT, V.; CONZELMANN, A. Systematizing coaches' 'eye for talent': Player assessments based on expert coaches' subjective talent criteria in top-level youth soccer. International Journal of Sports Science and Coaching, v. 12, n. 5, p. 565-576, 2017.

KILGER, M. Talent stories in youth sports: Discursively shared narratives of success. Narrative Inquiry, v. 27, n. 1, p. 47-65, 2017.

KILGER, M.; JONSSON, R. Talent production in interaction: Performance appraisal interviews in talent selection camps. Communication and Sport, v.5, n. 1, p. 101-129, $2017 \mathrm{~b}$.

KISS, M. A.; BOHME, M. T.; MANSOLDO, A. C.; DEGAKI, E.; REGAZZINI, M. Desempenho e Talento Esportivos. Revista Paulista de Educação Física, v. 18, p. 89-100, 
2004.

KLUND, F.; SÆTHER, S. A. Relationships Between Perfectionism, Training Load and Elite Junior Football Players' Self-Assessed and Coach-Assessed Skills. Sport Journal, p. 1-1, 2017.

KRISTIANSEN, E.; HOULIHAN, B. Developing young athletes: The role of private sport schools in the Norwegian sport system. International Review for the Sociology of Sport, v. 52, n. 4, p. 447-469, 2017.

LANARO FILHO, P. Referências para a detecção, seleção e promoção de talentos esportivos em GRD. Dissertação. Escola de Educação Física e Esporte da Universidade de São Paulo. 2001.

LI, C.; MARTINDALE, R.; WU, Y.; SI, G. Psychometric properties of the Talent Development Environment Questionnaire with Chinese talented athletes. Journal of Sports Sciences, v. 36, n. 1, p. 79-85, 2018.

LI, C.; WANG, C. J.; PYUN, D. Y. J. Q. Talent development environmental factors in sport: A review and taxonomic classification. Quest, v. 66, n. 4, p. 433-447, 2014.

LI, C.; WANG, C. K. J.; FYUN, D. O. Y. The roles of the talent development environment on athlete burnout: a qualitative study. International Journal of Sport Psychology, v. 48, n.2, p. 143-164, 2017.

LI, C.; WANG, C. K.; PYUN, D. Y. Impacts of talent development environments on athlete burnout: a self-determination perspective. Journal of Sports Sciences, v. 35, n. 18, p. 1838$1845,2017$.

LIBERATI, A.; ALTMAN, D. G.; TETZLAFF, J.; MULROW, C.; GOTZSCHE, P. C.; IOANNIDIS, J. P.; CLARKE, M.; DEVEREAUX, P.J.; KLEIJNEN, J.; MOHER, D. The PRISMA Statement for Reporting Systematic Reviews and Meta-Analyses of Studies That Evaluate Health Care Interventions: Explanation and Elaboration. Annals of Internal Medicine, v. 151, n. 4, Aug. 2009.

LIDOR, R.; CÔTÉ, J.; HACKFORT, D.. ISSP position stand: To test or not to test? The use of physical skill tests in talent detection and in early phases of sport development.

International journal of sport and exercise psychology, v. 7, n. 2, p. 131-146, 2009.

LIGHT, R. L.; EVANS, J. R. Learning as Transformation in the Development of Expertise by Elite Indigenous Australian Athletes. Sport Mont, v. 16, n.2, p. 93-96, 2018.

LIMA, D. A.; ESTRADA, L. F.; MASSA, M.; HIROTA, V. B. A maturação sexual e a idade cronológica durante um processo de detecção, seleção e promoção do talento esportivo nas categorias de base do futebol de campo. Revista Mackenzie de Educação Física e Esporte, v. 7, n. 3, 2009.

LIMPENS, V.; BUSZARD, T.; SHOEMAKER, E.; SAVELSBERGH, G. J.; REID, M. Scaling Constraints in Junior Tennis: The Influence of Net Height on Skilled Players' MatchPlay Performance. Research Quarterly for Exercise and Sport, v. 89, n. 1, p. 1-10, 2018. 
LUND, S.; SÖDERSTRÖM, T. To See or Not to See: Talent Identification in the Swedish Football Association. Sociology of Sport Journal, v. 34, n.3, p. 248-258, 2017.

MARQUES, A.C.P.; ROSADO, A.F.B. Situações estressantes nos atletas de basquetebol de alta competição. Revista Brasileira de Educação Física e Esporte, São Paulo, v.19, n.1, p.71-87, 2005.

MASSA. M. Seleção e promoção de talentos esportivos em voleibol masculino: análise de aspectos cineantropométricos. Dissertação. Universidade de São Paulo, 1999.

MASSA, M.; UEZU, R.; BÖHME, M. T. Judocas olímpicos brasileiros: fatores de apoio psicossocial para o desenvolvimento do talento esportivo. Rev. bras. Educ. Fís. Esporte, v.24, n.4, p.471-81, out./dez. 2010.

MASSA, M.; UEZU, R.; BÖHME, M. T.; SILVA, L. R.; KNIJNIK, J. D. Desempenho esportivo no judô olímpico brasileiro: o talento é precoce? Revista Brasileira de Ciência e Movimento, v. 18, n. 1, p. 5-10, 2010.

MATIN, V.; SAETHER, S. A. Talented High School Football Players' Perception of Talent Identification Criteria. Sport Mont, v. 15, n.2, p. 3-7, 2017.

MATSUDO, V. K. R.; MATSUDO S. M. Ciência e detecção de talentos. Âmbito Medicina Esportiva, n.30, abr. 1997.

MORRIS, R.; TOD, D.; EUBANK, M. From youth team to first team: An investigation into the transition experiences of young professional athletes in soccer. International Journal of Sport \& Exercise Psychology, v. 15, n. 5, p. 1-17, 2017.

MURTAGH, C. F.; BROWNLEE, T. E.; O'BOYLE, A.; MORGANS, R.; DRUST, B.; ERSKINE, R. M.. Importance of speed and power in elite youth soccer depends on maturation status. Journal of Strength \& Conditioning Research (Lippincott Williams \& Wilkins), v. 32, n.2, p. 297-303, 2018.

MUSCULUS, L.; LOBINGER, B. H. Psychological characteristics in talented soccer players Recommendations on how to improve coaches' assessment. Frontiers in Psychology, v.9, feb. 2018.

NAISIDOU, S.; KEPESIDOU, M.; KONTOSTERGIOU, M.; ZAPARTIDIS, I. Differences of physical abilities between successful and less successful young female athletes. Journal of Physical Education and Sport, Anavryta Experimental Lyceum, Kifisia, Greece, v. 17, n. 1, p. 294-299, 2017.

NOCE, F.; FERREIRA, T. S.; MOREIRA, C. Z.; ANDRADE, A. G.; MELLO, M. T.; COSTA, V. T. Influência do tempo de reação simples na seleção de jovens talentos no tênis. Journal of Physical Education. v. 23, n.3, p. 369-377, 3. trim. 2012. 
ONG, C. W.; MCGREGOR, P.; DALEY, C. The boy behind the bravado: Player advanced safety and support in a professional football academy setting. Sport \& Exercise Psychology Review, v. 14, n. 1, p. 65-79, 2018.

OWEN, A. L.; LAGO-PEÑAS, C.; DUNLOP, G.; MEHDI, R.; CHTARA, M.; DELLAL, A. Seasonal Body Composition Variation Amongst Elite European Professional Soccer Players: An Approach of Talent Identification. Journal of human kinetics, v. 62, p. 177-184, 2018.

PASTOR-VICEDO, J. C.; CONTRERAS-JORDÁN, O.; PRIETO-AYUSO, A. Performance indicators as a resource for the selection of talented football players. Journal of Human Sport \& Exercise, v. 12, p. S797-S806, 2017.

PAUŠEK, K.; PAUŠEK, D.; SERTIĆ, D.; MISSONI, S.; \& SINDIK, J. Psychological sporting talent and indicators of mental health at young male and female handball players. / Psihološki talent i obilježja mentalnog zdravlja kod rukometaša i rukometašica. Sports Science \& Health / Sportske Nauke i Zdravlje, v. 7, n. 1, p. 5-12, 2017.

PENA-GONZALEZ, I.; FERNÁNDEZ-FERNÁNDEZ, J.; MOYA-RAMÓN, M.; CERVELLÓ, E. Relative Age Effect, Biological Maturation, and Coaches' Efficacy Expectations in Young Male Soccer Players. Research quarterly for exercise and sport, v. 89, n. 3, p. 373-379, 2018.

PHILLIPS, E.; KEITH, D.; RENSHAW, I.; PORTUS, M. Expert performance in sport and the dynamics of talent development. Sports medicine, v. 40, n. 4, p. 271-283, 2010.

PION, J.; HOHMANN, A.; LIU, T.; LENOIR, M.; SEGERS, V. Predictive models reduce talent development costs in female gymnastics. Journal of Sports Sciences, v. 35, n.8, p. 806-811, 2017.

PRÁXEDES, A.; MORENO, A.; GARCÍA-GONZÁLEZ, L.; PIZARRO, D.; DEL VILLAR, F. The Relative Age Effect on Soccer Players in Formative Stages with Different Sport Expertise Levels. Journal of Human Kinetics, v. 60, n. 1, p. 167-173, 2017.

QUIJADA, M. R. Is the Successful Athlete Born or Made? A Review of the Literature. Apunts: Educació Física i Esports, n. 123, 2016, 2016.

RÉ, A. H.; TEIXEIRA, C. P.; MASSA, M.; BÖHME, M. T. S. Interferência de características antropométricas e de aptidão física na identificação de talentos no futsal. Revista Brasileira de Ciência e Movimento, v. 11 n. 4 p. 51-56 out./dez. 2003.

RÉGNIER, G.; SALMELA, J.; RUSSELL, S. J. Talent detection and development in sport. Handbook of research in sport psychology, p. 290-313, 1993.

ROMANN, M.; JAVET, M.; FUCHSLOCHER, J. Coaches' eye as a valid method to assess biological maturation in youth elite soccer. Talent Development \& Excellence, v.9, n. 1, p. 3-13, 2017.

ROMANN, M.; RÖSSLER, R.; JAVET, M.; FAUDE, O. Relative age effects in Swiss talent 
development - a nationwide analysis of all sports. Journal of sports sciences, v. 36, n. 17, p. 2025-2031, 2018.

ROSSING, N. N.; STENTOFT, D.; FLATTUM, A.; CÔTÉ, J.; KARBING, D. S. Influence of population size, density, and proximity to talent clubs on the likelihood of becoming elite youth athlete. Scandinavian Journal of Medicine and Science in Sports, v. 28, n. 3, p. 1304-1313, 2018.

RUBAJCZYK, K.; ROKITA, A. The Relative Age Effect in Poland's Elite Youth Soccer Players. Journal of Human Kinetics, v. 64, n. 1, p. 265-273, 2018.

RUBAJCZYK, K.; ŚWIERZKO, K.; ROKITA, A. Doubly Disadvantaged? The Relative Age Effect in Poland's Basketball Players. Journal of Sports Science \& Medicine, v. 16, n. 2, p. 280-285, 2017.

RYBA, T. V.; SCHINKE, R. J.; STAMBULOVA, N. B.; ELBE, A. M. ISSP position stand: Transnationalism, mobility, and acculturation in and through sport. International Journal of Sport \& Exercise Psychology, v. 16, n.5, p. 520-534, 2018.

SAVAGE, J.; COLLINS, D.; CRUICKSHANK, A. Exploring Traumas in the Development of Talent: What Are They, What Do They Do, and What Do They Require? Journal of Applied Sport Psychology, v. 29, n. 1, p. 101-117, 2017.

SCHORER, J.; RIENHOFF, R.; FISCHER, L.; BAKER, J. Long-Term Prognostic Validity of Talent Selections: Comparing National and Regional Coaches, Laypersons and Novices.

Frontiers in Psychology, v.8, 2017.

SEANOR, M.; SCHINKE, R. J.; STAMBULOVA, N. B.; ROSS, D.; KPAZAI, G. Cultivating Olympic champions: A trampoline development environment from grass roots to podium.

Journal of Sport Psychology in Action, v. 8, n. 2, p. 96-108, 2017.

SENF, G. Eignungsdiagnostik-und Normprogramme für die prozessbegleitende Auswahl im Verlauf des Grundlagen-trainings. Grundlagen sportartspezifischer Aunswahl, v.39, n.1, p.21-6, 1990.

SHERWIN, I.; CAMPBELL, M. J.; MACINTYRE, T. E. Talent development of high performance coaches in team sports in Ireland. European Journal of Sport Science, v. 17, n. 3, p. 271-278, 2017.

SILVA, P. V. C.; SOUZA FLEITH, D. Fatores familiares associados ao desenvolvimento do talento no esporte. Revista Brasileira de Psicologia do Esporte, v.3, n. 1, 2018.

SIQUEIRA, M. M. M.; BARBOSA, N. C.; ALVES, M. T. Construção e validação fatorial de uma medida de inteligência emocional. Psicologia: Teoria e Pesquisa, v. 15, n. 2, p. 143 $152,1999$.

SOUSA, A. M.; ELOY, E. R.; MATOS, F. S.; FURASTE, L. F.; Silva Filha, M. J. A gestão de pessoas alinhada à gestão do conhecimento. Gestão do Conhecimento, p. 103, 2001. 
SWANN, C.; CRUST, L.; JACKMAN, P.; VELLA, S. A.; ALLEN, M. S.; KEEGAN, R. Performing under pressure: Exploring the psychological state underlying clutch performance in sport. Journal of Sports Sciences, v. 35, n. 23, p. 2272-2280, 2017.

TAHA, Z.; MUSA, R. M.; MAJEED, A. P. A.; ALIM, M. M.; ABDULLAH, M. R. The identification of high potential archers based on fitness and motor ability variables: A Support Vector Machine approach. Human movement science, v. 57, p. 184-193, 2018.

TAYLOR, R. D.; CARSON, H. J.; COLLINS, D. The Impact of Siblings During Talent Development: A Longitudinal Examination in Sport. Journal of Applied Sport Psychology, v. 30, n.3, p. 272-287, 2018.

TAYLOR, R. D.; COLLINS, D.; CARSON, H. J. Sibling interaction as a facilitator for talent development in sport. International Journal of Sports Science \& Coaching, v. 12, n. 2, p. 219-230, 2017.

TE WIERIKE, S. C. M.; HUIJGEN, B. C. H.; JONKER, L.; ELFERINK-GEMSER, M. T.; VISSCHER, C. The importance and development of ball control and (self-reported) selfregulatory skills in basketball players for different positions. Journal of Sports Sciences, v. 36, n. 6, p. 710-716, 2018.

TEDESQUI, R. A. B.; YOUNG, B. W. Investigating grit variables and their relations with practice and skill groups in developing sport experts. High Ability Studies, v. 28, n.2, p. 167$180,2017$.

TEDESQUI, R. A. B.; YOUNG, B. W. Comparing the contribution of conscientiousness, selfcontrol, and grit to key criteria of sport expertise development. Psychology of Sport \& Exercise, v. 34, p. 110-118, 2018.

TILL, K.; MORLEY, D.; O’HARA, J.; JONES, B. L.; CHAPMAN, C.; BEGGS, C. B.; COBLEY, S. A retrospective longitudinal analysis of anthropometric and physical qualities that associate with adult career attainment in junior rugby league players. Journal of Science and Medicine in Sport, v. 20, n. 11, p. 1029-1033, 2017.

TOOHEY, K.; MACMAHON, C.; WEISSENSTEINER, J.; THOMSON, A.; AULD, C.; BEATON, A.; WOOLCOCK, G. Using transdisciplinary research to examine talent identification and development in sport. Sport in Society, v. 21, n. 2, p. 356-375, 2018.

UEZU, R.; AMARAL, R. M. V.; PAES, F. O.; MASSA, M. Critérios para a seleção de talentos esportivos no handebol masculino. Revista Mackenzie de Educação Física e Esporte, v.7, n.3, p. 71-78, 2008.

VAEYENS, R.; LENOIR, M.; WILLIAMS, A. M.; PHILIPPAERTS, R. M. Talent Identification and Development Programmes in Sport Current Models and Future Directions. Sports Med, v. 38, n. 9, p. 703-714, 2008.

VAN RENS, F. E.; BORKOLES, E.; FARROW, D.; POLMAN, R. C. Domain specific life satisfaction in the dual careers of Junior Elite football players: The impact of role strain. 
Journal of Clinical Sport Psychology, v. 12, n.3, p. 302-315, 2018.

VARGAS, J.; LOUREIRO, M.; NIKOLAIDIS, P. T.; KNECHTLE, B.; LAPORTA, L.; MARCELINO, R.; AFONSO, J. Rethinking Monolithic Pathways to Success and Talent Identification: The Case of the Women's Japanese Volleyball Team and Why Height is not Everything. Journal of human kinetics, v. 64, p. 233-245, 2018.

WATTIE, N.; SCHORER, J.; BAKER, J. Seeing the forest but not the trees: Heterogeneity in community size effects in Canadian ice hockey players. Journal of Sports Sciences, v. 36, n.4, p. 436-444, 2018.

WEINECK, J. Fundamentos gerais da biologia do esporte para a infância e adolescência. Biologia do esporte, p. 246-64, 1991.

WINN, C. O. N.; FORD, P. R.; MCNARRY, M. A.; LEWIS, J.; STRATTON, G. The effect of deprivation on the developmental activities of adolescent rugby union players in Wales. Journal of Sports Sciences, Applied Sport Technology Exercise and Medicine, v. 35, n. 24, p. 2390-2396, 2017.

WOODS, C. T.; VEALE, J.; FRANSEN, J.; ROBERTSON, S.; COLLIER, N. F. Classification of playing position in elite junior Australian football using technical skill indicators. Journal of sports sciences, v. 36, n. 1, p. 97-103, 2018.

WOODS, C. T.; WOODS, C. T.; Veale, J. P.; Collier, N.; Robertson, S. The use of player physical and technical skill match activity profiles to predict position in the Australian Football League draft. Journal of Sports Sciences, v. 35, n. 4, p. 325-330, 2017. 


\section{ANEXO A}

Tabela 1. Características descritivas dos artigos

\begin{tabular}{|c|c|c|c|c|c|c|}
\hline Primeiro autor & $\begin{array}{c}\text { Ano de } \\
\text { publicação }\end{array}$ & Título do trabalho & Jornal & $\begin{array}{l}\text { Local de } \\
\text { realização }\end{array}$ & $\begin{array}{c}\text { Modalidade (s) } \\
\text { esportiva (s) abordada (s) }\end{array}$ & $\begin{array}{l}\text { Objetivo } \\
\text { primário }\end{array}$ \\
\hline AGENGAARD, Sine & 2017 & $\begin{array}{l}\text { Learning in landscapes of } \\
\text { professional } \\
\text { sports: transnational } \\
\text { perspectives on talent } \\
\text { development and migration } \\
\text { into Danish women's handball } \\
\text { around the time of the } \\
\text { financial crisis, 2004-2012 }\end{array}$ & Sport in Society & Dinamarca & handball & $\begin{array}{l}\text { Quebrar o nacionalismo metodológico no } \\
\text { esporte, a partir de uma perspectiva } \\
\text { transnacional alternativa sobre as condições } \\
\text { de aprendizagem no desporto profissional, } \\
\text { utilizando o conceito conceptual de Etienne } \\
\text { Wenger. Wenger chama a atenção para as } \\
\text { opções de aprendizado nas comunidades e } \\
\text { para os ativos de aprendizado dos } \\
\text { encontros de fronteira. }\end{array}$ \\
\hline
\end{tabular}

BARTULOVIC, Dora

2017

Self-regulated learning

predicts skill group

differences in developing

Psychology of Sport \& Exercise

Canadá

esportes individuais

Examinar as diferenças de SRL em três athletes

grupos atléticos progressivamente menos elite, elite.

Descrever a organização do DT no handebol norueguês, (b) identificar como as características organizacionais inerentes do handebol norueguês

Talent development as an ecology of games: a case study of Norwegian handball

Sport, Education \& Society

Noruega

handebol

$$
\text { e (c) discutir se }
$$

modelos contemporâneos de TD fornecem

uma conceituação adequada do

modelo usado no handebol norueguês.

Spanish version of the Talent

Development Environment

Questionnaire for sport:

PLOS ONE

Espanha

atletismo, basquetebol, voleibol, judô e handebol Cultural adaptation and initial validation

Traduzir o Talent Development Environment Questionnaire em Espanhol e fornecer uma validação inicial 
Tabela 1. Características descritivas dos artigos

COLLINS, David J.

2017

Champs-Current Views,

Directions
Contradictions, and Future

Frontiers in Psychology

Reino Unido

desportivo em clubes de

natação: Um estudo

COSTA, Aldo M.

2017

preliminar sobre as perceções

dos nadadores portugueses

Biological maturity and the

anthropometric, physical and

CRIPPS, Ashley J.

2017 technical assessment of talen

identified U16 Australian

footballers

\section{Revista Iberoamericana de}

Psicologia del Ejercicio y el Deport

Portugal

International Journal of Sports

Science \& Coaching

Austrália

natação

futebol

Bio-banding in Sport:

CUMMING, Sean P.

2017

Applications to Competition,

Talent Identification, and

Strength and Conditioning of

Youth Athletes

Strength \& Conditioning Journal

(Lippincott Williams \& Wilkins)

Reino Unido

futebol

Talent development programmes: a retrospective analysis of the age and

BOSSCHER, Veerle support services for talented

European Sport Management Quarterly
Bélgica
Fornecer uma exploração mais aprofundada

das características psicológicas de

Desenvolver Excelência e seu papel nos processos de DT. Fornece sugestões para o progresso e estimular o debate crítico entre profissionais, pesquisadores e formuladores de políticas.

athletes in 15 nations

Analisar as percepções dos nadadores

Portugueses sobre o seu contexto de desenvolvimento desportivo.

Comparar as medidas de maturação biológica, antropométrica, física e técnica entre o talento $e$

não talentosos identificaram jovens jogadores de futebol australianos.

Descrever de modo geral o processo de BIO-

BANDING, indicando seus benefícios

potenciais e limitações, relatando os

avanços recentes em sua aplicação no esporte da juventude. Considerando que BIO-BANDING é o processo de agrupar atletas com base nos atributos associados ao crescimento e maturação ao invés de idade cronológica.

Contribuir para a literatura de

desenvolvimento de talentos a partir de uma perspectiva organizacional, abordando a questão: como e com que idade os atletas receberam apoio como futuros talentos de seus clubes esportivos e NGBs? 
Tabela 1. Características descritivas dos artigos

Selection of talents in

handball: anthropometric and

FERNÁNDEZ-ROMERO, Juan

José

performance analysis. /

selección de talentos en el

balonmano: análisis

antropométrico y de

rendimiento
Identificar quais variáveis de desempenh antropométrico e físico avaliadas nas categorias básicas (infantil, menores de 15 anos e cadete, menores de 17 anos) têm maior influência nos níveis profissionais alcançados por jogadores de handebol masculino e feminino ao longo de suas carreiras esportivas.

Analisar o efeito da idade em jogadores adolescentes de handebol.

GÓMEZ-LÓPEZ, M. $2017 \quad$ Relative age effect during the player Sport

Espanha

handbol

Examinar a

identificação e desenvolvimento de talentos

em jovens deficientes (TID) em três

HOULIHAN, Barrie $2017 \quad \begin{array}{r}\text { Talent identification and } \\ \text { development in elite youth }\end{array}$ disability sport

Sport in Society

Reino Unido

basquete em cadeira de rodas, tênis para deficientes e bocha

esportes (basquete em cadeira de rodas,

tênis para deficientes e bocha) no ReinoUnido e para

avaliar as evidências de convergência entre a identificação de talentos esportivos por deficiência e sistemas de desenvolvimento
Systematizing coaches' 'eye for talent': Player assessments

JOKUSCHIES, Nina 2017 based on expert coaches' subjective talent criteria in top-level youth soccer

\section{International Journal of Sports} Science and Coaching

Suiça
Fornecer uma visão aprofundada sobre os critérios de talento subjetivos dos treinadores e investigar a validade $e$ confiabilidade de suas avaliações de jogadores com base nesses critérios.
Abordar com atenção especial às histórias de sucesso nos esportes e investigar como jovens participantes em campos de seleção no futebol e no hóquei no gelo estão usando um conjunto de narrativas

compartilhadas para produzir suas histórias pessoais de sucesso. 
Talent production in

KILGER, M. interaction: Performance appraisal interviews in talent

selection camps
Communication and Sport

Suécia
Examinar de perto as PAI'S (Entrevistas de Avaliação em Acampamentos de seleção de talentos). Este artigo assume uma abordagem narrativa, enfatizando as Entrevistas de Avaliação

em Acampamentos como um gênero narrativo e uma estrutura para uma forma específica de interação.
Relationships Between

Perfectionism, Training Load

KLUND, Fredrik

2017

and Elite Junior Football
Players' Self-Assessed and

Descrever os jogadores de futebol júnior da elite norueguesa perfeccionismo e carga de treinamento atribuído e auto imposto e examinar como estes

os fatores estavam relacionados com as avaliações próprias e de seus treinadores de suas habilidades

Analisar o papel cada vez mais proeminente das escolas esportivas privadas no desenvolvimento de atletas de elite na
Developing young athletes:

KRISTIANSEN, E.

2017 sport system schools in the Norwegian
International Review for the Sociology of Sport
Noruega

golfe, judô, natação, esqui cross-country hóquei no gelo, handebol, xadrez, tênis de mesa, esportes aquáticos, esqui alpino
Noruega. 0 contexto pa aparente paradoxo entre o surgimento de uma rede de escolas esportivas, sendo as mais bem-sucedidas

e exigência que os pais paguem uma taxa $\mathrm{e}$ os valores socialdemocratas da Noruega.

Investigar os impactos dos fatores

The roles of the talent development environment on

International Journal of Sport athlete burnout: a qualitative Psychology

China

futebol, hóquei, tiro e natação ambientais de desenvolvimento de talentos study

Impacts of talent

LI, Chunxiao

$2017 b$
Pesquisar os efeitos dos fatores ambientais de desenvolvimento de talentos no

esgotamento de atletas, adolescentes 
Tabela 1. Características descritivas dos artigos

LUND, Stefan

To See or Not to See: Talent dentification in the Swedish

Football Association
Sociology of Sport Journal

Suécia

futebol

Explorar se o contexto e as culturas de

coaching influenciam a prática dos

treinadores experiência e seu conhecimento

não articulado e encarnado e, portanto,

suas diferentes maneiras de ver e definir

talento. Usando uma perspectiva

sociológica cultural, desafiamos a suposição

comumente de que talento a identificação é

ou pode ser feita em um processo racional e objetivo.

Explorar quais habilidades os jogadores do ensino médio acham mais importantes,

como avaliam suas próprias habilidades

em comparação com seus colegas de escola

e quais habilidades a escola e os treinadores

de clube consideram mais importantes,

comparando: meninas e meninos, um SSP e

uma escola ESSP e jogadores jogando

futebol de alto nível contra futebol de baixo

nível. Incluídos neste estudo foram 111

ensino médio jogadores de futebol ( 81

meninos e 30 meninas) representando um

SSP e um ESSP

From youth team to first

team: An investigation into

2017 the transition experiences of

young professional athletes in

International Journal of Sport \&

Exercise Psychology

Reino Unido
Differences of physical

NAISIDOU, S bilities between successful

and less successful young

female athletes
Journal of Physical Education and Sport
Grécia

handebol
Explorar a experiência dos jogadores do

Reino Unido que passaram por uma

transição de carreira para o primeiro nível

de equipe e avaliar as mudanças imediatas que ocorrem durante o movimento.

Identificar os atributos antropométricos e

características de desempenho físico técnico que diferenciam

bem-sucedida ou menos bem-sucedida jogadores de handebol feminino adolescentes. 
Tabela 1. Características descritivas dos artigos

Verificar a confiabilidade dos indicadores de desempenho. Primeiro, comparando o desempenho de um grupo de jogadores indicados para a bola de ouro e, em segundo lugar, comparando o desempenho de um grupo de jogadores nomeados cinco vezes nos últimos cinco anos com outro grupo de jogadores que nunca foram nomeados.

Psychological sporting talent

and indicators of mental

health at young male and

PAUŠEK, Katarina

2017

female handball players.

Sports Science \& Health / Sportske Nauke i Zdravlje

Croácia

handebol

Obter uma visão sobre as diferenças de

sihološki talent i obilježja

mentalnog zdravlja kod

rukometaša i rukometašica

PION, Johan

2017

Predictive models reduce

talent development costs in

female gymnastics

Journal of Sports Sciences

Bélgica

ênero nas características psicológicasque refletem talentos esportivos e alguns

indicadores de saúde mental nos melhores

jogadores jovens de handebol.

Comparação de diferentes modelo preditivos com base nos resultados de uma bateria de teste de identificação de

talentos para ginastas do sexo feminino.

Estudamos até que ponto esses modelos

têm o potencial de otimizar os

procedimentos de seleção e, ao mesmo

tempo, reduzir os custos de

desenvolvimento de talentos

na ginástica artística feminina.

Analisar, em clubes amadores, o efeito d idade relativa dos jogadores de futebol, de acordo com o nível de perícia esportiva da

Socce Relive Age Effect on

Soccer Players in Formative

Journal of Human Kinetics

Espanha

futebol

equipe (por exemplo, $A$

Expertise Levels

, C subsequente) que eles pertencem à mesma categoria de jogo.

Coaches' eye as a valid method to assess biological maturation in youth elite

Talent Development \& Excellence

Suiça

futebol

Avaliar a concordância entre classificações baseadas na maturidade esquelética, mediç̃̃es (por exemplo, APHV) e categorizações por olho de treinadores 
Tabela 1. Características descritivas dos artigos

\begin{tabular}{|c|c|c|c|c|c|c|}
\hline RUBAJCZYK, Krystian & 2017 & $\begin{array}{l}\text { Doubly Disadvantaged? The } \\
\text { Relative Age Effect in Poland's } \\
\text { Basketball Players }\end{array}$ & $\begin{array}{c}\text { Journal of Sports Science \& } \\
\text { Medicine }\end{array}$ & Polônia & basquete & $\begin{array}{l}\text { Identificar o efeito da idade relativa (RAE) } \\
\text { em jovens jogadores de basquete poloneses } \\
\text { ( } n=3849 \text { ) e mulheres ( } n=3419 \text { ) com idades } \\
\text { entre } 14 \text { e } 22 \text { anos competindo nos jogos de } \\
\text { elite do Campeonato da Juventude da } \\
\text { Polônia. }\end{array}$ \\
\hline SAVAGE, Jennifer & 2017 & $\begin{array}{l}\text { Exploring Traumas in the } \\
\text { Development of Talent: What } \\
\text { Are They, What Do They Do, } \\
\text { and What Do They Require? }\end{array}$ & Journal of Applied Sport Psychology & Reino Unido & $\begin{array}{l}\text { mountain bike downhill, arco e flecha, } \\
\text { hipismo, hóquei , judô, futebol e lacrosse }\end{array}$ & $\begin{array}{l}\text { Aprofundar a compreensão sobre o papel } \\
\text { do trauma durante o desenvolvimento de } \\
\text { profissionais seniores de sucesso. }\end{array}$ \\
\hline SCHORER, Jörg & 2017 & $\begin{array}{l}\text { Long-Term Prognostic Validity } \\
\text { of Talent Selections: } \\
\text { Comparing National and } \\
\text { Regional Coaches, Laypersons } \\
\text { and Novices }\end{array}$ & Frontiers in Psychology & Alemanha & handebol & $\begin{array}{l}\text { Avaliar a validade prognóstica da seleção de } \\
\text { talentos por grupos variados } \\
10 \text { anos depois de terem sido conduzidos. }\end{array}$ \\
\hline SEANOR, M. & 2017 & $\begin{array}{l}\text { Cultivating Olympic } \\
\text { champions: A trampoline } \\
\text { development environment } \\
\text { from grass roots to podium }\end{array}$ & $\begin{array}{c}\text { Journal of Sport Psychology in } \\
\text { Action }\end{array}$ & Canadá & trampolim & $\begin{array}{l}\text { Dar um passo preliminar para informar os } \\
\text { profissionaissobre fatores contextuais } \\
\text { únicos presentes no Skyriders Trampoline } \\
\text { Place no Canadá, ambiente voltado ao } \\
\text { desenvolvimento de talentos de atletas, os } \\
\text { apoiando desde as raízes até o pódio. }\end{array}$ \\
\hline SHERWIN, I. & 2017 & $\begin{array}{l}\text { Talent development of high } \\
\text { performance coaches in team } \\
\text { sports in Ireland }\end{array}$ & European Journal of Sport Science & Irlanda & $\begin{array}{l}\text { rugby, futebol gaélico, hurling, hóquei, } \\
\text { basquetebol }\end{array}$ & $\begin{array}{l}\text { Investigar qualitativamente as fontes atuais } \\
\text { de treinamento de coaches e os } \\
\text { esportes de equipe na Irlanda. }\end{array}$ \\
\hline SWANN, Christian & 2017 & $\begin{array}{l}\text { Performing under pressure: } \\
\text { Exploring the psychological } \\
\text { state underlying clutch } \\
\text { performance in sport }\end{array}$ & Journal of Sports Sciences & Austrália & $\begin{array}{l}\text { basquete, rugby, maratona, velocista de } \\
200 \mathrm{~m} \text {, corrida de longa distância, } \\
\text { tênis de cadeira de rodas, escalada, } \\
\text { netball, tenis, } 110 \text { m com barreiras, } \\
\text { triatlon, hockey, rugby, badminton B, } \\
\text { explorador polar }\end{array}$ & $\begin{array}{l}\text { Examinar o desempenho da embreagem } \\
\text { sob pressão e o estado psicológico } \\
\text { vivenciado pelos atletas nessas situações. } \\
\text { Portanto, este estudo qualitativamente } \\
\text { examinou a experiência subjetiva } \\
\text { subjacente ao desempenho da embreagem } \\
\text { em uma série de esportes (por exemplo, } \\
\text { equipe, individuais) e padrões (atletas } \\
\text { olímpicos para recreativos). }\end{array}$ \\
\hline TAYLOR, Robin D. & 2017 & $\begin{array}{l}\text { Sibling interaction as a } \\
\text { facilitator for talent } \\
\text { development in sport }\end{array}$ & $\begin{array}{l}\text { International Journal of Sports } \\
\text { Science \& Coaching }\end{array}$ & Reino Unido & $\begin{array}{l}\text { tênis, rugby, esqui, futebol, motocross, } \\
\text { basquete, hóquei, netball, squash, cricket } \\
\text { curling, badminton, curling, }\end{array}$ & $\begin{array}{l}\text { Explorar o impacto da interação entre } \\
\text { irmãos no processo de desenvolvimento de } \\
\text { talento }\end{array}$ \\
\hline
\end{tabular}


Tabela 1. Características descritivas dos artigos

\begin{tabular}{|c|c|c|c|c|c|c|}
\hline TEDESQUI, Rafael A. B. & 2017 & $\begin{array}{l}\text { Investigating grit variables } \\
\text { and their relations with } \\
\text { practice and skill groups in } \\
\text { developing sport experts }\end{array}$ & High Ability Studies & Canadá & $\begin{array}{l}\text { natação, atletismo, hóquei, futebol e } 1 \% \\
\text { dos atletas não relatou o esporte principal. }\end{array}$ & $\begin{array}{l}\text { Examinar a granulação no nível da subescala } \\
\text { e a mostrar a validade preditiva das } \\
\text { subescalas de granulação para os resultados } \\
\text { da perícia esportiva. }\end{array}$ \\
\hline TILL, $\mathrm{K}$. & 2017 & $\begin{array}{c}\text { A retrospective longitudinal } \\
\text { analysis of anthropometric } \\
\text { and physical qualities that } \\
\text { associate with adult career } \\
\text { attainment in junior rugby } \\
\text { league players }\end{array}$ & $\begin{array}{c}\text { Journal of Science and Medicine in } \\
\text { Sport }\end{array}$ & Reino Unido & rugbi & $\begin{array}{l}\text { Comparar retrospectivamente o } \\
\text { desenvolvimento físico longitudinal da liga } \\
\text { junior de ogadores de rugby entre as } \\
\text { categorias de menores de } 13 \text { e } 15 \text { anos em } \\
\text { relação ao resultado de obtenção de } \\
\text { carreira de adultos. }\end{array}$ \\
\hline TOWLSON, Chris & 2017 & $\begin{array}{l}\text { Relative age, maturation and } \\
\text { physical biases on position } \\
\text { allocation in elite-youth } \\
\text { soccer }\end{array}$ & $\begin{array}{l}\text { International Journal of Sports } \\
\text { Medicine }\end{array}$ & Reino Unido & futebol & $\begin{array}{c}\text { Avaliar e quantificar as diferenças entre } \\
\text { distribuição etária relativa, antropometria, } \\
\text { estado de maturação e } \\
\text { características da aptidão física na alocação } \\
\text { do papel posicional em uma amostra de } \\
\text { elite de jovens futebolistas inscritos em } \\
\text { múltiplos desenvolvimentos } \\
\text { centros na Inglaterra, }\end{array}$ \\
\hline WINN, C. O. N. & 2017 & $\begin{array}{l}\text { The effect of deprivation on } \\
\text { the developmental activities } \\
\text { of adolescent rugby union } \\
\text { players in Wales }\end{array}$ & Journal of Sports Sciences & Reino Unido & rugbi & $\begin{array}{l}\text { Comparar a participação em } \\
\text { atividades de desenvolvimento pela elite de } \\
\text { rugby adolescente jogadores por nível de } \\
\text { privação }\end{array}$ \\
\hline WOODS, Carl T. & 2017 & $\begin{array}{l}\text { The use of player physical and } \\
\text { technical skill match activity } \\
\text { profiles to predict position in } \\
\text { the Australian Football League } \\
\text { draft }\end{array}$ & Journal of Sports Sciences & Austrália & Futebol & $\begin{array}{l}\text { Esta investigação tem como objetivo } \\
\text { determinar em que medida a posição de } \\
\text { rascunho está associada ao perfil de } \\
\text { atividade de partida de habilidade física e / } \\
\text { ou técnica de um jogador. }\end{array}$ \\
\hline BOCCIA, Gennaro & 2018 & $\begin{array}{c}\text { Elite national athletes reach } \\
\text { their peak performance later } \\
\text { than non-elite in sprints and } \\
\text { throwing events }\end{array}$ & $\begin{array}{c}\text { Journal of science and medicine in } \\
\text { sport }\end{array}$ & Italia & $\begin{array}{c}\text { sprint, obstáculos, arremesso de disco e } \\
\text { atletismo. }\end{array}$ & $\begin{array}{c}\text { Descrever e analisar as trajetórias de } \\
\text { carreira de desempenho dos } \\
\text { atletas italianos que participaram de provas } \\
\text { de sprint, obstáculos, arremesso de disco e } \\
\text { atletismo. }\end{array}$ \\
\hline
\end{tabular}


Tabela 1. Características descritivas dos artigos

Training duration may not be a predisposing factor in potential maladaptations in

BROWNLEE, T. E.

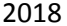

talent development

programmes that promote

early specialisation in elite youth soccer

\section{International Journal of Sports \\ Science and Coaching}

Reino Unido

Futebol

Determinar se a duração do treinamento é um fator predisponente em potenciais

desadaptações no desenvolvimento de

talentos nos programas que promovem a especialização precoce no futebol juvenil de

elite.
The relative age effect is

larger in Italian soccer top

level youth categories and

smaller in Serie A

O objetivo deste estudo foi investigar a presença da RAE em atletas de futebol de elite competindo no campeonato italiano, mesmo considerando as discriminações de séries mais jovens e antigas.

Anthropometric and Physical

Performance of Youth

CAMACHO-Cardenosa, Alba

2018

Handball Players: The Role of

the Relative Age
Sports (Basel, Switzerland)

Espanha

O objetivo do presente estudo foi analisar o papel da idade relativa nas características antropométricas e de desempenho físico de atletas jovens de handebol por sexo.

Athlete Lifestyle Support of

Elite Youth Cricketers: An

Ethnography of Player

Journal of Applied Sport Psychology

Inglaterra

Concerns Within a National

Talent Development Program
Compreender a natureza das preocupações contextualmente e culturalmente

$$
\text { específicas do estilo de }
$$

que os Cricketers da juventude da elite

procuram a sustentação, e o meaning pessoal atribuem-lhes.
ENGLISH, C.
The effects of structural

ange: an investigation into

the South African cricket

development pathway
International Journal of Sport Policy Reino Unido
O objetivo desta pesquisa foi investigar a via de desenvolvimento dos Cricketers sul-

africanos e o impacto da mudança na estrutura provincial em 2004. 
Tabela 1. Características descritivas dos artigos

Childhood football play and

practice in relation to self-

ERIKSTAD, Martin K.

rulation and national team

selection; a study of

Journal of Sports Sciences

Noruega

Futebol

Norwegian elite youth players objetivo deste estudo foi explorar como a participação de específicas atividades na

infância (6-12 anos de idade) relacionadas

ao futebol podem estar associadas

com habilidades de autorregulamentação e seleção de seleções

Elite norueguesa Sub-14 e Sub-15 (ou seja, Sub-14 e Sub-14

15 anos) jogadores de futebol.
Does a perceptuomotor skills

assessment have added value

FABER, Irene R.

2018

to detect talent for table

tennis in primary school children?
Journal of sports sciences

Países Baixos

tênis de mesa

N.I
Toward an Understanding of

2018 Players' Perceptions of Talent

GLEDHILL, Adam

Development Environments in UK Female Football

Portanto, os objetivos desta pesquisa são examinar as

percepções dos jogadores de futebol sobre seus TDEs, bem como quaisquer diferenças nos diferentes tipos de

futebol feminino, tendo em vista a

compreensão dos pontos fortes, as áreas de melhoria e recomendações aplicadas.

\section{O propósito deste}

estudo foi investigar os efeitos do

nascimento em jogadores de voleibol

portugueses, analisando o tamanho da

Influences of population size

and density on birthplace

Journal of Sports Sciences

Estados Unidos

voleibol

$$
\text { cidade }
$$

como densidade populacional - uma variável importante, mas pouco utilizada.

Player-Driven video analysis

to enhance reflective soccer practice in talent development

\section{International Journal of Game-} Based Learning
Dinamarca
O objetivo do estudo é investigar aspectos qualitativos usando feedback de vídeo no FCK SE - antes e durante o uso de PU. 
Tabela 1. Características descritivas dos artigos

HUTTER, R. I. Van 2018

ducation and training in the field of applied sport psychology in Europe

International Journal of Sport \& Exercise Psychology

Países Baixos

N.I

O estudo tem como objetivo fornecer uma visão geral da educação e formação para especialistas em ASP na Europa. A visão geral resultante da educação disponível pode servir aos futuros alunos e

profissionais; e fornece uma base para a futura cooperação entre educadores, avaliação da qualidade e gestão na educação e iniciativas para o desenvolvimento profissional continuado.

O objetivo deste artigo é examinar o impacto da participação no YOG sobre

The Youth Olympic Games: a

KRISTIANSEN, Elsa 2018 acilitator or barrier of the high-performance sport development pathway?
European Sport Management Quarterly
Noruega

natação, luta profissional, boxe, voleibol, luge, esqui alpino, esqui cross-country, biatlo e patinação de velocidade

Membros da equipe norueguesa de 2010

2012 e 2014, com ênfase especial em diferenças entre aqueles que continuaram no esporte de elite e aqueles que desistiram.

Psychometric properties of
the Talent Development

Environment Questionnaire

with Chinese talented athletes
Journal of Sports Sciences

China
Validar o

TDEQ-5 com jovens atletas talentosos na
Learning as Transformation in

the Development of Expertise

LIGHT, Richard L. by Elite Indigenous Australian Athletes
Sport Mont

Nova Zelândia futebol e rugby

investigar o papel que os jogos informais desempenharam no desenvolvimento de jogadores australianos da AFL e da NRL até a idade de treze anos.

Scaling Constraints in Junior

LIMPENS, Vera ennis: The Influence of $\mathrm{Net}$

Match-Play Performance
Research Quarterly for Exercise and Sport
Países Baixos

têni
O objetivo deste estudo foi examinar a influência de

reduções sistemáticas na altura da rede no match-play

características de desempenho de tenistas

$$
\text { talentosos }
$$


Tabela 1. Características descritivas dos artigos

IMPORTANCE OF SPEED AND POWER IN ELITE YOUTH

SOCCER DEPENDS ON

MATURATION STATUS
Journal of Strength \& Conditioning

Research (Lippincott Williams \&

$$
\text { Wilkins) }
$$

Reino Unido

Reino Unido

Os objetivos do nosso estudo foram estabelecer a importância das capacidades de aceleração, sprint, salto horizontal e salto vertical para determinar o status do futebol de elite em diferentes estágios de maturação.
MUSCULUS, Lisa

2018
Psychological characteristics

in talented soccer players -

Recommendations on how to

improve coaches' assessment
Frontiers in Psychology

Alemanha

Futebol

N.I
The boy behind the bravado:
Player advanced safety and

ONG, Chin Wei

2018 Player advanced safety and

football academy setting
Futebol

N.I
Seasonal Body Composition Variation Amongst Elite

OWEN, Adam Lee 2018
O principal objetivo da investigação foi estudar as mudanças sazonais na composição corporal em jogadores de futebol europeus de elite e identificar as principais diferenças posicionais.
PENA-GONZALEZ, Ivan

2018
Relative Age Effect, Biological

Maturation, and Coaches'

Research quarterly for exercise and

Efficacy Expectations in Young Male Soccer Players
O objetivo deste estudo foi testar a existência do efeito da idade relativa e sua possível influência na antropometria e

desempenho físico e analisar a

expectativas de eficácia dos treinadores. 
Tabela1. Características descritivas dos artigos

Relative age effects in Swiss talent development - a

ROMANN, Michae 2018 nationwide analysis of all sports

Journal of sports sciences

Suiça

futebol, voleibol, esqui alpino, natação, andebol, ginástica artística, tênis,

atletismo (atletismo), basquete, hipismo,

patinação artística, esqui cross country,

orientação (corrida), sincronizado

schwimming, judô, esporte escalada,

ginástica rítmica, tiro, hóquei no gelo,

badminton, remo, karatê, patinação

sincronizada, snowboard, ciclismo de mountain bike.

Influence of population size,

density, and proximity to

ROSSING, N. N.

flubs on the likelihood

of becoming elite youth athlete
Scandinavian Journal of Medicine

and Science in Sports

Dinamarca estudo teve como objetivo investigar o

RAE em todos os esportes do programa

nacional suíço de desenvolvimento de talentos (STDP).

\begin{tabular}{|c|c|c|c|c|c|c|}
\hline RUBAJCZYK, Krystian & 2018 & $\begin{array}{l}\text { The Relative Age Effect in } \\
\text { Poland's Elite Youth Soccer } \\
\text { Players }\end{array}$ & Journal of Human Kinetics & Polônia & Futebol & $\begin{array}{l}\text { Determinar } \\
\text { o alcance potencial do RAE em jovens de } \\
\text { elitejogadores de futebol dentro do CLJ e as } \\
\text { razões para este fenômeno. }\end{array}$ \\
\hline RYBA, Tatiana V. & 2018 & $\begin{array}{l}\text { ISSP position stand: } \\
\text { Transnationalism, mobility, } \\
\text { and acculturation in and } \\
\text { through sport }\end{array}$ & $\begin{array}{c}\text { International Journal of Sport \& } \\
\text { Exercise Psychology }\end{array}$ & Finlândia & N.I & $\begin{array}{l}\text { Nossos objetivos nesta posição são revisar } \\
\text { criticamente e analisar a crescente bolsa } \\
\text { pertinente a várias formas de mobilidade } \\
\text { transnacional e aculturação de migrantes } \\
\text { atléticos, e subsequentemente fornecer } \\
\text { recomendações para uso posterior em } \\
\text { pesquisa e contextos aplicados. }\end{array}$ \\
\hline SILVA, Paulo Vinícius Carvalho & 2018 & $\begin{array}{l}\text { Fatores familiares associados } \\
\text { ao desenvolvimento do } \\
\text { talento no esporte }\end{array}$ & $\begin{array}{c}\text { Revista Brasileira de Psicologia do } \\
\text { Esporte }\end{array}$ & Brasil & $\begin{array}{l}\text { natação, nado sincronizado, saltos } \\
\text { ornamentais, triatlo, ciclismo, atletismo, } \\
\text { remo, esgrima, ginástica rítmica, patinação } \\
\text { artística, judô, jiu-jitsu, karatê, taekwondo } \\
\text { e luta olímpica, futsal, basquete, vôlei, } \\
\text { vôlei de praia } \\
\text { e handebol. }\end{array}$ & $\begin{array}{c}\text { Construir e validar uma } \\
\text { escala, denominada Inventário Fatorial de } \\
\text { Práticas Parentais Relacionadas ao } \\
\text { Desenvolvimento do Talento no Esporte } \\
\text { (IFATE), que avalia a frequência com que } \\
\text { práticas parentais, relacionadas ao } \\
\text { desenvolvimento do talento no esporte, } \\
\text { eram implementadas por pais de atletas, } \\
\text { segundo a percepção dos } \\
\text { próprios atletas. }\end{array}$ \\
\hline
\end{tabular}


Tabela 1. Características descritivas dos artigos

The identification of high potential archers based on $2018 \quad$ fitness and motor ability variables: A Support Vector Machine approach
Este estudo teve como objetivo determinar se a habilidade de um arqueiro pode ser classificada com base em seu desempenho em uma seleção de

habilidades físicas e motoras avaliações: aperto de mão, salto vertical, salto em pé, equilíbrio estático, força muscular superior e força muscular central.

The Impact of Siblings Durin

Talent Development: A

Talent Development: A Journal of Applied Sport Psychology Reino Unido
Longitudinal Examination in

Este estudo teve como objetivo explorar potenciais mecanismos através dos quais os irmãos têm impacto sobre este processo.

The importance and

development of ball control

and (self-reported) self-

regulatory skills in basketball

players for different position
Journal of Sports Sciences

Países Baixos

basquetebo

Este estudo primeiro investigou a

importância do controle de bola e

(autorreferido) habilidades de autorregulação em alcançar o nível de elite no basquete.

Examinar as associações de

Comparing the contribution of

conscientiousness, self-

TEDESQUI, Rafael A. B.

2018

control,

of sport expertise

Psychology of Sport \& Exercise Canadá

N.I

$$
\text { development }
$$

conscienciosidade, determinação e SC com medidas de critério para (a) engajamento em vários contextos de prática (incluindo DP) e (b) medidas relacionadas, bem como

(c) essas características poderiam

discriminar escalando grupos de habilidades no esporte.

Using transdisciplinary

TOOHEY, Kristine 
Tabela 1. Características descritivas dos artigos

Domain specific life

satisfaction in the dual

VAN RENS, F. E. C. A. 2018 careers of Junior Elite football

players: The impact of role

strain
O objetivo deste estudo foi investigar possíveis relações entre o papel que os atletas de elite juniores experimentam em suas carreiras duplas e sua satisfação com a vida específica do domínio.
Rethinking Monolithic

Pathways to Success and

VARGAS, Jorge

2018

Talent Identification: The Case

of the Women's Japanese

Journal of human kinetics

olleyball Team and Why

Height is not Everything
Austrália

futebo
Seeing the forest but not the trees: Heterogeneity in

community size effects in

Canadian ice hockey players
Journal of Sports Sciences

Canadá
O objetivo do presente estudo foi analisar a Seleção Nacional Japonesa de Voleibol

Feminino e identificar itens diferenciando-a de outras equipes.

Portanto, o objetivo do presente estudo foi testar a heterogeneidade do efeito

tamanho da comunidade entre os recrutas

da Canadian National Hockey League (2000-

2014: $n=1505$ ), de 7 regiões provinciais

dentro do Canadá (por exemplo, British

Columbia, Alberta, Saskatchewan,

Manitoba, Ontário, Quebec e as Províncias Atlânticas).
WOODS, Carl T.

2018
Classification of playing

position in elite junior

Australian football using

technical skill indicators
Journal of sports sciences
Este estudo teve como objetivo determinar se os jogadores de elite de $\mathrm{FA}$ júnior

poderiam ser classificados com precisão de

acordo com suas posições de jogo

designadas, utilizando indicadores de

habilidades técnicas comumente relatados gerados durante o jogo. 


\section{ANEXO B}

Tabela 2. Características metodológicas dos artigos

Primeiro autor

Ano de publicação

Faixa etária

2017

N.I

Gênero
asulino ofeminino)

feminino

Reportagens da mídia e entrevistas com treinadores de handebol

Exame da Escala de Auto Relato de Auto Regulação da Aprendizagem. Pesquisa para validade de face com um painel de especialistas. Posteriormente, 272 participantes $(200 \mathrm{~m}, 72 \mathrm{f}$ idades 18e35) completaram uma versão de treinamento esportivo do SRL-SRS, que incluiu itens modificados de acordo com o painel recomendações e refinamentos para a validade fatorial. Os participantes também completaram as medidas de pesquisa para prática semanal e nível de desempenho. Análises de regressão logística serviram para determinar: a) como (global) processos de SRL, e b) como seis processos de SRL constituintes, explicou o nível de desempenho.
Maior engajamento geral em SRL de complexo foi associado a estar no grupo de elite em comparação com grupos menos elitistas e competitivos. Dos processos constituintes de SRL, apenas o auto monitoramento previu a participação no grupo de elite e menos elite em comparação com o competitivo. Análises adicionais revelaram planejamento, auto monitoramento, esforço e auto eficácia separadamente participação prevista no grupo de elite, em relação ao grupo menos elitista, e competitivamente competitive grupo.
Os resultados revelam que a ampla base de iniciativas de TD cria vários pontos de acesso ao fluxo de talentos para adolescents. Contudo, porque a estrutura heterárquica envolve muitos atores, a conseqüências não intencionais são frequentemente relacionadas ao (im) gerenciamento adequado cargas de treinamento e competição. Portanto, há necessidade de desenvolvimento mecanismos de coordenação e boa comunicação entre os principais intervenientes envolvidos. 
Tabela 2. Características metodológicas dos artigos

BRAZO-SAYAVERA, J.

2017

$12-18$ anos

masculino e feminino

entrevistas cognitivas usando 'sondagem' metodologia "paráfrase"
A Com a exclusão de um item devido ao baixo fator de carga, o Talent Development Environment Questionnaire- 5 teve suporte estatístico robusto para sua estrutura fatorial $(\chi 2(\mathrm{df}=305)=$ $499,64, p<0,01, \mathrm{CFI}=0,90, \mathrm{RMSEA}=0,045$, SRMR $=0,055$ ).

Também demonstrou adequada validade convergente $e$ discriminante. Enquanto o interno

a confiabilidade foi menor do que em estudos anteriores, revelou níveis aceitáveis. Especificamente

o questionário de ambiente de desenvolvimento de Talent-5 global de 27 itens teve um Cronbach $\alpha$

escore de 0,877 , e os escores de confiabilidade para os fatores individuais $1 \pm 5$ foram 0,$622 ; .761 ; 0,658 ;, 605$;

602 respectivamente. Como tal, recomenda-se que o

ambiente espanhol de desenvolvimento de talentos

Questionário-5 pode ser usado com confiança na Espanha tanto em pesquisa aplicada quanto

definições.
COLLINS, David J.

2017

N.I

masculino e feminino

de habilidades válidas para a vida por meio de medidas esportivas; c) um exame

de diferenças de tipo de programa de esporte; d) investigação de avaliação

COSTA, Aldo $\mathrm{M}$

2017 masculino e feminin

aplicação do questionário proposto por Martindale et al. (2010)
É necessária a realização de várias metodologias e uso de projetos prospectivos e longitudinais, para que se estabeleça um foco "acadêmico", unindo acadêmicos e profissionais para gerar respostas eficazes e aplicáveis.

Obteve-se o valor de 0.814 , sendo este superior ao patamar crítico de 0.60 sugerido pela literatura (Field, 2005). Verificou-se ainda que o teste de esfericidade de Bartlett é estatisticamente significativo $(p<.000)$. Deste modo, foi possível confirmar a adequação da análise. Resultados da significância no teste do qui-quadrado do valor médio e desvio padrão $(* p<.05)$ 
Tabela 2. Características metodológicas dos artigos

CRIPPS, Ashley J.

2017

$15-18$ anos

masculino

bateria de avaliações de habilidades antropométricas, físicas e técnicas.

A maturidade foi estimada usando anos de cálculos de velocidade de pico de altura.
Talento identificado em 16 jogadores

eram biologicamente mais velhos, tinham maiores saltos estacionários e dinâmicos e habilidades superiores de handebol quando comparados com seus não-talentosos

contrapartes identificadas. O modelo mais forte de status incluiu altura em pé, dinâmica vertical não dominantes resultados de salto e handebol (AUC $1 / 483,4 \%$, IC $1 / 472,1$ a $95,1 \%)$. Maturação biológica influencia antropométrica e capacidades físicas que são vantajosas para o desempenho no futebol australiano
CUMMING, Sean $P$

2017

8-18 anos

masculino

Relato de jogadores e técnicos a partir das experiências nos processos de BIO-BANDING
A prática de BIO-BANDING está recebendo renovado interesse no contexto de esportes para jovens e está sendo aplicado em uma variedade de contextos. Embora o processo de BIO-

BANDING tenha o potencial de contribuir positivamente às experiências e desenvolvimento de jovens atletas, é importante reconhecer que não é um "remédio" e que deve funcionar como parte de um programa multifacetado e holístico do desenvolvimento.

Os atletas praticaram seu esporte em média por quase seis anos e meio antes de receberem atenção especial como um atleta emergente do governo. Receberam serviços de suporte BOSSCHER, Veerle masculino e feminino
Análise de variação (ANCOVA e MANCOVA) foi usado para examinar os dados e identificar diferenças entre esportes, países e atletas níveis de desempenho esportivo. Um total de 2041 atletas de elite de 15 nações e 37 esportes diferentes foram pesquisados. do governo em uma idade relativamente avançada. A idade em

que os atletas se especializaram variam de esporte para esporte. Existem também pequenas diferenças de gênero: os homens são, em média, cerca de meio ano mais velhos quando receberam pela primeira vez apoio, suporte. Os atletas de nível superior (por exemplo, os oito principais do mundo) receberam serviços de suporte um pouco mais cedo do que atletas de nível 
Tabela 2. Características metodológicas dos artigos

FERNÁNDEZ-ROMERO, Juan

Jose

201

por volta dos $15 \mathrm{e}$

17 anos

masculino e feminino

Uma multivariada

análise do teste de covariância (MANCOVA)

Os dados resultantes foram classificados de acordo com o nível de desempenho (regional $n=109$; nacional $n=36$ ), sexo e

categoria (infantil, cadete). Resultados: a análise do MANCOVA indicou que o estágio de maturação do jogador é um dos principais parâmetros a serem contabilizados ao selecionar as variáveis que devem configurar um modelo de detecção de talentos para o handebol, que também é condicionado pelo sexo. Variáveis antropométricas são altamente influentes no caso de jogadores do sexo masculino, enquanto variáveis de desempenho físico (salto agachamento, salto contra

movimento, salto contra movimento com braço, corrida de

$10 \times 5 \mathrm{~m}$, corrida de $20 \mathrm{~m}$ e VO2 max) têm um efeito semelhante em homens e mulheres.

A análise dos resultados com base no trimestre e semestre de nascimento revelou a existência de diferenças significativas que nascimento revelou a existência de diferenças significativas que
comprovam que os atletas nascidos nos primeiros meses do ano são mais propensos a fazer parte de uma equipe campeã.

Em relação ao gênero e à posição específica, não foram
GÓMEZ-LÓPEZ, M
aproximadamente
masculino e feminino
chi-quadrado e Z-testes

16 anos

encontradas diferenças estatisticamente significativas, mas uma

porcentagem dos efeitos relativos da idade foi notável neste

estágio do treinamento. A análise de desempenho gerou diferenças significativas nas equipes femininas.

2017

anos
As dimensões que exibiram

Entrevistas semiestruturadas. Uma busca por relevantes documentos, tais como relatórios anuais e declarações de objetivos

e atividades disponíveis em

Foram também levados em conta websites que forneceram dados contextuais, do

desenvolvimento do cronograma de entrevistas, em vez de fornecer uma visão direta dos processos de

dentificação e desenvolvimento de talentos juvenis. a evidência mais clara de convergência foram números um, dois e três - "motivos", "Agenda e aspiração" e "contextualização do discurso / ideologia / valores". O padrão

de mudança em relação à "implementação" encontrada nos três esportes (em termos de investimento em treinamento, competição e campos de treinamento, por exemplo) alto gra

de uniformidade em motivos, aspirações e valores. Embora houvesse algumas diferenças contínuas nas fontes de

financiamento entre o mainstream e esporte deficiência havia considerável semelhança entre os três esportes. 
Tabela 2. Características metodológicas dos artigos

JOKUSCHIES, Nina

2017

$10-17$ anos

masculino

entrevistas indutivas semiestruturadas e a técnica de grade de repertório.
Os resultados revelam que treinadores de futebol experientes tem critérios subjetivos de talento e indicam a natureza

multidimensional de seus conceitos de talento. Existe uma alta

correlação entre a avaliação dos treinadores de seus jogadores com base em seus próprios critérios de talento e sua avaliação do potencial global destes jogadores, indicando validade de critério. Avaliações repetidas dos jogadores

De acordo com os critérios de talento de um treinador, é apresentada uma adequada confiabilidade teste-reteste durante um período de 10 semanas.
KILGER, M

2017

N.I

masculino

entrevistas gravadas em áudio com jogadores, que totaliza um total de 9 horas de material gravado

A análise mostra como as histórias pessoais de sucesso estão equilibrando o espaço dilemático da agência e como lidar com narrativas discursivamente compartilhadas e bem conhecidas de sucesso, enquanto um ao mesmo tempo produzindo um narrativa pessoal. Este ato de equilibrar as narrativas dilemáticas é mostrado no material, incluindo como isso é feito de forma retorica. Os extremos narrativos parecem trabalhar para afastar a crítica de ser, por exemplo, egocêntrico.

Um entrevistado de sucesso envolve o equilíbrio entre auto aperfeiçoamento, precisão e humildade. Além disso, em suas narrativas, os jogadores precisam encontrar um equilíbrio entre não exibir muita ou pouca autoestima, isto é, entre o orgulho e a modéstia muito autor espeito pode ser visto como mal adaptativo ou, em outras palavras, egocentrismo. Além disso, a tarefa é mostrar potencial de desenvolvimento e

autoconsciência, estar ciente das áreas de desenvolvimento, sem aparecer como um mau desempenho. No contexto de uma pessoa jovem que faz a transição da juventude para a elite adulta, indicadores de desenvolvimento mostram-se através de níveis de maturidade percebida.

pesquisa narrativa em dois campos de seleção para as seleções uvenis suecas no hóquei e no futebol compreende 26 avaliações individuais entrevistas, entre um ou por vezes mais técnico (es) 
KLUND, Fredrik

2017

18 anos

masculino

Coleta de dados após sessaõ de treinamento nos clubes, utilizando

a Escala Multidimensional de Perfeccionismo de Futebol (MPSFootball;

et al., 2002) para avaliar o perfeccionismo dos atletas, com respostas dadas em uma escala de Likert de cinco pontos, variando de 1 = nada fiel a 5 = completamente verdadeir
As auto avaliações sobre as dimensões do perfeccionismo foram maiores para os padrões pessoais

menor para a percepção da pressão dos pais. Os jogadores relataram participar em 6.2 organizou sessões semanais de formação com um total de 10,6 horas e 2,1 semanais auto organizadas sessões com duração total de 4,4 horas.

A análise de correlação mostrou que a habilidades do jogador correlaciona-se positivamente com os padrões pessoais e frequência e duração da formação organizada, mas não

formação independente. Avaliação correlaciona positivamente as habilidades do jogador com padrões pessoais. Os testes comparam jogadores com habilidades altas e baixas avaliadas pelo treinador mostraram que jogadores altamente habilidosos tem formação mais organizada, tanto em termos de frequência como de duração das sessões, e relataram padrões pessoais mais elevados. Os jogadores menos habilidosos percebem pressão dos pais e treinadores.

KRISTIANSEN, E.

2017

16-19 anos

masculino e feminino

entrevistas com 35 participantes de nove grupos de partes interessadas, incluindo atletas, treinadores, pais e gestores escolares esportivos. O quadro analítico principal é o de Kingdonestrutura de múltiplos fluxos aumentada pela teoria da dependência do caminho.
A pesquisa descreve um sistema esportivo de elite que é bemsucedida na produção de atletas ganhadores de medalhas, mas que é fragmentada organizacionalmente, descoordenada e

subfinanciada no que diz respeito à identificação e

desenvolvimento de talentos jovense suscetível a tensões entre atores-chave. Os resultados incluem, uma imagemde um sistema de desenvolvimento esportivo juvenil de elite no qual vários problemasrecebeu, na melhor das hipóteses, apenas

soluções políticas parciais, algumas das quais, como o crescimento doescolas, surgiram por padrão. 
LI, Chunxiao

$2017 a$

14 anos

masculino e feminino

entrevistas com atletas selecionados com base em seu esgotamento, medido pelo Athlete Burnout Questionnaire (Raedeke \& Smith, 2001).
De acordo com o BPNT (Deci \& Ryan, 2000), as pessoas têm três autonomias (necessidade de apropriação de ações e escolhas) competência (necessidade de sentir competente na realização de tarefas idealmente desafiadoras) e parentesco (a

necessidade de pertencimento de sentido e conectividade). Consistente com o BPNT (Deci \& Ryan, 2000), os participantes com alto esgotamento, confrontaram-se com antecedentes ambientais mais negativos e menos positivos, frustrando a realização de suas necessidades e, posteriormente, resultou em experiências de esgotamento. Por outro lado, os participantes com baixos níveis de esgotamento, experimentam antecedentes ambientais mais positivos e menos negativos análise de formulário de pesquisa, preenchidos por atletas adolescentes para medir os fatores ambientais de desenvolvimento de talentos, precisa de satisfação e esgotamento.
Os três talentos de desenvolvimento ambiental apresentaramse como fatores importantes para facilitar a satisfação das necessidades dos atletas e evitar o esgotamento. 
Tabela 2. Características metodológicas dos artigos

LUND, Stefan

2017

$14-15$ anos

masculino

entrevistas com 15 treinadores de futebol em quatro distritos dentro do programa de organização do talento da Federação Sueca de Futebol

A identificação dos talentos dos distritos está fortemente relacionada ao senso prático dos treinadores e seus gostos e experiências orientam e restringir esse processo. Os treinadores argumentam que a velocidade de um jogador, inteligência e atitude em relação à formação e aprendizagem do jogo são

critérios que eles procuram quando identificam talentos. Esses critérios são semelhantes aos encontrados em pesquisas (Vrljic \& Mallett, 2008; Cushion \& Jones, 2006; Christensen, 2009; Sæther, 2014), com uma exceção: os treinadores argumentam que o controle ou a técnica da bola é um critério que muitos jogadores neste nível possuem, mas também é algo que eles podem desenvolver através da prática. Portanto, eles

argumentam que este critério não é útil quando classificam jogadores talentosos de jogadores não talentosos.

Os resultados mostraram que os jogadores classificaram e habilidades táticas como mais importantes em comparação com a escola e treinador de clube que classificaram, respectivamente, técnico e físico, e habilidades táticas e

técnicas como as mais importantes. As meninas consideraram as habilidades táticas e físicas significativamente $(<0,01)$ mais

Auto-avaliação de habilidades do jogador de habilidades. As perguntas usadas para auto-avaliaça pediram aos jogadores para avaliar suas próprias habilidades em comparação aos 
Entrevistas semiestruturadas com cinco jogadores do sexo masculino que passaram por uma transição do futebol juvenil em tempo integral para jogadores em tempo integral em um clube de futebol profissional de elite
Os resultados sugeriram que quando os atletas passaram para categoria sênior, passam sentir-se sem motivação para ser um iniciante bem-sucedido na equipe, ao invés de estarem contentes com estar na nova categoria, que foi sua motivação antes de subir. Aparentemente, os motivos dos atletas podem mudar antes e depois da transição, o que correspondem a mudanças em seus níveis de ansiedade e confiança. Os

participantes do presente estudo alegaram que ao subir para a primeira equipe acreditavam que o futebol teria um padrão muito melhor do que o tinham experimentado a nível juvenil. Na pós-transição, no entanto, os atletas não sentiram que o companhar o padrão foi tão difícil quanto eles esperavam, eles estavam menos ansiosos e mais confiantes sobre seus próprios níveis de habilidade.
NAISIDOU, S.

2017

13 anos

feminino
Realizaram-se procedimentos de testes, no quais as jogadorasforam separadas em uma preliminar equipe nacional (jogadores de sucesso, $S P, n=25$ ), com base nas opiniões de especialistas de três equipas nacionais de jovens treinadores responsáveis pela primeira fase da seleção. As jogadoras, que não foram selecionadas, formaram a amostra menos sucedida (LSP, $n=66$ ). As atletas do sexo feminino foram selecionadas durante um acampamento esportivo de 4 dias no início de julho 2015, quando suas equipes participaram de jogos abertos de verão.
Os resultados mostram que a força muscular dos membros superiores e inferiores em combinação com estatura e agilidade, distinguiu o sucesso das jovens jogadoras das menos sucedidas. $O$ estudo constatou que as jogadoras de handebo feminino adolescentes bem-sucedidas, realizaram em média maior em uma bateria de habilidades motoras e testes de habilidades técnicas. Em esportes de equipe que usam uma bola, a morfologia da mão combinada com suas habilidades desempenha um papel decisivo no desempenho. Além disso como em outros esportes coletivos, atletas adultos de longa estatura tem uma vantagem em cobrir o espaço do tribunal devido às suas longas extremidades e também se beneficiam no músculo produção de energia em relação aos sistemas de alavancagem do corpo. 
Coleta de dados a partir do banco de dados WhoScored e a anális do mesmo através do programa SPSS v. 22.0. A amostra foi composta por 103 jogadores de futebol.
O desempenho dos jogadores indicados e não indicados para a bola de ouro é semelhante, portanto, é possível concluir a baixa confiabilidade dos indicadores de desempenho mais utilizados em estudos anteriores.
Sete instrumentos de medição Escala Multidimensional de Talentos Psicológicos do Esporte (MSSPT) foram utilizados, a partir da aplicação de questionários de Likert de 1 a 5 (sendo: 1=discordo totalmente e $5=$ concordo plenamente)
Entre todas as diferenças de genero analisadas em talentos e características da saúde mental em jovens jogadores de

handebol, seis diferenças estatisticamente significativas encontram-se, nas subescalas, os seguintes: entusiasmo e motivação (médias mais altas para as mulheres), extroversão, resiliência, autoconfiança e concentração (médias mais altas para jogadores masculinos de handebol) 
PION, Johan

2017

N.I

feminino multidimensional de identificação de talentos desenvolvido por Vandorpe et al. (2011), consistindo em 5 dados antropométricos

(estatura, peso, IMC, percentual de gordura e altura do assento), 6 testes de desempenho físico (sentar e alcançar, sprint $20 \mathrm{~m}$, contador

salto de movimento, flexões de joelho, abdominais e pular corda
Bateria de testes de desempenho para a avaliação e 5 testes de coordenação motora
Dos 243 ginastas iniciais, apenas 35 ginastas $(14,4 \%)$ permanecem em competição ao mais alto nível, enquanto 208 jovens potenciais param a prática após 5 anos. Para esse estudo, foi levado em consideração o custo do desenvolvimento de talentos na ginástica feminina. Seleções errôneas

representam um impacto não apenas financeiro, mas geram outros inconvenientes igualmente importantes, a considerar o compromisso dos treinadores, clubes e esportes, federações e a decepção do ginasta. Outros fatores para o abandono como conflitos de interesse, perda de motivação, esgotamento e lesões devem ser considerados. Poderia ter redução no custo do desenvolvimento de talentos, se menos ginastas fossem selecionadas na linha de base, embora implicasse no risco de perder altos potenciais.

\section{Categorias inferiores}

dos quatro clubes federados espanhóis, apenas o alto nível e as equipes de nível intermediário $\mathrm{A}$ e $\mathrm{B}$ apresentaram diferenças significativas entre os quartis diferentes, a porcentagem de jogadores nascidos no Q1 sendo maior. Portanto, pode ser apontado que o RAE ocorre nessas equipes. Estes achados confirmam que a idade relativa ainda constitui problema em esportes coletivos. Este fenômeno deve-se à busca por o análise comparativa, a partir da distribuição das datas de nascimento e o impacto relativo do efeito da idade dos jogadores de futebol de acordo com o nível da equipe.
PRÁXEDES, Alba
06-18 anos

masculino desempenho prevalece sobre a identificação de talento, cujo objetivo é alcançar mais longo prazo

resultados (Augste e Lames, 2011). Assim, em categorias formativas, jogadores nascidos no início do ano (relativamente mais antigo) têm mais vantagens quando o tempo de seleção comparado para os nascidos no final do ano (relativamente mais jovem), porque físico, fisiológico e desenvolvimento psicológico é mais avançado em o primeiro (Musch e Grondin, 2001). No entanto, parece que a maturidade é um dos fatores que mais determinam a seleção processos de jogadores de futebol e seus consequentes

formação. 
Tabela 2. Características metodológicas dos artigos

Análise experimental a partir de seleções realizadas por treinadores quanto às habilidades técnicas dos jogadores, inteligência dos jogos, personalidade e

ROMANN, Michae

13-14 anos

masculino
Os resultados mostram que o olho dos treinadores é um método válido para avaliar a maturação biológica. Treinadores olho foi ainda melhor do que a avaliação amplamente utilizada APHV. Em comparação com o

o método clássico de raio-X, o olho dos treinadores oferece

coleta de informações muito mais rápida, menor

custos e sem exposição à radiação. Nos esportes, uma implementação sistemática e ampla

classificações de maturidade podem ter um impacto

significativo na avaliação de desempenho, avaliação, seleção e

treinamento durante o desenvolvimento do atleta nálise de dados quanto à data de nascimento, altura do corpo e estatísticas de jogo dos jogadores, fornecidos pelo Escritório Central de Estatística da população polonesa (PP) entre 1994 e 2003, o que correspondeu às datas de nascimento nos grupos analisados. Os dados foram obtidos de acordo com o Data Protection Act na Polônia.
$O$ efeito da idade relativa foi observado no grupo masculino feminino, independentemente da idade dos jogadores. No entanto, a maior desproporção na distribuição das datas de nascimento foi encontrada no grupo de meninos U16 $(V=0,25$, $p<0,0001$ ). Diferenças significativas na estatura corporal foram identificadas nos grupos U14 e U16 dos meninos ( $p<0,0001)$ e do grupo U14 das meninas $(p<0,01)$. O RAE foi o mais prejudicial no grupo de meninos das equipes de 9 o lugar ou menos $(p<0,0001)$. Os grupos de jogadores de basquetebol masculino e feminino das 3 melhores equipas tiveram a maior altura corporal média $(p<0,001)$. Nos meninos do U14 resultados de partidas e índices de desempenho (PIR) significativamente mais altos foram observados para jogadores nascidos no primeiro semestre de um ano civil. 
Tabela 2. Características metodológicas dos artigos

SAVAGE, Jennifer

20-29 anos

masculino e feminino

Análise epistemológica, focada no processo de vivenciar o trauma nos consideramos co-construtores de conhecimento, e, finalmente, destinada a identificar
Constatou-se que muitos atletas se beneficiam da adversidade, é sugerido que aqueles que não têm "habilidades iniciais" suficientes terão menos probabilidade de atinjir o seu potencial e será mais provável se retirar do desporto. Assim sendo, o talento parece necessitar de trauma em vez de ser causado por ele (cf. Howells \& Fletcher, 2015). masculino e feminino
Análises comparativas entre todos os grupos com melhor modelfit derivado dos testes motores. Utilizada abordagem única, multifásica. A fase 1 envolveu jogadores (n D 68) em 2001 completando uma bateria de testes específicos de esporte de 'talento' e desempenho de handebol. Na Fase 2, nacional e treinadores regionais ( $\mathrm{n}$ D 7) em 2001, que participaram de campos de treinamentojogadores talentosos. Na Fase 3 , os atuais novatos e avançados jogadores de handebol ( $\mathrm{D}$ D 12em cada grupo) selecionou os mais talentosos de vídeos curtos de partidas disputadaso campo de talentos.
$\mathrm{O}$ uso dos testes motores superou todas as previsões de outros modelos, presumivelmente porque essa abordagem usou todos os dados disponíveis para criar o melhor ajuste de modelo. Precisa ser corrigido aqui que pode só deve ser considerado com cautela, porque não é uma previsão real, masisso dá uma ideia de quanta variação pode ser possível explicar. A validade prognóstica dos preditores parece questionável. A partir de um ponto de vista do praticante, estes provavelmente não seriam os testes escolhidos como o mais previsível do desempenho posterior, porque eles não medem habilidades específicas de handebol (por exemplo, distância do handball). Os treinadores nacionais foram melhores na previsão do sucesso futuro dos talentos. Por outro lado, eles estavam no "tryout" acampamento e utilizaram informações coletadas durante os 5 dias para tomar sua decisão (assim como qualq pessoal pode ter tido); além disso, e talvez mais importante, eles podem ter tido um papel em influenciar o desempenho futuro treinando os jogadores selecionados na equipe nacional e tambémidentificá-los como jogadores altamente talentosos para o profissional clubes, o que pode ter resultado em maior quantidade e qualidade de treinamento. 
SEANOR, M.

2017

N.I

masculino e feminino

análise descritiva observacional
Skyriders Trampoline Place no Canadá é um ambiente esportivo adequado para descobrir os processos únicos de

desenvolvimento de atletas de nível olímpico de sucesso no trampolim, dado que a equipe desenvolve atletas do início d prática esportiva ao pódio. Skyriders produziu muitas

conquistas em nível internacional, incluindo quarto Olimpianos que conquistaram todos os sete trampolins do México

olímpicos. Esta contagem de medalhas é a segunda maior do que qualquer país na história olímpica de trampolim. 0 modelo empírico do Skyriders ESF aumenta nossa compreensão de um esporte único, em um ambiente que facilita as transições do atleta do início ao pódio Olímpico. Considerando que os

pesquisadores já destacaram ambientes esportivos que apoiam

atletas durante uma única transição, o ambiente do Skyriders apoia atletas ao longo de toda carreira
SHERWIN, I.

2017

até 47 anos

masculino
Treinadores de cinco esportes coletivos na Irlanda foram solicitados a preencher um questionário on-line.

Posteriormente, técnicos do sexo masculino $(n=19)$ de cinco esportes de equipe que completaram o questionário e preencheram os criterios de inclusão foram convidados a participar de uma entrevista semi-estruturada de acompanhamento. Os critérios de inclusão para treinadores foram que eles possuam pelo menos 10 anos de experiência treinando seu esporte e treinando mais de 4 horas por semana
O Treinamento Formal

da educação não atende às necessidades de treinadores de alto desempenho que dependem mais da aprendizagem e de treinamentos autodirecionados

como suas principais fontes de DPC. Embora a experiência de jogo anterior em um nível alto seja valiosa e desejável. Há preocupações sobre o rastreamento rápido de ex-jogadores em papéis de coaching de alto desempenho. 
Tabela 2. Características metodológicas dos artigos

SWANN, Christian

2017

27 anos

masculino e feminino

Entrevistas semi-estruturadas em profundidade, principalmente após um desempenho excepcional
Os dados foram analisados de forma indutiva e temática.

Estados de embreagem envolvidos 12 características, incluindo concentração aumentada e deliberada, esforço intenso aumento consciência, que distinguia a experiência da embreagem de outros estados psicológicos ótimos, tais como fluxo. Outras características, como percepcões de controle, também foram relatadas e apoiadas

pesquisa experimental anterior em embreagem. Esses achados apresentam insights qualitativos em profundidade

o estado psicológico subjacente ao desempenho da embreagem e são discutidos em relação a literatura sobre estados psicológicos ótimos no esporte.

TAYLOR, Robin D.

2017

44 anos

masculino e feminino

Entrevistas fenomenológicas retrospectivas foram realizadas com quatro

conjuntos de irmãos (n9), sendo que pelo menos um irmão competiu em nível de elite.
Irmãos podem facilitar a progressão positiva durante o processo de desenvolvimento do talento, através da regularidade de interação no esporte, emocional, habilidades interpessoais (proximidade, apoio e empatia) e cooperação. Nós estendemos esses mecanismos destacando que a rivalidade entre irmãos pode positivamente impactar sobre o DT e que os irmãos podem contribuir para o desenvolvimento da resiliência - uma característica psicológica, que pode ajudar os atletas a lidar com

o alto nível desafio. É importante notar também o

comportamento não-linear papel do subsistema de irmãos, como refletido pelo tema da separação como experiência desenvolvida, reduzindo o papel facilitador que os irmãos podem desempenhar no DT. 
Tabela 2. Características metodológicas dos artigos

TEDESQUI, Rafael A. B.

23 anos

masculino e feminino
Pesquisa on-line por e-mail, questionário Survey contendo questões demográficas (por exemplo, idade e sexo), perguntas, perguntas sobre o nível de habilidade dos atletas e a Escala Grit (Duckworth et al., 2007).
Houve diferenças entre grupos de habilidades em PE, associações entre EP e medidas práticas e associações inversas entre IC e medidas que representam ameaças ao compromisso. Embora esperássemos que $\mathrm{PE}$ e $\mathrm{Cl}$ tivessem diferenças na força de suas associações com medidas relacionadas à prática, na verdade, foi descoberto que as duas variáveis de cascalho mostraram associações diferentes com o resultado das medidas
TILL, K. masculino e feminino
Desenho longitudinal retrospectivo. Cinquenta ex-jogadores da modalidade junior foram agrupados retrospectivamente, de acordo com os ressultado que atingiram na carreira adulta (por exemplo, amador, academia ou profissional). Como juniores, os jogadores se comprometeram a realizar uma bateria de testes físicos em três ocasiões anuais consecutivas (Sub-13, 14, 15) incluindo altura, massa corporal, soma de quatro dobras cutâneas, maturação, salto vertical, uso de bola medicinal, 10 a $60 \mathrm{~m}$ sprint, agilidade 505 e estimativa de OV O2max.
O desenvolvimento de aspectos antropométricos, maturacionais e físicas, qualidades em jogadores juniores de rugby league entre 13 e 15 anos contribuíram para a carreira na vida adulta. 
Tabela 2. Características metodológicas dos artigos

TOWLSON, Chris

2017

13-18 anos

masculino

estudo experimental
Os resultados aqui confirmam a hipótese geral de que os jogadores podem ser separados por atributos antropométricos em determinadas posições de futebol juvenil de elite. No entanto, a magnitude dos efeitos padronizados (moderada) entre as diferenças de posição era tipicamente maior do que o relatado em jogadores de futebol juvenil de elite belga
WINN, C. O. N.

2017 Dos 6 aos 15 anos
N.I
Durante o estágio de mini rugby (6-10 anos de idade), os jogadores acumularam uma média de $113 \pm 105,89 \pm 69$ e $43 \pm$

$19 \mathrm{~h}$ por ano no jogo de rugby, prática e competição,

respectivamente. Além disso, 461 jogadores participaram em média de dois outros esportes durante o mini rugby. Durante o estágio junior de rugby (11-15 anos de idade), os jogadores acumularam $179 \pm 98,115 \pm 90$ e $64 \pm 26 \mathrm{~h}$ por ano na prática de rúgbi, jogo e competição, respectivamente, e 538 jogadores participaram outros três esportes. Os jogadores que foram mais necessitados acumularam menos horas de rugby e participaram menos outros esportes, mas os marcos da idade não foram diferentes entre os quintis de privação. Não havia diferenças dentro de atividades de desenvolvimento no rugby entre

$$
\text { grupos de privação. }
$$


WOODS, Carl T.

2017

Por volta dos 18

anos

N.I

estatística descritiva
As métricas de desempenho físico foram positivamente

associadas à posição de draft em 27 dessas rodadas.

Correlações enfraquecidas para a terceira / quarta rodadas. As possessões / marcas contestadas estavam associadas a uma seleção preliminar anterior. As métricas de desempenho físico foram associadas a uma seleção posterior de 29 rascunhos. Os recrutadores alteram o tipo de jogador U18 que eles criam à medida que o pool de seleção é reduzido. 30 juniores com habilidade contestada parecem priorizados.
BOCCIA, Gennaro

No geral, ao controlar a idade de entrar na competição, os atletas de nível superior alcançaram o melhor desempenho pessoal depois (isto é, em torno de 23-25 anos) para todos os eventos em comparação com o resto dos atletas.

Além disso, a análise de regressão mostrou que a entrada em competições mais tarde foi associada a melhores desempenhos durante a idade adulta. Além disso, apenas $17 \%-26 \%[90 \% \mathrm{Cl}]$ dos atletas adultos de alto nível foram considerados quando eles tinham 14-17 anos de idade. 
BROWNLEE, T. E.

2018

9-18 anos

masculino

uma Premier League inglesa, categoria uma academia.

Cento e oitenta e quatro jogadores foram monitorados

durante um período de oito semanas durante o período 2013-2014

temporada (Tabela 1). Grupos sub-18 e sub-21 foram

em treinamento em tempo integral, cinco dias / semana com um

partida competitiva (90 min) / semana.
Os dados confirmaram que, embora o treinamento tenha sido composto em grande parte no campo relacionado atividades ao futebol, refletindo assim em um alto grau de especialização precoce, se comparado com as diretrizes, o volume total não aparentou ser prejudicial para o desenvolvimento dos jogadores do clube em questão.
Os resultados mostraram uma grande reapresentação dos jogadores carregados em Q1 em todas as categorias do jogador do Soccer. Entretanto, o tamanho do efeito dessa tendência resultou menor com o aumento da idade. Indivíduos nascidos em Q1 têm cerca de duas dobras mais chances de se tornar um jogador. Série A em comparação com aqueles nascidos em Q4. A análise de regressão de Poisson mostrou que a RAE foi maior para os defensores do que para a frente entre todas as categorias. 
por volta dos 14 anos. masculino e feminino testes de capacidade física, chi-square e t-test
Houve uma representação significativamente maior de jogadores no primeiro semestre, em comparação com 0 segundo semestre, para todos os grupos de gênero, exceto para

os jogadores selecionados do sexo masculino. No sexo

masculino, diferenças estatisticamente significantes foram

encontradas em altura, altura sentada, peso, envergadura,

circunferências de braço e perna, e na velocidade de

arremessos (em apoio e em suspensão) entre os jogadores que nasceram no primeiro e segundo semestre.
DEVANEY, Darren J.

2018

entre 15 e 19

anos discurso doss atletas
Os jogadores discutiram desafios de estilo de vida e apoio, com cinco temas emergentes: (a) jogadores que apreciem o apoio ao estilo de vida, (b) adaptar-se ao novo ambiente, c) gerir as exigências concorrentes, d) escolhas educativas e contratos profissionais, e (e) negociação de identidade em momentos críticos. Os desafios impactaram o sentido dos jogadores de auto, bem-estar e, finalmente, desempenho. 
ENGLISH, C.

8-46 anos

masculino

As mudanças reduziram as oportunidades de jogar na elite e as opções de vias estreitas. Padrões de Cricket Club caiu,

reduzindo sua viabilidade como piscina para identificação de talentos e desenvolvimento efetivo. Isto colocou o stress em academias relacionadas com a idade como um fundamental ambiente de desenvolvimento e a necessidade de selecionar talentos "no sistema" anteriores, o que tem implicações para os desenvolvedores atrasados e a extensão para que a chance influencia o desenvolvimento. Consequências práticas, no a longo prazo, não só reduzir a base de participação e restringir o desempenho, mas também o impacto na saúde geral do Sul Jogos africanos domésticos e internacionais. Os achados reforçam também os modelos teóricos, reconhecendo o desenvolvimento esportivo como um indivíduo e processo nãolinear e confirmar Cricket como um esporte em

desenvolvimento tardio, salientando a importância desses ambientes de desenvolvimento entre

participação em massa e desempenho de elite

(escola/clube/Universidade) para manter a estrutura, a

concorrência e apresentar a maior flexibilidade e coerência.
ERIKSTAD, Martin K. por volta dos $14 \mathrm{e}$

15 anos masculino

Os jogadores autorregulados foram mais propensos a serem selecionados para iniciativas nacionais e aumentaram seu envolvimento em práticas de futebol conduzidas por pares e práticas durante a infância, em comparação com jogadores com níveis mais baixos de autorregularão. 
Tabela 2. Características metodológicas dos artigos
FABER, Irene R.
2018
8-10 anos
masculino e feminino
Análise discriminante, z-scores, modelo linear geral univariado (GLM).

Habilidades perceptuomotoras holandesas medição de avaliação "controle de bola" e "função motora grossa". Uma análise de função discriminante confirmou o valor acrescentado através da identificação de crianças do ensino básico que se enquadram no tênis de mesa perceptumotor perfil dos jovens talentosos tenistas de mesa (28\%). Análises gerais de modelos lineares para os itens de teste individuais da avaliação mostraram que os jogadores de tênis de mesa tiveram desempenho colegas escolares em todos os itens de "controle de bola" $(\mathrm{P}<0,001)$
GLEDHILL, Adam
2018
16 anos
feminino
Análise descritiva e
análise de variânciade Bonferroni

Os jogadores tiveram percepções mais positivas de foco de

desenvolvimento a longo prazo e rede de apoio, enquanto as

percepções menos positivas foram de comunicação e compreensão do atleta. 
Tabela 2. Características metodológicas dos artigos

HANCOCK, David J.

2018

média de 33 anos

com intervalo de

19-64. masculino e feminino

ANOVAs
Os resultados indicaram que atletas homens e mulheres

nascidos em distritos de 200.000-399.999 tinham 2,4 vezes mais chances de atingir o status de voleibol de elite, enquanto outros

distritos diminuíram as chances de desenvolvimento de especialistas.
HJORT, A.

2018
N.I

método analítico Chamberlain
Os resultados mostram que o sistema PU pode melhorar as habilidades de reflexão dos jovens jogadores de futebol através de análise de vídeo e marcação; os treinadores são importantes como modelos e fornecedores de feedback; e essa o uso da plataforma estimulou principalmente atividades práticas deliberadas 
HUTTER, R. I. Vana

2018

N.I

N.I

análise descritiva
Aeducação em ASP está disponível na maioria dos países europeus, mas os programas e cursos variam muito em termos de nível, tamanho e foco aplicado. Os educadores em ASP querem interagir, principalmente com os objetivos de formar rede, colaborar e intercambiar
KRISTIANSEN, Elsa

2018

N.I

\section{Questionário:}

YOG desempenho e experiência, educação, deixando o esporte perseguindo uma carreira de elite, aprendizagem e legado; escala likert de 5 pontos e análise descritiva.
No momento da pesquisa, no final de 2015, a maioria dos entrevistados ainda estava envolvida esporte de elite, embora uma minoria substancial, $29 \%(n=17)$, tenha desistido. Assim sendo, a maioria dos atletas permaneceu no esporte. A maioria dos entrevistados $(84,5 \%)$ indicaram que o YOG não foi sua primeira competição esportiva internacional, tiveram experiências competitivas internacionais prévias em seu esporte. Mais uma vez, a maioria observou que sua experiência com YOG foi positiva (84\%). Em termos de desempenho e experiência ( $n=15,31 \%$ sentiram-se muito satisfeitos, $n=26$,

$53 \%$ sentiram-se satisfeitos). $O$ desempenho geral de

os atletas noruegueses eram fortes, com 17 atletas

conquistando medalhas - 4 de ouro, 7 de prata e

13 medalhas de bronze - nas 3 edições do YOG. 
LI, Chunxiao

2018

por volta de 17

anos

masculino e feminino

Talent Development Environment Questionnaire (TDEQ-5)
A análise fatorial confirmatória revelou adequação do modelo da escala. A confiabilidade interna, validade concorrente e discriminante e confiabilidade teste-reteste da escala foram adequadamente suportadas. A escala também era invariável entre os sexos.
LIGHT, Richard L.

2018

N.A

N.A

N.A
Identificamos três fatores que mais facilitaram os participantes desenvolvimento de talento e experiência até cerca de

a idade de treze anos, por ordem de importância, eram (1)

aprendendo através de jogos, (2) jogando uma variedade de outros esportes, e (3) o ambiente sociocultural. 
Tabela 2. Características metodológicas dos artigos

LIMPENS, Vera

2018

9. anos

masculino e feminino

t-tests, Shapiro-Wilk test, Friedman test, Eta parcial quadrado, $\mathrm{d}$ de Cohen
Resultados mostraram que baixar a altura líquida para 0,65 me $0,52 \mathrm{~m}$ levou os jogadores a adotarem atacando estilo de jogo, como evidenciado por um aumento significativo no número de vencedores sem um aumento proporcional de erros e mais tiros atingidos dentro da linha de base. Redes mais baixas também levaram a uma porcentagem maior de primeiros saques bemsucedidos. A rede mais baixa $(0,52 \mathrm{~m})$, no entanto, reduziu o rali comprimento significativamente e, portanto, diminuiu as oportunidades de acerto.

MURTAGH, Conall F.

$$
21 \text { anos. }
$$

masculino
O ESP demonstrou desempenho mais rápido de $10 \mathrm{~m}(\mathrm{P}<0,001)$ e $20 \mathrm{~m}(\mathrm{P}<0,001)$ do que o CON em todos os estágios de maturação. O VPH médio e o pós-HPV atingiram maior altura do CMV-V $(P<0,001)$ e distância do CMJ (ESP x CON; VP médio: $164,32 \pm 12,75$ vs. $136,53 \pm 21,96 \mathrm{~cm}$; pós-VP: $197,57 \pm 17,05$ vs. $168,06 \pm 18,50 \mathrm{~cm} ; \mathrm{P}<0,001)$ em comparação com o CON, mas não houve diferença no $\mathrm{BV}$ ou $\mathrm{BH} C \mathrm{CMJ}$ entre o ESP e o CON pré-PHV. Enquanto 10 e 20 meo desempenho de sprint podem ser determinantes do status de futebol de elite em todas as fases de maturação, as capacidades de avanço horizontal e salto vertical discriminam apenas os participantes ESP e CON em meados e pós-PHV. 
Tabela 2. Características metodológicas dos artigos
2018

ONG, Chin Wei

N.A

N.A

N.A

OWEN, Adam Lee

2018

Por volta dos 24

anos. masculino teste de Kolmogorov-Smirnov, ANOVA de duas vias de Friedman para medidas repetidas, chi-test.

Avaliação de treinamento e matchplay

exposição também foram registrados. Sites-4, Sites-7, Sites-8 e massa gorda diminuíram drasticamente de T0 para T1 e T2 em

todas as posições de jogo $(p<0,01)$, enquanto nenhuma

diferença notável foi encontrada entre T2, T3 e T4. Exceto por

os defensores, a circunferência da panturrilha e a massa magra

foram maiores em T2, T3 e T4 em relação a T0 e T1 $(p<0,01)$.

Meio-campistas foram encontrados para ser mais magros do

que para a frente e defensores em todas as sessões de ponto de tempo de coleta de dados.

Pon volta dos 12, 2018 masculino distribuição das datas de nascimento, MANCOVA, T test,
14 e 16 anos.
2018

7-20 anos. masculino e feminino distribuição das datas de nascimento, odds ratio.

Jogadores nascidos prematuramente foram super-

representados $(p<.05)$. Jogadores iniciantes não eram

estatisticamente mais altos, pesados ou melhores no

desempenho físico $(p>0,05)$ quando a maturação e a idade cronológica eram controladas como fatores de confusão. No entanto, os treinadores esperavam mais dos jogadores que nasceram cedo $(p<0,05)$, e a análise inferencial mostrou que provavelmente vale a pena diferir entre as expectativas dos técnicos para jogadores nascidos no primeiro quartil do ano e aqueles nascidos no quarto quartil. Do ano.

RAE foram semelhantes em atletas do NLS do sexo feminino (OR 1,30 (IC 95\% = 1,08; 1,57)) e maior em atletas do NLS do sexo masculino (OR $2,40($ IC95\% $=1,42 ; 1,97))$ em comparação o menor nível de seleção. No STDP, RAE são evidentes para ambos os sexos em vários esportes com esportes populares

mostrando maior RAE. RAE foram maiores nos grupos masculinos do que no feminino. Um maior nível de seleção mostrou maior RAE apenas para homens.

Os dados mostraram variações no tamanho e densidade ideais da comunidade

através dos esportes. Análises geoespaciais de proximidade a clubes de talentos destacaram uma tendência

indicando que a maioria dos atletas nacionais e de elite da liga juvenil de ambos os esportes

lugar de desenvolvimento inicial em seu esporte perto de um clube de talentos. 
Tabela 2. Características metodológicas dos artigos

RUBAJCZYK, Krystian

2018

masculino

chi-square

os resultados revelaram a existência de EAR nos grupos examinados (CU 2013/2014, $\chi^{2} 3=15,411, p<0,01$, CL $2014 / 2015, \chi^{2} 3=20,891, p<0,001$ U17-U21, $\chi 3=25,110, p$ $<0,001)$. Além disso, os resultados diferiram pelo nascimento mensal distribuição na população polaca (PP) entre 1995 e 1999.

RYBA, Tatiana V. N.A N.A N.A N.A

masculino e feminino
Construção do Inventário Fatorial de Práticas ParentaisRelacionadas ao Desenvolvimento do Talento no Esporte (IFATE), a partir dateoria e o modelo de elaboração de instrumenta psicológicoproposto por Pasquali (1999).
Os dados podem indicar uma longevidade e persistência maior dosatletas de gênero masculino, em virtude de um maior reconhecimento àatividade esportiva praticada por eles. Conforme apontado pela literatura, o incentivo e

reconhecimento atribuídos às atividades esportivaspraticadas por homens geralmente são maiores do que em relação àsatividades esportivas praticadas pelas mulheres. Eles se sentem mais encorajados a persistirem em suas carreiras esportivas, enquanto as mulheres, a partir de um determinado período, podem buscar outras atividades devido à falta de apoio na prática esportiva. Realmente é menos aceita a participação feminina no esporte. 0 esporte, culturalmente, tem sido mais associado aos homens.
TAHA, Zahari
Aplicação da análise de Cluster hierárquica aglomerativa para definir os membros do grupo como HPA ou LPA. Realização de de

pontuação de tiro, e análise do desempenho de seis variáveis motoras, sendo: aperto da mão, salto vertical, salto largo estando, equilíbrio estático, força de músculo superior e força de músculo do núcleo.
A atribuição dos arqueiros de baixo e alto potencial foi determinada com base na pontuação de tiro, bem como no desempenho de seis variáveis (isto é aperto da mão, salto vertical, salto largo estando, equilíbrio estático, força de músculo superior e força de músculo do núcleo). A análise de cluster hierárquica aglomerativa foi utilizada para definir os membros do grupo como HPA ou LPA. O HPA superou o LPA em todas as variáveis de desempenho incluindo a pontuação de tiro. Esse método permite a designação correta dos membros definidos, já que não apenas o tiro é considerado, mas outras variáveis de adequação de desempenho também foram levadas em conta. Essas variáveis que são mostradas nas plotagens de caixa são, portanto, considerados como atributos essenciais que distinguem o HPA do LPA. 
Tabela 2. Características metodológicas dos artigos

TAYLOR, Robin D.

2018

dos 8

até 14 anos

masculino e feminino

pacote de software qualitativo (QSR NVIVO 10)
Os resultados revelaram vários temas (regularidade de interação, habilidades interpessoais emocionais, rivalidade, resiliência e separação), alinhados com estudos anteriores,

juntamente com dois novos temas: comunicação e desenvolvimento de habilidades. $\begin{array}{lll}\text { TE WIERIKE, S. C. M. } 2018 \text { por volta dos } 16 \quad \text { masculino } & \begin{array}{r}\text { Software SPSS Statistics (versão 20.0; Inc., Chicago, Illinois, } \\ \text { Estados Unidos da America. Análise descritiva. }\end{array}\end{array}$
Os resultados mostraram que as habilidades reflexivas foram mais importantes para alcançar o nível de elite $(O R=11,76$; $P$ $<0,05)$. Não houve melhora significativa na reflexão

(autorreferida) ao longo do tempo para guardas, forwards e centros. A melhoria no controle da bola foi evidente para os guardas $(r=-0,65 ; P<0,05)$. Além disso, os guardas e atacantes tiveram melhor controle da bola em relação aos centros ( $\mathrm{P}$

$<0,01)$. Para essas duas posições, foram encontradas

correlações negativas entre a reflexão e o controle da bola.
TEDESQUI, Rafael A. B.
por voltas dos 18
anos de idade
masculino e feminino
chi-square

No Estudo 1, a consciencialização ampla previu o envolvimento em ambos os contextos de prática e menos ameaças ao compromisso. No nível de faceta, o esforço de conquista foi o melhor preditor de DP e envolvimento em contextos práticos.

Nenhuma faceta de consciência previu ameaças ao

comprometimento ou maior participação no grupo de habilidades. Nas análises comparativas entre facetas de conscienciosidade, autocontrole e determinação (Estudo 2), as variáveis de grão tiveram melhor desempenho: perseverança

de esforço, explicação da prática deliberada e maior participação de grupo de habilidades e consistência de interesses associados a menos pensamentos de desistir / trocar de esporte. 0 esforço de realização, a obediência e a autodisciplina também mostraram efeitos associados a critérios-chave. 
Tabela 2. Características metodológicas dos artigos

$\begin{array}{llll}\text { VAN RENS, F. E. C. A. } & 2018 & \begin{array}{c}\text { por voltas dos } 18 \\ \text { anos de idade }\end{array} & \text { masculino }\end{array}$

Os resultados indicaram que o estresse do papel explicou doze a vinte e quatro por cento da variação na satisfação com a vida nos domínios da vida dos jogadores. As experiências de tensão relacionada às carreiras duplas dos jogadores foram associadas à diminuição da satisfação com a vida nos domínios do esporte, amizades, família, você mesmo e satisfação global com a vida. Situações em que os jogadores perceberam que suas

habilidades foram subutilizadas também foram negativamente associadas à satisfação com a vida em vários domínios da vida,

Data sugeriu a existência de diferenças entre a jogabilidade do Japão e das outras cinco equipes, a saber, a probabilidade de mais jogabilidade com a utilização do salto de flutuação $(20,42$;

VARGAS, Jorge

2018

N.I

Feminino

análise descritiva

maito grande) e ritmo de ataque $2(61,89$; + / - 29.67\%, grande magnitude), enquanto exibindo menos jogabilidade com zero bloqueadores opostos ao ataque (-42.06; $+/-21.28 \%$, grande magnitude).

A proporção de atletas nas 9 categorias populacionais do censo

foi comparada às distribuições da população geral nacional e regional nas categorias censitárias. Os resultados sugerem a

variabilidade dos efeitos de tamanho da comunidade entre as 7 regiões provinciais dentro do Canadá, com apenas a província de Ontário demonstrando um efeito de tamanho da comunidade congruente com os efeitos relatados em pesquisas anteriores. A utilização de distribuições regionais de população em geral como comparador de populações de atletas mudou a direção, o significado e a magnitude dos efeitos de tamanho da comunidade. 
WOODS, Carl T.

por voltas dos 18 anos de idade
Os dados de habilidades técnicas foram adquiridos da Champion Data (C) (Champion Data @, Melbourne, Austrália). A aprovação de ética foi concedida pelo Comitê de Ética em Pesquisa com seres

humanos. Os indicadores técnicos relatados por esse provedor são confiáveis para $99 \%$ ao analisar as atividades de jogo dos jogadores dentro da AFL (O'Shaughnessy, 2006). O conjunto de dados continha contagens de 12 indicadores técnicos
O LDA produziu uma precisão de classificação de $56,8 \%$, com erros de classe variando de 19,6\% (meio-campistas) a 75,0\% (ruck). O modelo florestal aleatório apresentou um nível um pouco pior $(51,62 \%)$, com erros de class variando de $27,8 \%$ (meio-campistas) a $100 \%$ (ruck). A lista de decisões revelou 6 regras capazes de classificar a posição de jogo com precisão de $70,1 \%$, com erros de classe variando de $14,4 \%$ (meio-campistas) a $100 \%$ (ruck). Embora a lista de decisão da PART tenha produzido a maior precisão de classificaçao relativa, os indicadores de habilidades técnicas relatados geralmente não conseguiam classificar os jogadores de acordo com sua posição usando as três abordagens de analise. Essa homogeneidade do jogador pode complicar o recrutamento restringindo a capacidade do recrutador de talentos de reconhecer objetivamente os atributos posicionais distintos. 
ANEXO C

Primeiro autor

Ano de

publicação

AGENGAARD, Sine

Conclusões

Limitações

Classe do estud

A aprendizagem se desenvolve nas relações sociais. Os conhecimentos práticos que um atleta adquire em contato com diferntes comunidades, parecem cruciais para o desenvolvimento profissional. Os jogadores imigrantes deram aos jovens talentos nacionais a chance de experimentar abordagens para handebol profissional que são fundamentais em um cenário mais amplo. É preciso considerar a quebra do nacionalismo metodológico na governança do esporte.

BARTULOVIC, Dora
Atletas de elite se automonitoram com mais frequência e podem integrar outros processos constituintes melhor dentro de um ciclo de SRL. desenvolvimento do talento
Resultados dizem respeito esportes individuais e não podem generalizar como os atletas regulam

em esportes coletivos, enquanto houve melhorias em muitas escalas da SRL-SRS, resta trabalho para ser feito especificamente na escala de automonitoramento, a

fim de aumentar validade convergente e divergente.

Em terceiro lugar, embora muitos os processos do ciclo

SRL de Zimmerman (2006) foram representados,

trabalho futuro poderia considerar processos

complementares (por exemplo, auto-reação,

estabelecimento de metas, atribuições causais), a

corrente estudo não examinou como as diferenças nas

quantidades de esportes prática contribuem para o

status do grupo de habilidades, que pode ser visto como limitação
BJøRNDAL, Christian Thue

2017

Embora pesquisas de política esportiva sugerem que modelos que se assemelham a SMTD são de especial importância para nações menores como a Noruega, as descobertas mostram que $O$ modelo SMTD carece de validade empirica no contexto do handebol norueguês
A estrutura do EG assume que "a incerteza é desenfreada" (Lubell, 2013, p. 545) dentro do mundo gestão de talentos, devido à pouca informação disponível aos personagens envolvidos. 
COLLINS, David J.

2017

crescendo. Apoio desenvolvimento, ajudando com uma ampla

variedade de questões (por exemplo, recuperação de lesões )

oferecendo amplobenefício educacional para os personagens

$$
\text { envolvidos. }
$$

Identificadas diferenças significativas em três questões, mas que não foram suficientes para surtir um efeito generalizado ao fator

$$
\text { correspondente. }
$$

Os métodos de identificação de talentos referentes aos fatores de maturação biológica podem confundir na busca por jogadores

CRIPPS, Ashley J.

juniores que são mais propensos a ter sucesso na modalidade sênio

Um programa de desenvolvimento de atletas pode incluir a prestação de ambos faixa etária e atividades BIO-BANDING, que oferecem aos atletas uma maior diversidade, multifacetada e de

desenvolvimento estímulo de aprendizagem sensível.
A longo prazo, mantendo os atletas talentosos por mais tempo nos clubes em vez do centralizá-los programas governamentais, pode
Não ficou claro se o desempenho nos testes de habilidades da AFL se associa com desempenho habilidoso nos jogos

BIO-BANDING não é um substituto para a formação por idade em grupo ou competições, mas sim uma atividade adjunta que

tem o potencial de desafiar o atleta

de uma maneira única e integrar a diversidade ao longo do desenvolvimento

A relevância desses achados diz respeito ao papel que clubes esportivos (podem) ter no desenvolvimento total de uma carreira atlética. Este artigo tem implicações práticas para a gestão de talentos desenvolvimento por órgãos governamentais e clubes, associações esportivas nacionais e treinadores

educacionais. Embora os dados atuais confirmem a

idade relativamente tardia de suporte, eles não puderam confirmar achados anteriores, nos quais os atletas de nível mundial receberam serviços de suporte em uma idade mais avançada em comparação com os de nível inferior.

Certas variáveis, como massa muscular e força explosiva, distinguem jogadores de handebol masculino e feminino que atingiram os níveis 
Tabela 3. Conclusões

GÓMEZ-LÓPEZ, M.

2017 jovens talentos em jogadores de handebol.

A medida em que os elementos de um sistema de esporte de deficiência de elite são ocolocados em prática espelham aqueles que já existem no esporte sem deficiência.

Porém, permanece o debate em torno da questão se deve existir uma ampla gama de esportes de deficiência nos Jogos da Escola -

isto é, já que frequentemente um estágio é um estágio inicial na

HOULIHAN, Barrie carreira esportiva dos jovens - ou se preservar um número limitado de esportes de gateway é mais benéfico tanto para o atleta e para o sucesso paraolímpico. Por enquanto os pontos de entrada significativos) para atletas com deficiência são: natação, atletismo e

ciclismo. De qualquer forma, os benefícios do esporte são experimentados por aqueles jovens talentosos que são capazes de desfrutar da emoção e satisfação da competição ao mais alto nível e também aqueles que procuram participar em um nível recreativo. estudo esteja limitado a um pequeno número de esportes e organizações em um país detecção do talento
O estudo sugere que os coaches devem ser incentivados a especificare aperfeiçoar seus critérios de subjetivos de talento.
Pesquisa com amostra pequena e regional de técnicos entrevistados. detecção do talento
JOKUSCHIES, Nina

Não foi possível estabelecer no estudo como diferentes histórias afetam o processo de seleção. Sem dúvida, é preciso mais do que apenas habilidades em campo para se tornar um talento

selecionável. Durante as entrevistas, histórias especificas são

$$
\text { enfatizadas e repetidas pelos jogadores, }
$$

como a importância de "ter o personagem certo" e "ser um jogador

de equipe". Esse potencial dilema entre aparecer como um indivíduo

do coletivo faz um espaço dilemático que precisa ser equilibrado.

KILGER, M. notável e, ao mesmo tempo, ser beneficiado seleção do talento 
KILGER, M.

Os jogadores devem ter domínio para mostrar sinais de desenvolvimento como bem como auto-reflexão e compreensão do próprio desenvolvimento. Além disso, neste gênero narrativo das Entrevistas de Avaliação em Acampamentos, os jogadores precisam mostrar vontade de melhorar. Isso é de particular importância quando a seleção está em jogo. Aqui, duas estratégias retóricas foram empregadas em nossos dados: (a) o uso de indicadores temporais no relato de futuro (Bo"rjesson \& Blomberg, 2013) e (b) uma demonstração de autoestima positiva, sem inclinar a balança para o reino da divulgação. detecção do talento
Variância nas escalas utilizadas e

inconsistencia nos tipos de treinamento que estão

incluídos; alguns incluem atividade escolar

enquanto outros não.
Os padrões pessoais são essenciais para o desenvolvimento de habilidades e os treinadores devem encorajar os jogadores a lutar por bons padrões pessoais. desenvolvimento do talento

Há um clima ambivalente no governo: por um lado, demonstrando uma relutância contínua para invadir muito obviamente sobre a autonomia da NIF e das federações e, por outro, reconhecendo que o desenvolvimento de atletas de elite no nível da juventude estava precisando de reforma.

KRISTIANSEN, E.

É necessário pesquisas quanto quais escolas esportivas agregam valor ao desenvolvimento dos jovens atletas e se há é uma variação significativa no benefício entre os esportes. Uma terceira área para estudo adicional é, se há perda de jovens talentos da elite para escolas de esportes, e ainda, até que ponto as escolas de esportes promovem seus interesses dentro do governo, pelos seus processos.

As descobertas vão ao encontro dos princípios do BPNT e a ligação entre o desenvolvimento de cinco talentos com fatores ambientais e esgotamento de atletas. As descobertas das pesquisas atuais

LI, Chunxiao os resultados estão relacionados a talentosos jovens atletas em Cingapura e podem não ser generalizados para outras populações

desenvolvimento do talento fornecem evidências qualitativas sobre os papéis dos cinco fatore ambientais do desenvolvimento de talentos ao longo do esgotamento do atleta

É importante preparar melhor o adolescente talentoso para níveis de elite atlético, facilitando a satisfação de suas necessidades

e evitando assim, o esgotamento através do fornecimento da evoluçaõ efetiva de talentos antecedentes ambientais. questões de pesquisa foram examinadas usando-se abordagem quantitativa para conclusões causais

evoluçaõ efetiva de talentos antecedentes ambientais.


LUND, Stefan

MATIN, Vazjwar
Expõe que diferentes fatores contextuais e relacionados à cultura influenciam as maneiras pelas quais as qualidades dos jogadores são ou não priorizadas. Os treinadores são guiados pelo que parece

"bem no coração e no estômago" (Trondman etal., 2011, p. 11), mas

o que aparentemente é correto, é influenciado pela própria

experiência e cultura na qual estão inseridos. O talento é uma

construção social: "... o talento só acontece quando é reconhecido e valorizado." (Tranckle \& Almofada 2006, p. 266).
Os resultados baseiam-se em entrevistas regionais, partir de descrições e reflexões pessoais dos treinadores sobre sua prática detecção do talento

Os jogadores de nível superior consideraram as habilidades técnicas e mentais como mais importantes do que os jogadores de baixo nível. Estes resultados estão alinhados ao que treinadores de nível superior destacaram como importante em seu processo de identificação de talentos (Sæther, 2014). Isso poderia indicar que os jogadores e treinadores concordam sobre a importância aumentada dessas duas habilidades. Sem diferenças foram encontrados entre os jogadores de alto e baixo nível termos dos critérios da TID ou as competências em que a escola e o foco dos treinadores, com exceção das habilidades mentais, que foram considerados significativamente mais importantes pelo nível superior de jogadores. Naturalmente, os jogadores de nível superior consideravam habilidades próprias como significativamente melhores em técnicas e táticas. Estudos anteriores apontaram para 0 fato de que o nível juvenil dos jogadores se relaciona a avaliar suas próprias habilidades de jogo

distorção em relação ao número de meninas e meninos (apenas 30 dos entrevistados eram meninas), inclusão de apenas duas escolas no estudo, mesmo que com o número satisfatório de sujeitos, composto por 111 jogadores. detecção do talento

As experiências de transição dentro da carreira de atletas muito motivados, podem dar origem a uma série de desafios psicológicos, nos quais com nos quais comumente, existe pressã interna extern possível que muitos jogadores não tenham sucesso fazendo

as experiencias dos atletas podem variar dependendo

das exigências do ambiente esportivo e cultura em que desenvolvimento do talento transições dentro da carreira e terão que lidar com as consequências

do fracasso. As experiências de jovens jogadores podem ajudar no desenvolvimento de outros jovens jogadores de futebol no futuro. 
A força muscular dos membros superiores e inferiores em combinação com estatura e agilidade, influenciem no sucesso das jogadoras, mas quando o objetivo é a seleção de atletas em uma base longitudinal, deve-se tomar cuidado ao basear a seleção exclusivamente em atributos antropométricos e habilidades motoras, pois essas características são por maturação biológica. Atributos antropométricos e físicos habilidades combinadas com

características técnicas devem ser avaliadas em freqüentes intervalos de tempo período pré-púbere. Uma razão importante é
NAISIDOU, S

PASTOR-VICEDO, Juan Carlos que atletas selecionados que possuem uma vantagem de maturação durante o início da adolescência provavelmente não reterão essas vantagens até a idade adulta. Por outro lado, a avaliação desses atributos fornece informações importantes sobre os pontos fortes e

fracos dos atletas, bem como sobre adaptações individuais de

treinamento. No entanto, a fim de selecionar os atletas que

demonstram o potencial de evoluir e tornar-se parte do que definido como esporte de nível de elite. Outros parâmetros também devem ser considerados.

Deve-se considerar a utilização de outros instrumentos de avaliação validados que sejam responsáveis pela mensuração do aspecto tático do futebolista. Não é útil guiar-se apenas pelas estatísticas ferecidas nas bases de dados dos jogadores, deve-se considerar também fatores como elementos táticos e aspectos ambientais (família e amigos), para serem mais precisos na

$$
\text { seleção. }
$$

a maturação biológica não foi avaliada no estudo, há escassez de dados sobre atletas de handebol do sexo feminino, tornando a comparação de resultados relativamente difícil seleção do talento
Foram encontradas seis diferenças de gênero estatisticamente significativas. Entusiasmo e motivação tiveram maior expressividade entre as mulheres, enquanto extroversão, resiliência, autoconfiança e concentração, tiveram maior expressividade para jogadores de handebol do sexo masculino. Apesar das características semelhantes em muitos aspectos da saúde psicológica e mental, entre os sexos, detecção do talento

thes fornecem informaçōes quanto a abordagem

diferenciada por parte dos treinadores, quando se trabalha com

jogadores de handebol masculino ou feminino. 
Tabela 3. Conclusões

PION, Johan
PRÁXEDES, Alba
O melhor caminho para a identificação de talentos é a combinação dos modelos preditivos com uma velocidade excepcional, ou seja, 20 $\mathrm{m}$ em menos de $3.780 \mathrm{~s}$. Esse equilíbrio ideal de custo-risco leva a uma previsão precisa de sucesso futuro e um custo $33,3 \%$ menor para o desenvolvimento de talentos na ginástica feminina. Deve-se considerar investir em uma breve avaliação dos aspectos

psicológicos e ambientais características em uma idade mais jovem para evitar o desgaste precoce não avaliação dos aspectos psicológicos e ambientais

detecção do talento

Ao estudar o efeito da idade relativa, conclui-se que que deve-se considerar a influência da maturidade como um fator decisivo na seleção de jogadores. Como consequência da idade relativa na formação de atletas, os jogadores mais velhos se beneficiam do acúmulo de experiência em termos de prática. $O$ problema da idade relativa pode ser neutralizado pelos técnicos dos clubes desportivos, introduzindo outros critérios para selecionar jogadores, de acordo de talento esportivo em vez de alcançar resultados de curto prazo. Ao longo desta linha, énecessário garantir a todos os jovens jogadores possibilidade de fazer parte do mais avançado time em cada categoria, dependendo do seu talento e não em sua idade cronológica. Para este fim, competições devem ser organizadas de acordo o nível de conhecimento esportivo da criança, com nível mais alto equipes jogando contra seus iguais.

processo de seleção limitado aojovens de sua cidade natal
Os programas de desenvolvimento de talento exigem a implementação da maturidade biológica no processo de TID. Assim ha uma necessidade de classificar os jovens nos estágios inicial, no prazo e de maturação tardia para o TID e projetos de treinamento e programas de competição. Muitos clubes de futebol e federações de futebol

já selecione seus jogadores com base nas avaliações subjetivas de olheiros e treinadores. s resultados não pode ser transferidos para a população em geral, pois o estudo examinou 119 jogadores masculinos de futebol com grande experiência de treino no ambiente esportivo com 
Tabela 3. Conclusões

RUBAJCZYK, Krystian

SCHORER, Jörg
Os resultados da pesquisa mostram o impacto da idade relativa no sucesso das equipes de basquete juvenil na Polônia. O mês de

nascimento, a altura do corpo e o sexo podem determinar

conquistas esportivas no basquete juvenil. Os treinadores devem

considerar a idade cronológica e a aceleração do crescimento

puberal (idade APHV na velocidade máxima de altura) dos jogadores

para otimizar o processo de identificação dos jogadores de basquete

superdotados, especialmente entre os meninos de 14 anos de idade.
Os traumas ou desafios memoráveis

que interrompem o desenvolvimento de um artista, desempenham um papel importante no desenvolvimento de talento.

Especificamente, nossas descobertas apoiam a proposta de que o talento precisa e não é causado

por trauma, com este trauma sendo primariamente de natureza esportiva e negociado com um hospedeiro

de habilidades que são trazidas para a experiência. De fato, os traumas parecem ser mais uma prova

Em resumo, a seleção de talentos é uma tarefa muito difícil; que deve ser repensada com frequência, considerando as mudanças decisões são e deveriam ser tomadas, parece um campo aberto para futuras pesquisas em todos os tipos de talentos domínios. risco de interação de vieses retrospectivos e de autopreservação, não foi possível ter conclusões

concretas sobre qualquer relação causativa entre os mecanismos relatados pelos participantes e seu desenvolvimento final e sucesso, nem nos permitiu desmentir sugestões em outro trabalho que implique

relações causativas entre trauma e progresso

dificuldade em obter amostras de jovens de alt qualidade e para rastreá-los durante longos perioc fim de determinalvimento do talento que eles atingem.

\section{desenvolvimento do talento}

Skyriders fornece insight sobre como os fatores ambientais podem interagir para criar uma organização cultura conducente a

realizações em nível olímpico. Praticantes abertos ao aprendizado

de Skyriders vai ajudar os futuros atletas olímpicos a "pegar a

sensação de voar" em seus próprios empreendimentos atléticos. 
As fontes preferenciais de

educação como melhor ambiente de aprendizado para treinadores

de esportes coletivos na Irlanda, são mais informais do que formais.

Mais adiante Mais distante é necessário examinar como esta

aprendizagem aplica-se de maneira prática, examinando os

desenvolvimento do atleta.
SWANN, Christian

2017

As presentes descobertos sugerem que os estados da embreagem sentimentos positivos análogos (recompensas intrínsecas) e autorrealizáveis experiências (realização de metas), e podem ser incluídos em o melhor conceito de experiência.
Estudo incacapaz de explorar todos os aspectos

importantes relacionados aos estados de embreagem e

outros temas podem incluir sua inibição e possível

resssalva. 0 estudo não podeser generalizado
Irmãos podem impactar positivamente no desenvolvimento dos atletas talentosos: regularidade da interação no esporte, habilidades interpessoais, rivalidade, resiliência, cooperação e separação. A separação foi mostrada quando o atleta alcançou a posição de elite, sugerindo que esses mecanismos anteriores impactam

principalmente durante a fase de desenvolvimento. Sugere-se realizar um planejamento cuidadoso tanto dentro quanto fora do

realizar um planejamento cuidadoso tanto dentro quanto fora do
ambiente esportivo e em diferentes períodos para garantir um bom efeito do desenvolvimento

$$
\text { efeito do desenvolvimento }
$$

Nem todos os irmãos foram entrevistados devido a dificultade de acesso. Além disso, entrevistas

retrospectivas dependem das memórias dos participantes e, portanto, podem ser criticados por sua subjetividade desenvolvimento do talento$$
\text { subjetividade }
$$

\author{
desenvolvimento do talento
}

A tendência de trabalhar bastante para objetivos de longo prazo pode permitir que os atletas persistam com atividades práticas que são fundamentais para o desenvolvimento de especialistas. estudo limitado por basear-se em autorelatos e com escopo um estudo transversal desenvolvimento do talento 
TILL, K.

Os resultados sugerem que a idade, a maturidade e as vantagens de tamanho, comumente observadas em adolescentes pesquisa e prática focada na identificação de talentos pode não ser sensivel a mudanças em estágios posteriores de desenvolvimento, a fim de identificar corretamente a realização de carreira. Os profissionais devem identificar, monitorare desenvolver qualidades físicas de

adolescentes jogadores da liga de rugby com o desenvolvimento do

atleta a longo prazo em mente.
TOWLSON, Chris
Os achados identificaram que independentemente da faixa etária cronológica, atributos antropométricos específicos caracterizados em posições de jogo em programas de desenvolvimento de futebo juvenil de elite ingleses, com relativamente mais velhos, mais

$$
\text { maduros, mais altos, mais pesados, sendo os jogadores }
$$

predominantes selecionado para papéis GK e CD. Características

distintivas dejogadores defensivos e de meio-campo alocados a

jogadores centrais ou laterais posições, também revelaram diferenças específicas de posição na aptidão física

atributos nos últimos estágios dos programas de desenvolvimento.

Tendências sugeriram que as vantagens transitórias do tamanho

corporalpor idade relativa e estado de maturação podem influencia

o papel posicional alocação em programas existentes de futebol juvenil. Desde o desenvolvimento físico

trajetórias são específicas do indivíduo e moderadas por

maturação biológica, o mandato do EPPP para os auditar pode

ajudar treinadores e selecionadores na adoção de uma abordagem

"plástica" atribuição de funções até que a maturidade completa seja alcançada existência de limitações

que confundem a estimativa precisa de aPHV ao administrar desenvolvimento de talentos e processos de seleção. detecção do talento 
Em resumo, não houve diferenças entre privações grupos para atividades de desenvolvimento na união de rugby por ogadores adolescentes de elite. Houve poucas diferenças no marcos e atividades desenvolvimentistas entre os atores de elite por quintil
WINN, C. O. N. de privação. No entanto, maior privação afetam algumas atividades de desenvolvimento, porque o mais

jogadores de elite privados acumularam menos horas em rugby e envolvido em menos outros esportes em comparação com alguns dos menos jogadores de elite privados.
O questionário contempla apenas os esportes mais populares. desenvolvimento do talento
As métricas de desempenho físico parecem estar mais 259

associadas a uma posição de rascunho posterior nessas rodadas;

sugerindo que à medida que o grupo de seleção de talentos se torn

menor, os recrutadores da AFL mudam o tipo de jogador que
WOODS, Carl T.

BOCCIA, Gennar

2018

BROWNLEE, T. E. métricas de desempenho e o rascunho da posição parece enfraquecer na terceira rodada do draft 262; indicando que a AFL

seleciona os jogadores mais tarde no draft nacional usando indicadores de desempenho 263 que não foram investigados aqui.

\section{O sucesso precoce do esporte não é um forte preditor de alto níve} desempenho em nível sênior. Entrando em competições esportivas específicas mais tarde e alongando a carreira esportiva além dos 2325 anos de idade podem ser fatores importantes para atingir um desempenho de alto nível em sprint e eventos de lançamento.

Os dados sugerem que, embora a maioria dos treinamentos seja focada no desenvolvimento técnico, é improvável

que a duração o treinamentoo como um todo contribua para potenciais desajustesnos programas de desenvolvimento de talentos na elite. futebol juvenil. não foram considerados dados do histórico de lesões

ou outros motivos que afetam a parada da competição desenvolvimento do talento e os dados se referem-se apenas a atletas italianos

\section{os programas de treinamento podem refletir uma} consciência pontual

das necessidades do atleta em desenvolvimento e dos perigos de carga excessiva dentro da equipe do clube. Isto é, porém uma limitação deste estudo é que ja que a duração é usada como um marcador de volume.

Portanto, uma seleção fortemente tendenciosa surgiu entre os

ogadores de futebol de elite competindo em campeonatos italianos, 
CAMACHO-Cardenosa, Alba

DEVANEY, Darren J.
Os resultados confirmaram um efeito da idade relativa nos jogadores nascidos em 2002 que foram selecionados para participar do campeonato espanhol, que era diferente para machos e fêmeas. Apesar desse efeito, que só apareceu no sexo feminino, diferenças significativas nas condições antropométricas e físicas apareceram nos atletas do sexo masculino. trabalhou com dados gerais obtidos nos campeonatos

seleção do talento
Os achados sugerem que os praticantes devem ser apoiados através de abordagens de aconselhamento, relações de jogador forte e ambiente imersão com o fim de impactar o desempenho. dados obtidos através de relatos dos atletas podem não ser totalmente precisos. desenvolvimento do talento

a) a redução das oportunidades no nível superior das Cricket, b) a perda do padrão competitivo do clube e da filial (provincial)-Cricket nível levou a uma redução nas opções de vias viáveis, c) os

treinadores de nível provincial e de franquia reduzem a identificação de talentos de ambientes de Cricket Clube, terciário e provincial, devido à percepção falta de competitividade, d) a importância das academias representativas da idade é ambiente de desenvolvimento fundamental, e) a importância da identificação relacionada com a idade removidos jovens talentosos Cricketers adolescente da estrutura do clube, f) os clubes jogam menos de um papel no caminho de desenvolvimento devido a um ambiente de clube mais fraco e menos competitivo não permitindo uma cultura de desenvolvimento de talentos e modelagem de papel positivo, g) os

Cricketers adolescentes podem começar especializando-se anteriormente na tentativa de fazer parte de cada afiliado internamente controlado desenvolvimento estrutura e h) os Cricketers adolescentes que se desenvolveram mais tarde. desenvolvimento do talento
Em conclusão, os resultados indicam que a participação do esporte infantil pode contribuir diferenças posteriores na auto regulação, e destaca a importância do envolvimento da infância nas brincadeiras
e práticas específicas de futebol no desenvolvimento de jogadores de futebol juvenil noruegueses.

Dados obtidos através de relatos dos atletas podem não ser totalmente precisos. desenvolvimento do talent
ERIKSTAD, Martin K. 
Em conclusão, a avaliação parece ser de

FABER, Irene R

2018

Estudos longitudinais precisam revelar 0

valor preditivo para a participação esportiva e esportes de elite.
Não houve controle quanto ao ganho de habilidades na

prática desta tarefa e não houve estimativadaidade biológicado público alvo. detecção do talento
Os TDEs do futebol feminino no Reino Unido eram geralmente bem percebidos pelos jogadores neste estudo. Os TDEs têm pontos fortes em áreas de foco de desenvolvimento de longo prazo, percepções menos positivas estão nas áreas de comunicação e compreensão do atleta. Há uma visão de que os jogadores podem ser eliminados antes de atingir seu potencial. Pesquisa aplicada futura

poderia examinar a eficácia de abordar as oportunidades de

desenvolvimento aqui relatadas, para melhorar as experiências de

desenvolvimento e os resultados de talentosas jogadoras de futebol feminino. dificuldade de generalizar a medida e ela carece de outros elementos. desenvolvimento do talento 
HANCOCK, David J.
Os resultados destacam a complexidade dos efeitos do local de nascimento. Estudos adicionais desses efeitos são necessários, especialmente para delinear as contribuições do tamanho da cidade / infra-estrutura e densidade populacional / estrutura social. Tal estudo pode envolver uma abordagem epidemiológica, responsáve pela infra-estrutura e estrutura social de cidades geograficamente diversas. Também é importante considerar como criar estudos que pode ser generalizável entre países e culturas (isto é,

um desafio na literatura dos efeitos do local de nascimento). Essas investigações ideaispodem examinar a densidade da cidade para os rácios de densidade do país, instalações per capita ou espaços verdes per capita, todos com intenção de melhorar a compreensão de como as atividades internas de uma cidade estrutura contribui para o sucesso. Até o momento em que um estudo pode ser

realizado, acreditamos que seria negligente considerar o tamanho da população ou a densidade populacional isoladamente.
Este estudo não incluiu jogadores jovens e dificuldade desenvolvimento do talento em generalizar os achados
PU pode ser visto como uma fontede inspiração para jogadores de futebol e clubes sobre como plataformas analíticas podem motivar melhorar a aprendizagem reflexiva para melhor desempenho no
O instrumento não se provou eficiente para todos os sujeitos. 
HUTTER, R. I. Vana

Nós fornecemos informações sobre programas educacionais da ASP na Europa. Espera-se que esta informação sirva aos futuros alunos que estão procurando rotas educacionais para obter experiência em ASP. No futuro próximo, divulgaremos essa informação ainda mais, de preferência também on-line, e nos encarregaremos de manter as informações atualizadas quanto possível. Se os educadores

desejarem ter informações sobre seu programa incluído em nossa visão geral, ou deseja se envolver na rede EASY, eles são convidados a entrar em contato com o primeiro autor
Dificuldades de obter asinformações necessárias podendo causar viés. desenvolvimento do talento
As principais conclusões incluem: (a) o

a taxa de abandono escolar foi inferior à relatada para grupos

semelhantes; b) as principais razões para o abandono foram pressões escolares e pobres

relações com o treinador; (c) houve pouca diferença no

nível percebido de apoio de escolas, pais e treinadores

entre aqueles que desistiram e os que não desistiram; $d$ )

KRISTIANSEN, Elsa

A participação no YOG foi um fator motivador significativo para permanecendo no esporte de elite para alguns atletas; e) vencedores de medalhas eram tão propensos a abandonar como vencedores não-medalhistas; e (f) o contexto nacional para o desenvolvimento de jovens de elite pode ter um

papel no engajamento mais profundo no esporte do que a participação do YOG.
É necessário aplicar o questionário em outros países para avaliar sua validade. desenvolvimento do talento

Esta pesquisa fornece evidência inicial de validade concorrente e confiabilidade teste-reteste para o TDEQ-5 com jovens chineses

LI, Chunxiao

Estudo apenas realizado em atletas chineses e dificuldade de replicar os achados. desenvolvimento do talento validade discriminante e confiabilidade interna. Isto é portanto,

recomenda-se que a escala possa ser usada com confiança

em ambos os aplicados e configurações de pesquisa na China. 
Jogando outros esportes e cultura aborígine garantiu

para o desenvolvimento de experiência dos participantes como

crianças, mas é a participação ao longo prazo na informalidade, auto-

jogos, criados e modificados pelos participantes que

desenvolvimento do talento

colocou no caminho para o desempenho de nível elite em seu

$$
\text { esporte. }
$$

LIMPENS, Vera

MURTAGH, Conall F.

de talentos de futebol devem incluir sprint, mas não avaliações de

$$
\text { salto em jogadores pré- }
$$

duporte para escalonamento de equipamentos para melhorar o

desempenho de jogo por tênis júnior qualificado jogadoras.

Propomos que as atuais recomendações de altura líquida para o

$$
\text { tênis júnior devem ser revisadas. }
$$

Nossos dados, portanto, sugerem que os protocolos de identificação

$$
\text { velocidade de pico prevista. }
$$

Psicólogos do esporte devem ajudar os clubes e treinadores a

melhorar o diagnóstico de características psicológicas, bem como na

incorporação de diagnósticos psicológicos e intervenções no

processo de desenvolvimento de talentos.
O estudo foca em performance e não em aprendixado. Tempo de jogo de apenas $25 \mathrm{~min}$. desenvolvimento do talento

City PASS é uma estrutura de formulação psicológica de equipe que

facilita aidentificacão, compreensão e gestão de preocupações e comportamentos desafiadores de jogadores da academia em vários contextos. City PASS e a ativação do pessoaltomada de perspectiva através da intervenção "O Menino Por Trás do Bravado", destaca importância da equipe da academia em: 1) compreender as

ONG, Chin Wei imporães e os comportamentos desafiadoresexperimentado por

jogadores em múltiplos contextos e as possíveis razões subjacentes

que são responsável por eles; 2) assumir responsabilidade

compartilhada e trabalhar juntos como uma equipe para ajudar os

adolescentes que jogam, com suas preocupações e desafios; e 3)

engajar-se em comportamentos positivos para criar uma cultura

empática e solidária dentro do futebol profissional na qual as

preocupações sobre os jogadores e comportamento desafiador são vistos com curiosidade, em vez de julgamento.
Benefícios podem ser oriundos do perfil genético já pré-existente.

detecção do talento

desenvolvimento do talento 
Tabela 3. Conclusões

OWEN, Adam Lee

PENA-GONZALEZ, Ivan

ROMANN, Michael

ROSSING, N. N. no desenvolvimento de conhecimentos especializados em esportes.

A principal conquista deste estudo é a sua identificação do RAE no futebol juvenil polonês.

Os resultados são importantes para os treinadores que trabalham com os jogadores jovens para criar uma avaliação mais abrangente do jogador que considera o desenvolvimento biológico. Pesquisas futuras são necessárias para desenvolver ferramentas que levem em conta o RAE para otimizar a identificação de talentos de futebol. Em

Além disso, identificar o RAE em outra idade categorias de futebol juvenil na Polônia é crucial.
RUBAJCZYK, Krystian
Necessidade de outras variáveis correlatas e dificuldade de generalizar os dados. detecção do talento

Aém disso, mudanças significativas são prevalentes e ocorrem

durante toda a temporada de LBM, FFM, MG e skinfold

As variáveis de desempenho antropométrico e físico não foram

fetadas pelo quartil de nascimento, e as expectativas de eficácia

dos treinadores foram relacionadas ao efeito da idade relativa.

detecção do talento

seleção do talento

Neste trabalho, procuramos incentivar a pesquisa e a prática da psicologia do esporte relacionada ao atleta

migrantes. Para atingir este objetivo, definimos termos-chave relevantes para a migração atlética, desde que

RYBA, Tatiana V.

transições culturais, aculturação e aculturação de atletas

ambientes complementados por insights de experiências de praticantes de psicologia do esporte móvel.

Este estudo tem várias limitações. 0 primeiro é a apresentação do RAE a partir da perspectiva de jogadores de futebol juvenil de elite sem abordar sua presença em outro jogo da CLJ estágios. A segunda limitação é a falta da

relação entre a escala do RAE e o

número de minutos ou uma posição tocada. detecção do talento

desenvolvimento do talento 
SILVA, Paulo Vinícius Carvalho

TAYLOR, Robin D.

TE WIERIKE, S. C. M.

Conclui-se que as habilidades reflexivas (autorreferidas) são importantes para atingir o nível de elite, enquanto o controle de bola parece ser especialmente importante para os guardas
É enfatizada a importância da família para que o atleta alcance um maior desempenho em suas modalidades.Ela exerce diversos papéis ao longo do desenvolvimento do atleta eé importante em relação vários aspectos: suporte material, suporteinformativo, suporte emocional, valores que são transmitidos aosatletas, crenças e expectativas depositadas no desempenho dos filhosatletas e envolvimento com a prática esportiva dos jovens. Apesardisso, ressalta-se que outros aspectos também são importantes para odesenvolvimento de um atleta de alto desempenho: relação estabelecidacom o técnico, treinamentos de alta qualidade, acesso equipamentos mais aprimorados e a uma alimentação adequada, apoio financeiro paraparticipar de competições em outros locais e para treinar com atletasde outros centros esportivos. $O$ alcance de um desempenho superior é resultado de uma combinação de fatores que possibilitam condições propícias para que o atleta possa se aperfeiçoar constantemente, superando eventuais desafios que surjam.
O envolvimento da família com a Prática Esportiva do Filho pode sofrer modificações ao longo da trajetória esportiva do atleta, entretanto, os itens da escala são respondidos de uma forma geral, o que é uma limitação do IFATE.
A aptidão vital e as variáveis de habilidades motoras como: aperto de mão, salto vertical, salto em pé, equilíbrio estático, força muscular superior e força muscular central influenciam a determinação da

classe de desempenho dos arqueiros. O estudo também revelou que a aplicação de algoritmos de aprendizado de máquina, em particular, a variação de SVMs é capaz de prever com precisão a classe dos arqueiros com base nas variáveis de desempenho escolhidas.

A natureza longitudinal do estudo expôs importantes diferenças de mecanismos po

limitação no desenho experimental

desenvolvimento do talento

Essas descobertas sugerem, por exemplo, que a triagem para perseverança do esforço pode ajudar os selecionadores de talentos a identificar quais atletas têm uma vantagem de personalidade para perseverar nas condições altamente dispendiosas da DP. Outras implicações de identificação e desenvolvimento de talentos são discutidas. 
"Este projeto de pesquisa forneceu evidência empírica firme e orientação para abordar as lacunas de conhecimento em TID e informar a futura gestão de TID na Austrália. O projeto avançado tanto o conhecimento prático como o metodológico, utilizando um sistema transdisciplinar abordagem do programa, aproveitando a experiência e experiência de uma grande equipe. Na perspectiva do praticante, este projeto revelou a importância de uma gestão eficaz para programas TID. Além de exigir estratégias eficazes de ciências do esporte, recursose programas, os programas de TID precisam de um forte foco na gestão das pessoas

e processos envolvidos (Chalip 2006). Entendendo e considerando o alcance do TID fatores secundários identificados neste estudo transdisciplinar, um estudo mais abrangente e uma abordagem eficiente em termos de recursos para programas e políticas australianas de TID pode ser desenvolvida, que simplesmente concentrando-se em fatores primários de TID, usando uma abordagem de ciência do esporte. Essa mudança é importante, dados os debates de décadas e vigorosos sobre se as verbas de financiamento esportivo dos governos federal e estadual devem ser direcionadas esporte recreativo ou de elite (Toohey 2008). 
VAN RENS, F. E. C. A.

2018

Para concluir, esta pesquisa confirma as preocupações de que as experiências de tensão de papel nas carreiras duplas de atletas de elite podem chegar ao custo do componente de bem-estar da

satisfação de vida do adolescente (Miller \& Kerr, 2002). O aumento das experiências de tensão relacionada às carreiras duplas dos

jogadores ARF de elite júnior foi associado à diminuição da satisfação

com a vida nos domínios do esporte, amizades, família, você mesmo

e satisfação global com a vida. Situações em que os jogadores da ARF

acham que suas habilidades são subutilizadas também foram

negativamente associadas à sua satisfação com a vida em vários

domínios da vida. A satisfação com a vida está positivamente

associada ao funcionamento físico, mental, social e emocional dos

adolescentes (Huebner, Suldo, Smith \& McKnight, 2004).

Compreender a satisfação com a vida dos jogadores de elite ARF é,

portanto, não só importante para desenvolver estratégias baseadas

em evidências para melhorar o bem-estar dos atletas juniores, mas

também pode afetar seu desempenho esportivo e acadêmico.

Com base nesses resultados, concluiu-se que o sucesso esportivo

poderia ser alcançado mesmo quando faltava uma característica

VARGAS, Jorge

central dos modelos de desempenho principais (por exemplo, altura

$$
\text { no voleibol). }
$$

Em conclusão, os efeitos de tamanho de comunidade de jogadores

de hóquei no gelo de elite podem não ser generalizáveis para todas as regiões dentro do Canadá. RESUMO DO EDITOR

WATTIE, N.

"Este estudo mostra um alto nível de homogeneidade entre as posições de jogo ao usar indicadores de habilidades técnicas adquiridos nos campeonatos nacionais da AFL, delineados usando três técnicas estatísticas lineares e não lineares. Diante disso, os

recrutadores de talentos da AFL podem encontrar dificuldades

indicadores de habilidades técnicas descritos neste estudo para

reconhecer objetivamente os juniores com 13 atributos posicionais

distintivos. Estes resultados incluem implicações práticas claras para

os recrutadores de talentos da AFL e analistas de desempenho, que

são discutidos abaixo. " 